\title{
NEGATIVE CAPABILITY: DOCUMENTARY AND POLITICAL WITHDRAWAL
}

A THESIS SUBMITTED IN FULFILMENT OF THE REQUIREMENTS FOR THE DEGREE OF MASTER OF ARTS IN ART HISTORY

VICTORIA UNIVERSITY OF WELLINGTON 2017 


\section{CONTENTS}

ABSTRACT 2

ACKNOWLEDGEMENTS 3

LIST OF ILLUSTRATIONS

INTRODUCTION

EXIT STRATEGIES

CHAPTER ONE

16

NAMING AS SUCH

CHAPTER TWO

32

'THE PURE FLIGHT OF A METAL BAR CRASHING THROUGH A WINDOW'

CHAPTER THREE

47

TROUBLE IN THE IMAGE WORLD

CHAPTER FOUR

65

'THE QUEER OPAQUE'

CONCLUSION

83

$\begin{array}{ll}\text { BIBLIOGRAPHY } & 86\end{array}$

$\begin{array}{ll}\text { ILLUSTRATIONS } & 92\end{array}$ 
This thesis thinks with, alongside, and against several theories of political withdrawal that have emerged during the past three decades as they have been taken up by artists working with documentary video. Political withdrawal here refers to a set of tactics that position themselves in opposition to existing models of belonging, civic engagement, and contestation.

The context in which this study takes place is one in which qualifying for citizenship in the liberal western state increasingly requires one remain transparent, docile, and willing to acquiesce to whatever demands for information the state may make. In response to these conditions, the theories and artworks examined in this thesis all propose arguments in favour of anonymity, opacity, and indeterminacy.

Situating itself, sometimes uncomfortably, within the archives of feminist, queer, and anarchist thought, this thesis engages with selected video works by Martha Rosler, Bernadette Corporation, Hito Steyerl, and Zach Blas in order to understand the ways in which withdrawal may constitute a generative framework for enabling meaningful social change.

These video works are here described as documentary, but not in the conventional sense that they are objective or transparent attempts to capture or record actual fact. Rather the term is understood as a historically pedagogical genre - notably deployed in the service of both oppressive regimes and oppositional movements - that provides a means through which to engage with, and creatively reimagine, political languages. The artists in this study take a critical approach to troubling times. Suspending the truth claims historically associated with documentary, they offer a range of ways to think through how complaint might be articulated and commitment sustained. 
This thesis was by all means a collective effort. I would first like to thank my supervisor, Christina Barton, for her support, encouragement, and critical eye.

I would also like to thank Pippa Wisheart, who works tirelessly, and all too often thanklessly, to keep the Art History department running smoothly. I am grateful as well to my officemates, Anna-Marie White and Kirsty Baker, who have provided good company and good humour throughout this year. They have both forced me to remain reflexive about my research process, and asked vital questions of my work I could not have anticipated myself.

Geoffrey Batchen, Roger Blackley, Peter Brunt, David Maskill, and Raymond Spiteri have been generous teachers throughout my university career. They have instilled in me the importance of thorough and precise research methods, and encouraged me to remain sensitive to the power of images to make and remake the world.

I am grateful to Zach Blas for being so generous with his time and so willing to answer my questions.

Alexandra Hollis and Ursula Robinson-Shaw offered valuable feedback and advice throughout this year, for that I am grateful.

I would finally like to thank my partner, Ben Speak, for his patience, care, and unwavering belief in me. 


\section{LIST OF ILLUSTRATIONS}

figure 1 Martha Rosler, Vital Statistics of a Citizen, Simply Obtained (still), 1977, courtesy Electronic Arts Intermix (EAl), New York

figure 2 Martha Rosler, Vital Statistics of a Citizen, Simply Obtained (still), 1977, courtesy EAI, New York figure 3 Martha Rosler, Vital Statistics of a Citizen, Simply Obtained (still), 1977, courtesy EAI, New York figure 4 Martha Rosler, Vital Statistics of a Citizen, Simply Obtained (still), 1977, courtesy EAI, New York figure 5 Martha Rosler, Vital Statistics of a Citizen, Simply Obtained (still), 1977, courtesy EAI, New York figure 6 Bernadette Corporation, Get Rid of Yourself (still), 2003, courtesy EAI, New York figure 7 Bernadette Corporation, Get Rid of Yourself (still), 2003, courtesy EAI, New York figure 8 Bernadette Corporation, Get Rid of Yourself (still), 2003, courtesy EAI, New York figure 9 Bernadette Corporation, Get Rid of Yourself (still), 2003, courtesy EAl, New York figure 10 Bernadette Corporation, Get Rid of Yourself (still), 2003, courtesy EAI, New York figure 11 Bernadette Corporation, Get Rid of Yourself (still), 2003, courtesy EAI, New York figure 12 Hito Steyerl, November (still), 2004, courtesy the artist and Andrew Kreps Gallery, New York figure 13 Hito Steyerl, November (still), 2004, courtesy the artist and Andrew Kreps Gallery, New York figure 14 Hito Steyerl, November (still), 2004, courtesy the artist and Andrew Kreps Gallery, New York figure 15 Hito Steyerl, November (still), 2004, courtesy the artist and Andrew Kreps Gallery, New York figure 16 Hito Steyerl, How Not To Be Seen: A Fucking Didactic Educational .MOV File (still), 2013, courtesy the artist and Andrew Kreps Gallery, New York

figure 17 Hito Steyerl, How Not To Be Seen: A Fucking Didactic Educational .MOV File (still), 2013, courtesy the artist and Andrew Kreps Gallery, New York

figure 18 Hito Steyerl, How Not To Be Seen: A Fucking Didactic Educational .MOV File (still), 2013, courtesy the artist and Andrew Kreps Gallery, New York

figure 19 Hito Steyerl, How Not To Be Seen: A Fucking Didactic Educational .MOV File (still), 2013, courtesy the artist and Andrew Kreps Gallery, New York

figure 20 Hito Steyerl, How Not To Be Seen: A Fucking Didactic Educational .MOV File (still), 2013, courtesy the artist and Andrew Kreps Gallery, New York

figure 21 Hito Steyerl, How Not To Be Seen: A Fucking Didactic Educational .MOV File (still), 2013, courtesy the artist and Andrew Kreps Gallery, New York

figure 22 Zach Blas, Facial Weaponization Communiqué: Fag Face (still), 2012, courtesy the artist figure 23 Zach Blas, Facial Weaponization Communiqué: Fag Face (still), 2012, courtesy the artist figure 24 Zach Blas, Facial Weaponization Communiqué: Fag Face (still), 2012, courtesy the artist figure 25 Zach Blas, Facial Weaponization Communiqué: Fag Face (still), 2012, courtesy the artist figure 26 Zach Blas, Facial Weaponization Communiqué: Fag Face (still), 2012, courtesy the artist figure 27 Zach Blas, Facial Weaponization Communiqué: Fag Face (still), 2012, courtesy the artist 
INTRODUCTION EXIT STRATEGIES

Theories and tactics of escape, withdrawal, and refusal abound. These theories, though varied in their political, disciplinary, and methodological outlooks, are united in their shared insistence that withdrawal from existing modes of political engagement and subjectification may constitute a generative framework for imagining meaningful social change. This thesis is an attempt to think with, alongside, and against several of these theories as they have been taken up by contemporary artists engaging with documentary video.

Documentary video is, in some ways, an artificial constraint. It is not my intention to argue there is anything particular about documentary video that lends itself to the articulation of political withdrawal, but to engage with a small selection of the many examples of artist's documentary that have appeared in the last four decades. The proliferation of artist's documentary video, according to T.J. Demos, can be attributed to several interrelated factors, among them the widespread availability of relatively cheap imaging and editing technologies, the growth of the international biennial circuit and the influence of major art events such as Documenta, and a continued engagement with the problematic implications of the truth claims the documentary image has historically made. ${ }^{1}$ All of the works analysed in this thesis openly stage an argument. They all engage with political languages, and, in many cases, find themselves testing the limits of existing political vocabularies. All of the works in this thesis engage critically, playfully, and ambivalently with the manifold histories of political documentary practice, and each, in its own way, works towards a rearticulation of art's activist potential.

Withdrawal goes by many names. During the past several decades, tactics for hiding, refusing, and escaping from contemporary regimes of biopolitical control have emerged from diverse fields including queer and feminist studies, critical race studies, anarchist literature, literary studies, and art criticism. At times, these theories and tactics bypass each other. Elsewhere, a common ancestry is able to be detected and drawn out. All share an insistence, however, that withdrawal, however it is named, does not constitute an acquiescence to oppressive power, but provides a means to imagine and enact

\footnotetext{
1 T.J. Demos, The Migrant Image: The Art and Politics of Documentary During Global Crisis, Durham: Duke University Press, 2013, pp. xvi-xvii; Julian Stallabrass, Documentary, London: Whitechapel Gallery and Cambridge, MA: The MIT Press, 2013, p. 12-16
} 
creative forms of resistance to it. In a recent essay, Leo Bersani makes an argument for becoming unnamable. ${ }^{2}$ Drawing on Pierre Bourdieu's writings on systems of social classification and their incorporation into the selfhood of those subjects they classify, Bersani writes, 'We are distinguished - made distinct from one another - by the attitudes, beliefs, and behaviours assigned to the social stratum or class to which each of us belongs... What makes this system of classificatory control work is, according to Bourdieu, its internalization by those subjected to it. We recognise the identity imposed on us as always already ours.' 3 The limitations imposed upon these distinctions owe their potency to this recognition, to what Bourdieu calls a 'sense of one's place.' 4 The authority that assigns and summons these names has the power to bestow or withhold legitimacy on that which it names. Bersani's argument does not call for an affirmation of those modes of performance, social arrangements, and kinds of attachment that fall outside or in between the legitimate, but rather a refusal of the very terms that names them as such,

The Law that names us, that legitimizes or delegitimizes the identities it names, is not an agency that can be negotiated with, and to reject its authority may necessitate a potentially irreversible negativizing not only of the world but also of the the subject him-or herself. ${ }^{5}$

In the first chapter of this thesis, I consider Bersani's negativity alongside Martha Rosler's video Vital Statistics of a Citizen, Simply Obtained (1977). In Rosler's work, the artist plays both narrator and performer. During the course of the video's thirty nine minute duration, her body is commanded, manipulated, and evaluated by two scientists. Here, we witness the performative reenactment of a gendered subject being thrown into the interpellative apparatuses of late-twentieth century biopolitical governance. Rosler's video is an illustration of the means by which the violent manipulation of the body takes place as much through the application of measurement, discipline, and statistical comparison as it does through one's own willingness to adjust one's body, behaviour, and speech to

\footnotetext{
2 Bersani's essay belongs within a larger project within queer theory, the major proponents of which are Bersani and Lee Edelman. Often called the 'anti-social turn', this school of knowledge, as Jack Halberstam writes in his critique of Bersani and Edelman, 'produces a counter-intuitive but crucial shift in thinking away from projects of redemption, reconstruction, restoration and reclamation and towards what can only be called an anti-social, and anti-relational theory of sexuality.' Jack Halberstam, 'The Anti-Social Turn in Queer Studies,' Graduate Journal of Social Sciences 5:2, p. 140. See also: Leo Bersani, Homos, Cambridge, MA: Harvard University Press, 1996; Leo Bersani, Thoughts and Things, Chicago: University of Chicago Press, 2015; Lee Edelman, No Future: Queer Theory and the Death Drive, Durham: Duke University Press, 2005

3 Bersani, 2015, pp. 20-21

${ }^{4}$ Bersani, 2015, p. 21

${ }^{5}$ Bersani, 2015, p. 25
} 
normative prescription. ${ }^{6}$ Reading Bersani alongside Rosler opens up the limitations of Bersani's proposal. At stake here is where, how, and to what extent, one should invest in the capacity of human agency to resist and transform the repressive power to which subjects find themselves submitting. If inhabiting the social realm means always already finding oneself within the taxonomic structure of that realm, how might one go about becoming unnamable while remaining attached to the world?

Another example of withdrawal can be found in Giorgio Agamben's book The Coming Community. Agamben describes a model of community which departs from a logic of belonging and exclusion any political discourse of identity (whether national, racial, sexual, or otherwise) would always presuppose. Agamben names this model the 'whatever singularity,' a term intended to describe 'a being whose community is mediated not by any condition of belonging (being red, being Italian, being Communist) nor by the simple absence of conditions... but by belonging itself?'7 Such a model of community constitutes a withdrawal in its hostility towards the state as an arbiter of legitimacy and illegitimacy. For Agamben, the 'whatever singularity' is anathema to the organising principles of the liberal state,

The State... is not founded on a social bond, of which it would be the expression, but rather on the dissolution, the unbinding it prohibits... What the State cannot tolerate in any way, however, is that the singularities form a community without affirming an identity, that humans co-belong without any representable condition of belonging (even in the form of a simple presupposition). ${ }^{8}$

Agamben cites the example of the uprisings in Tiananmen Square in 1989 as a speculative example of how the 'whatever singularity' might appear. Vitally, for Agamben, the protesters made no reducible demands of the state. Far from being a flaw in the protesters' organisational strategy, the absence of demands constitutes a joyous refusal to negotiate within the terms of discourse already established by the state. ${ }^{9}$ Agamben's

\footnotetext{
6 The potency of this normativity's coercive force is outlined by Michel Foucault in series of lectures delivered College de France in 1974-75. Foucault writes, 'the norm brings with it a principle of both qualification and correction. The norm's function is not to exclude and reject. Rather, it is always linked to a positive technique of intervention and transformation, to a sort of normative project.' Michel Foucault, Abnormal: Lectures at the Collège de France 1974-75, trans. Graham Burchell, London: Verso, 2003, p. 50

7 Giorgio Agamben, The Coming Community, trans. Michael Hardt, Minneapolis: University of Minnesota Press, 1993, p. 84

8 Agamben, p. 85

${ }^{9}$ Agamben, p. 84
} 
work has been embraced by anarchist, ultraleft, and Marxist Autonomist groups. ${ }^{10}$ In the second chapter of this thesis, I track Agamben's writing as it has been taken up by the French collective Tiqqun, and further manipulated by Bernadette Corporation in their video Get Rid of Yourself (2003). Get Rid of Yourself, which purports to document the antiglobalisation protests in Genoa in 2001, is the product of a 'provisional' alignment between Bernadette Corporation and Genoa's Black Bloc. ${ }^{11}$ In the film, the Black Bloc - a loosely organised programme of infiltration, property destruction, and open hostility towards police forces which emerged during protests in the 1990s - represents a problematic illustration of Agamben's 'whatever singularity.' The Black Bloc, who are united by their shared black attire, who make no demands, and would appear to have no communicable political position, might bring to mind Agamben's enthusiasm for the Tiananmen Square protesters. In the film, however, the Bloc appears only as a spectre. It is only able to be rendered in fleeting moments of testimony from protesters who participated in the Bloc's actions in Genoa. This forces us to ask, if Agamben's model of community is one in the future tense, one which is always 'coming' or becoming, is it possible to represent this community in the here and now? And in what ways does representation inevitably fail in transcribing or imagining that which is not yet here?

Both Bersani and Agamben, in different ways, take as their object of critique the transparency the state seeks to elicit from its subjects. In the past several decades, with the widespread adoption of complex and invasive surveillance technologies, massive programs of data collection and monitoring, and the increasing militarisation of border protection programmes, transparency has taken on a new urgency. ${ }^{12}$ As Lauren Berlant writes, the state's project of cultivating docile citizen-suspects renders everyday life a perpetual 'audition.' If one hesitates, stutters, or stumbles in admitting what the state

\footnotetext{
10 Agamben's text has also appeared in many other places since its publication in 1993. In November 2016, the exhibition Potentially Yours, The Coming Community, curated by Tendai John Metambu at Artspace, Auckland, engaged with Agamben's text as a prompt for an exercise in imagining 'the promise of alternative approaches to potential.' Tendai John Metambu, 'Potentially Yours, The Coming Community,' Artspace, November 2016, http://www.artspace.org.nz/exhibitions/2016/default.asp, Accessed 2 February 2017

${ }^{11}$ Bernadette Corporation, 'Get Rid of Yourself,' http://www.bernadettecorporation.com/getrid.htm, Accessed 2 February 2017

12 Citing the security protocols inside airports introduced during the first years of the 2000s, Rachel Hall proposes that the present may be defined by an 'aesthetics of transparency.' Now commonplace rules requiring personal hygiene products be stored in a ziploc bag during air travel is one emblematic example. Hall writes, 'The aesthetics of transparency belongs to a rationality of government that understands security in terms of visibility. The aesthetics of transparency is motivated by the desire to turn the world (the body) inside-out such that there would no longer be any secrets or interiors, human or geographical, in which our enemies (or the enemy within) might find refuge.' Rebecca Hall, 'Of Ziploc Bags and Black Holes: The Aesthetics of Transparency in the War on Terror,' The Communication Review 10:4, 2007, pp. 320-321
} 
requires of them, one is automatically rendered suspect. ${ }^{13}$ 'In the security state,' Berlant writes, 'no one knows when the citizen's audition for citizenship is happening, through what channels, and according to what standards. '14 This project of transparency is deeply entangled with new technologies of capital accumulation, in particular the business models of Facebook, Google, and other social media companies, in which willingly volunteered information about oneself becomes a commodity. Every indication of routine, predilection, or confession is sold to advertisers, and contributes to an increasingly precise image of consumer habits. ${ }^{15}$ Writing in the context of thoroughly networked relations of sovereignty, power, and discipline, Alexander Galloway and Eugene Thacker propose what they call the 'tactics of nonexistence' as their version of political withdrawal. 'We are nostalgic' the authors write, ' ... for a time when organisms didn't need to produce quantitative data about themselves, for a time when one didn't need to report back.' ${ }^{16}$ They go on:

When existence becomes a measurable science of control, then nonexistence must become a tactic for any thing wishing to avoid control... Thus we should become devoid of any representable identity. Anything measurable might be fatal. These strategies could consist of nonexistent action (nondoing); unmeasurable or not-yet-measurable human traits; or the promotion of measurable data of negligible importance. Allowing to be measured now and again for false behaviors, thereby attracting incongruent and ineffective control responses, can't hurt. A driven exodus or a pointless desertion are equally virtuous in the quest for nonexistence. The bland, the negligible, the featureless are its only evident traits. The nonexistent is that which cannot be cast into any available data types. The nonexistent is that which cannot be parsed by any available algorithms. This is not nihilism; it is the purest form of love. ${ }^{17}$

The tactics of subterfuge, withholding data, and the dissemination of erroneous information, are deployed by the final two artists in this thesis, Hito Steyerl and Zach Blas. I analyse two works by Steyerl. The first work, November (2007), begins with a kind of lamentation for the avant-garde practices and politics of the previous century. Beginning with the death of her childhood friend, Andrea Wolf, at the hands of the Turkish military, Steyerl peers back towards revolutionary moments in European political history in order to

\footnotetext{
${ }^{13}$ There are, of course, those for whom suspicion is always closer at hand. Hall quotes Algerian novelist Réda Bensmaïa's The Year of Passages, 'They've glued on us a face that looks like a mugshot,' to demonstrate concisely that the racializing gaze of the state always presumes some subjects appear more worthy of suspicion than others. Hall, p. 342

14 Lauren Berlant, Cruel Optimism, Durham: Duke University Press, 2011, p. 240

15 John Cunningham, 'Clandestinity and Appearance,' Mute 2:16, 8 July 2010, http://www.metamute.org/ editorial/articles/clandestinity-and-appearance, Accessed 1 February 2017

${ }^{16}$ Alexander Galloway and Eugene Thacker, The Exploit: A Theory of Networks, Minneapolis: University of Minnesota Press, 2007, p. 124

17 Galloway and Thacker, pp. 136-137
} 
ask how the spirit of coalition and collective complaint might be accessed in the twentyfirst century. The place she arrives in the film is melancholic, though not without hope. She terms the present moment 'November,' a reference to Sergei Eisenstein's film October: Ten Days That Shook The World (1928). 'November' designates a protracted post-revolutionary juncture. Steyerl narrates, 'November is the time after October, a time when revolution seems to be over and peripheral struggles have become particular, localist, and almost impossible to communicate.' For Steyerl, however, this designation is not necessarily an admission of defeat. Rather, it might be a call for creative ways of thinking about struggle, community, and worldmaking within contemporary networks of power.

In the second half of my third chapter, I analyse Steyerl's more recent work, How Not to be Seen: A Fucking Didactic Educational .MOV File (2013) as an example of the kind of creative political engagement November would seem to necessitate. In How Not to be Seen, parody is deployed in a deeply sincere project of comings to terms with, and resisting, contemporary regimes of surveillance, data mining, and post-War on Terror policing. The context Steyerl's video speaks to is one in which we are thoroughly, and perpetually, accounted for. In How Not to be Seen, old divisions between online and offline, digital and analogue, virtual and real life all blur. The pedagogical project of Steyerl's video involves playing with these ambiguities. Figures in the film are seen wearing grey and black boxes. They assume the form, as the narrator of the video tells us, of pixels, and in doing so seek to trick satellite cameras into recording their material presence as negative space. Elsewhere in the film, figures are seen wearing 'invisibility cloaks' which bear a striking resemblance to niqabs. Humour, in Steyerl's video, is serious business. Humour is a way to operate at the limits of the distribution of the sensible, where things cling desperately to making sense, and that which seems immanent finds itself transformed into changeable matter. ${ }^{18}$

In the final chapter of my thesis, I examine a work from Zach Blas' project, Facial Weaponization Suite (2011-2014). Here, the 'tactics of nonexistence' take on a performative tendency. By augmenting the body using masks, the artist proposes a means of avoiding detection by facial recognition technology - now commonplace in

\footnotetext{
18 On humour, Lauren Berlant and Sianne Ngai write, humour is 'epistemologically troubling, drawing insecure boundaries as though it were possible to secure confidence about object ontology or the value of an "us" versus all its others.' Lauren Berlant and Sianne Ngai, 'Comedy Has Issues,' Critical Inquiry 43, 2017, p. 235; See also: Jacques Rancière, The Politics of Aesthetics, trans. Gabriel Rockhill, London: Continuum, 2004, p. 13
} 
airports, welfare offices, and on smartphones. The masks, as well, work to bind a community of subjects into a shared project of resistance and, similar to Agamben's writing, seek to create community out of the subject's presumed illegibility. The masks demonstrate a radical refusal - a refusal both to appear to the state and its technologies when interpellated, as well as a refusal to abide by the language and praxis of any nameable, fixable identity. Another artist, Sterling Crispin, has responded to Blas' work by training facial recognition software to recognise the pink, blobby surface of the masks. ${ }^{19}$ Crispin's gesture may be in bad faith, and, I would argue, misplaces emphasis on the teleology of Blas' project, but it demonstrates succinctly the ways in which power is able to assimilate its resistance. Politically committed art, then, is always held in a fugitive relation to the machinations of capital, state repression, and obsolescence. I hope to demonstrate in this thesis that artists offer creative, unpredictable, and sometimes counterintuitive ways to think about political engagement and withdrawal, but I hope as well to demonstrate that the project of formulating, theorising, and enacting a creative politics is an always ongoing task.

It is important not to reduce the proliferation of theories of withdrawal, of which I have cited only a small sample, into a coherent field of knowledge. Each example comes from a different place, each with its own epistemological lineage and outlook, its own audience in mind, its own means and ends. Therefore, with the exception of my chapter on Rosler and Bersani, in which each figure acts as a kind of test case for the other, I have chosen to follow the many, often convoluted, trails of citations left by the artists whose work is discussed. The form of the documentary, as a didactic, argumentative medium, invites this kind of activity. The documentary form encourages a methodological approach that situates the art object and its audience within a complex network of economic, social, and affective relations. Further, these works are objects of knowledge that all presume art is not only situated within the social world, but also bears a responsibility to intervene in the repair of what is broken or unjust about this social world. As will become evident, the argumentative nature of the artist's documentary is often not deployed to convince the viewer of one particular version of reality over another. More often, the argumentative is deployed to unsettle the very conventions of documentary that render the medium

\footnotetext{
19 Sterling Crispin, Data-Masks: Biometric Surveillance Masks Evolving in the Gaze of the Technological Other, Masters of Science Thesis, University of California Santa Barbara, 2014, pp. 11-12
} 
intelligible to the viewer, and by extension, to open up holes in the fabric of our epistemic regime. In doing so, these artists aim to expand the horizon of political possibility. ${ }^{20}$ In the case of Get Rid of Yourself, for example, argumentative enunciation is rendered suspect. In the film, texts by the French anarchist collective Tiqqun, which tend to be deeply sincere in tone, even when they stray towards the hyperbolic, are read aloud by Chloë Sevigny. As if Sevigny's iconic late-90s drawl were not enough to render these screeds strange, the actress elsewhere in the film is seen standing in a suburban kitchen smoking and fidgeting with her dress - reading aloud the very testimony we might previously have assumed to be the untampered recollections of Black Bloc protesters.

For Steyerl, the kind of doubt conjured by Sevigny's recitations is by no means exceptional, nor reason to worry. In her essay, 'Documentary Uncertainty,' Steyerl notes that the presence of doubt is a precondition of viewership in the twenty first century. Steyerl names this condition the 'uncertainty principle' of contemporary documentary, and writes, 'this uncertainty is not some shameful lack, which has to be hidden, but instead constitutes the core quality of contemporary documentary modes as such. The questions which they invariably trigger, the disavowed anxieties hidden behind apparent certainties, differ substantially from those associated with fictional modes.' 21 Doubt, then, is productive in that it provokes a realignment of the commonsense, and, in the space of realignment, invites otherwise subordinated possibilities for worldmaking, kinship, and political organisation to come into being. ${ }^{22}$ Steyerl ends her essay by writing, 'the only possible critical documentary today is the presentation of an affective and political constellation which does not even exist, and which is yet to come.'23

Each artist in this study assumes many roles, including writer, teacher, joker, and provocateur. I have engaged with the writing of all of the artists studied in this thesis,

\footnotetext{
20 Or, as Rancière writes, 'Artistic practices are "ways of doing and making" that intervene in the general distribution of ways of doing and making as well as in the relationships they maintain to modes of being and forms of visibility.' Rancière, p. 13

${ }^{21}$ Steyerl goes on to admit that incredulity towards documentary's truth claims is 'as old as the documentary form itself.' In a similar vein, Rachel Hall cites Alan Sekula's comments on the untrustworthy nature of early police photography. Sekula writes, 'Contrary to the commonplace understanding of the 'mug shot' as the very exemplar of a powerful, artless, and wholly denotative visual empiricism, early instrumental uses of photographic realism were systematized on the basis of an acute recognition of the inadequacies and limitations of ordinary visual empiricism.' The truth claims of the lens, perhaps, have only ever existed as an impossible to realise aspiration. Hito Steyerl, 'Documentary Uncertainty,' Re-Visiones, 2011, http://www.revisiones.net/spip.php\%3Farticle37, Accessed 1 June 2016; Hall, p. 321, italics in original

22 Steyerl, 2011

${ }^{23}$ Steyerl, 2011
} 
though it is not necessarily with the intent of 'decoding' works when they would appear to be opaque. ${ }^{24}$ Such an exercise, I believe, would be a hermeneutic misstep. In many cases, writing offers these artists another outlet through which political commitments can be laid bare, tested, and arrived at. Writing might be considered, then, a medium among media, with its own advantages and limitations; less supplementary to each artist's practice than an intrinsic element of it. With this in mind, considering the artist-as-writer, or artist-as-teacher, forces us to think through what it means to be a practicing artist today.

The writing of these artists is unapologetically interdisciplinary, and, in following this writing, my own approach to interpretation is necessarily interdisciplinary as well. Although interdisciplinarity, in the contemporary moment, seems almost beyond worthy of commenting upon, Hito Steyerl's work in particular points towards the common mistranslations, misrecognitions, and awkward hiccups that occur when disciplinary languages are unmoored from their original contexts and forced to traverse spaces of inquiry they could not have otherwise anticipated. In How Not to Be Seen, subaltern, art historical, and military understandings of terms such as 'visibility,' and 'disappearance' congeal around one another. One result, for instance, is a strange, and estranging, list of strategies for going undetected in which going undetected refers at once to the exclusion of certain groups from representation in popular media, the limitations of satellite imaging technology, and to the legal grey zones migrants are forced to inhabit under contemporary regimes of border control. The list is heard as follows, 'Living in a gated community; living in a military zone; being in an airport, factory, or museum... being female and over fifty... being a wifi signal moving through human bodies; being undocumented, or poor; being spam caught by a filter; being a disappeared person as an enemy of the state, eliminated, liquidated, and then dissimulated.'

In writing this thesis, I have been forced to ask how one might anchor oneself within a disciplinary setting while remaining open to the necessity to improvise, supplement, and borrow from other frameworks and fields of knowledge. What is art historical about these close readings, and how might the answer to this question be complicated when the very

\footnotetext{
${ }^{24}$ In an interview with Łukasz Zaremba, Steyerl says, 'I was taught that the image should never be an illustration of a text, so I think in a similar way about my writing - it should never be an illustration of my images either. There should be a tension between them. It's all about keeping tension and respect the autonomy of each language.' Łukasz Zaremba, 'To Work as a Pixel. Interview with Hito Steyerl,' Szum, 20 December 2014, http://magazynszum.pl/rozmowy/to-work-as-a-pixel-interviev-with-hito-steyerl, Accessed 2 February 2017
} 
terms and limits by which we understand the field of contemporary art practice are nebulous at best? One answer to this question might come from an unlikely source. In her study of Botticelli's La Primavera (1477-1482), Rebecca Zorach proposes a reconsideration of subject-object relations in reference to the work of interpretation. She writes, "Beyond a simple opposition between "object of aesthetic contemplation" and "medium for conveying iconographic meaning," objects, in what they "said" and in what they didn't say, in what they did and what they didn't do, acted. ${ }^{25}$ I would adjust Zorach's comment to take place in the present tense, and in doing so suggest that it is in paying attention to what these objects of inquiry do as they inhabit, upset, or struggle with the networks of power and affect in which they exist, and the ways in which this doing is rendered intelligible as something, that we might approach a means to attend to the questions I have asked myself. ${ }^{26}$

The artists studied in this thesis live and work in the United States and Europe. All have had works exhibited recently in Aotearoa, but my own access to the works examined in this thesis has been mediated through the internet. ${ }^{27}$ This mode of interaction bears consideration. The means by which these works found themselves online differs depending on the work in question. For Blas, the online dissemination of works is part of his practice. The video from Facial Weaponization Suite on which my final chapter is based was posted to his personal Vimeo account. ${ }^{28}$ Several versions of Bernadette Corporation's Get Rid of Yourself appear on Vimeo and YouTube. A quick Google search reveals that these videos have subsequently been distributed among anarchist blogs and

25 Rebecca Zorach, 'Love, Truth, Orthodoxy, Reticence; or, What Edgar Wind Didn't See in Botticelli's Primavera,' Critical Inquiry 54, 2007, pp. 213-214, italics in original

26 Such an understanding of the object's capacity to act recalls Gilles Deleuze's approach to the paintings of Francis Bacon, as well as, more recently, Jill Bennett's writing on Deleuzian affect theory as an art historical methodology. See: Jill Bennett, Empathic Vision: Affect, Trauma, and Contemporary Art, Stanford: Stanford University Press, 2005; Gilles Deleuze, Francis Bacon: The Logic of Sensation (1981), trans. Daniel W. Smith, London: Continuum, 2003; Gilles Deleuze and Felix Guattari, Anti-Oedipus (1984), trans. Robert Hurley, Mark Seem, and Helen R. Lane, London: Continuum, 2004

27 A video from Zach Blas' Facial Weaponization Suite was featured in Surveillance Awareness Bureau, a collaborative project between Modelab and Urban Dream Brokerage in Wellington in 2015. An installation of works by Bernadette Corporation was staged by the collective Terror Internationale at Halloween Gallery, Auckland in 2016. Martha Rosler's The Bowery in two inadequate descriptive systems (1975) was exhibited at Adam Art Gallery, Wellington in 2013, and Martha Rosler Reads Vogue (1982) was featured in Imaginary Audience Scale at Artspace, Auckland in 2015. Hito Steyerl's After the Crash (2009) was exhibited at Artspace in 2009, Is the Museum a Battlefield? (2013) was exhibited at Adam Art Gallery in 2014, In Free Fall (2010) was screened at City Gallery, Wellington in 2014, Duty Free Art (2014) was exhibited at Artspace and Blue Oyster Gallery, Dunedin in 2016.

${ }^{28}$ Zach Blas, 'Facial Weaponization Communiqué: Fag Face,' Vimeo, 21 January 2013, https://vimeo.com/ 57882032, Accessed 2 February 2017 
artist run journals. In the case of Steyerl, her online presence is entangled in the international network of art publishing and journalism by whom she is celebrated. ${ }^{29}$ How Not to be Seen can be viewed on ArtForum's website. ${ }^{30}$ Rosler's works were viewed on UbuWeb. UbuWeb, which was founded by poet Kenneth Goldsmith in 1996, describes itself as, 'the Robin Hood of the avant-garde.' 31 The website hosts what Goldsmith terms 'the detritus and ephemera of great artists' - videos, audio recordings, and rare texts are all featured on the website. The legality of Ubuweb is dubious, and Goldsmith admits that it has been subject to accusations of copyright infringement, but its existence may contain within it a spectre of the utopian language with which early video artists spoke of the medium in its nascent decades. ${ }^{32}$

The questions this thesis seeks to ask are as follows: How have artists imagined, engaged with, and illustrated a broad notion of political withdrawal, as outlined in this introduction? How have artists deployed, and problematised, specific theories of political withdrawal that have circulated in the last few decades? And how can art, specifically a critical documentary art, lend itself to reimagining, rearticulating, and reinvigorating a project of resistance against the oppressive forces of biopolitical governance and control? It is not my intent to argue for one model of political withdrawal over another (although it may become clear that I am more sympathetic towards some than I am to others). Rather it is to insist upon the necessity of committed art to stay attached to the always unfolding technologies of power and oppression it would seek to undo, while, simultaneously, examining the ways in which the artists in this study have creatively examined, illustrated, and enacted joyous forms of political refusal.

\footnotetext{
29 In 2016, Steyerl was ranked number seven on ArtReview's list of the 100 'most influential people in the contemporary artworld.' While the validity of such a list leaves itself open to well deserved scrutiny, I cite it as a single example of Steyerl's status within the institutional matrix of contemporary art. 'Power 100,' ArtReview 68:8, 2016, p. 106

30 'Hito Steyerl, How Not to be Seen: A Fucking Didactic Educational .MOV File, 2013,' Artforum, 2013, https://www.artforum.com/video/mode=large\&id=51651, Accessed 2 February 2017

${ }^{31}$ Kenneth Goldsmith, 'Resources,' Ubuweb, 2011, http://www.ubu.com/resources, Accessed 2 February 2017

32 Martha Rosler writes, "video posed a challenge to the sites of art production in society, to the forms and "channels" of delivery, and to the passivity of reception built into them.' Martha Rosler 'Video Shedding the Utopian Moment,' in Decoys and Disruptions, Cambridge, MA: The MIT Press, 2004, p. 54
} 
We hear before we see. We hear a woman's voice, flat and measured. We can detect a Brooklyn accent. She utters a prologue over a black screen; she establishes a position, provides a frame through which the viewer can begin the work of interpretation. 'This is an opera in three acts. This is a work about perception.' Over the course of the video, we witness a woman being made. In the first act of the video, which lasts just over thirty three minutes, two men in white coats perform upon this woman a series of measurements, charting every imaginable metric of her body. The men are polite, professional, a little aloof, and yet something violent appears to be taking place. The woman is asked a series of questions - her sex, age, ethnic background - to which she dutifully responds. She is then directed, either vocally or physically, to adopt certain poses, as a tape measure charts a topographical representation of her body, which gets transcribed upon a large sheet of white paper hanging on the wall behind her (fig. 1). Her limbs are pulled, shoulders pushed down, other inconvenient parts of her body shoved aside. She is made malleable, made available for these men to perform their labour. She is told to remove her clothes, and does so without delay. Her 'crotch-to-floor' height, her 'knee-girth', her 'sitting height' are all measured. The height of her toes, the width of her hips, the depth of her vagina are all measured. This violation, in its description, is shocking, but in the time of the video this shock has time to dissipate. The video propels itself through flat affect, through the monotony of repeated action undertaken without much conscious thought. More than anything else, we might say, Martha Rosler's Vital Statistics of a Citizen, Simply Obtained (1977) is dull.

This is a chapter about visibility. Its aim is to examine, through a close reading of Rosler's video, the ways in which visibility is always unequally distributed. What does it mean for a body to be made intelligible? And how does this video, as an exercise in defamiliarising the means by which bodies find themselves interpreted against and among other bodies, open the possibility of remaking, repairing, or even shattering these matrices of intelligibility? If, as Rosler's narrator says in her opening address, Vital Statistics is a work about 'being done to,' then this chapter seeks to attend to the spaces in the video that leave themselves open to conceiving of being undone, to allowing its audience to imagine new possibilities for bodies to exist among each other. Rosler's video, produced while the artist was living in California, during a period of concentrated political energy, provides an 
opportunity to establish a solid ground from which to examine the more recent formal and political interventions that will be discussed in my subsequent chapters. The chapter ends with an attempt to problematise Leo Bersani's appeal towards 'unnamability.' I argue that Bersani invests too heavily in a model of agency that would allow political subjects to remake themselves and, in doing so, neglects the disciplinary matrices that compel subjects to enact and repeat the performances, often performances that provide a blockage towards the subject's thriving, Bersani seeks to undo.

Rosler's performer, played by Rosler herself, remains docile, almost serene. Partway through the examination, Rosler and her scientists are joined by a chorus of three women. These women interject, punctuating the scientist who enunciates the measurements of the performer's body (fig. 2). One rings a bell when she meets the standard measurement, another blows a whistle when she exceeds the measurement, the third blows a kazoo when she falls below. These women are distinct from the woman being examined. They wear the same coats as the men, they are referred to, like the men, as 'examiners' in the work's transcript. ${ }^{1}$ The whistleblower is tall and thin, the kazoo player short and a little plump, and the bell ringer somewhere in between the two. Shortly after the women enter, we hear the voice of another narrator, a man, who tells us a story of Tommy Smith, a child whose development appears to be stunted by a living situation in which traditional gender roles have been reversed. ${ }^{2}$

Accompanying this performance is a narration which presents an argument, both lucid and lyrical, regarding what Rosler calls, in the prelude, 'the tyranny of expectation.' Rosler's performer is a case study who demonstrates the ordinary violence of gendered normativity. Doing womanhood well, for Rosler's narrator and performer, becomes a practice in learning what femininity is and performing it seamlessly. This point is demonstrated most clearly in a refrain that is repeated twice during the video:

Her mind learns to think of her body as something different from her "self." It learns to think, perhaps without awareness, of her body as having "parts." These parts are to be judged. The self has already learned to attach value to itself.

To see itself as a whole entity with an external vision.

She sees herself from the outside with the anxious eyes of the judged who has within her the critical standards of the ones who judge.

\footnotetext{
${ }^{1}$ Martha Rosler, Vital Statistics of a Citizen, Simply Obtained Transcript, supplied to the author by the artist, 29 July 2016

${ }^{2}$ Though not revealed until the end of the first act, the male narrator reads directly from an article published in Scientific American in 1953. George W. Gray, 'Human Growth,' Scientific American 180:4, 1953, pp. 65-77
} 
Repetition emphasises, but it also estranges. In drawing attention to the linguistic matrix by which ideology transmits itself, we are forced to observe its mechanics. For instance, in the final moments of the first act we see two scenes cut together. In one, Rosler, with the assistance of female examiners, is seen donning a black cocktail dress. In the other, slightly more clumsily, she puts on a wedding dress. As Rosler's performer prepares her body for public display, the narrator lists a series of gestures women find themselves compelled to perform in order to align with normative ideals of femininity:

To add paint on top of flesh, a liquid mixture of thin mud, colored material, grease, tar derivatives, and other, unknown, artificial and derived substances.

To add colored powder.

To learn what is called the color of flesh.

To see one's features from up close.

To regard them as invisible, as in a raw state, until outlined or painted over.

To see some hairs as important and needed and others as bad, unwanted.

To approximate an ideal.

The narrator refers to things by the elements which make up their whole, and in doing so defamiliarises them. The materials of femininity become strange, even hostile, and their application ritualised. Womanhood becomes a verb, something always in the doing, something which requires a constantly renewed scrutiny of oneself, what Judith Butler describes as a 'a complexity whose totality is permanently deferred, never fully what it is at any given juncture in time.'3 Rosler ends this list by underscoring its purpose, the control of the self. 'The Total Woman remembers to bathe every day, to manage her image in such a way that her personality disappears and her ability to absorb and to be projected upon, to present herself for delectation, substitutes for private desires of the self-as-self.' To refer to Vital Statistics as dull is not a matter of evaluation. Rather, it is an attempt to speak to ways in which the work operates by reproducing the very ordinariness with which normativity is exercised, internalised, and made to seem invisible.

In Louis Althusser's famous description of the transmission of ideology between states and bodies, a man feels himself come together at the call of a police officer. ${ }^{4}$ In this scene, a transformation takes place. Upon being interpellated, the man ceases to be an 'individual,' and becomes a 'subject,' and in becoming a subject, is subjected to the apparatuses of law, criminality, and penalty the officer represents. ${ }^{5}$ Vitally, Althusser

\footnotetext{
3 Judith Butler, Gender Trouble (1990), London and New York: Routledge, 1999, p. 22

4 Louis Althusser, 'Ideology and Ideological State Apparatuses (Notes towards an Investigation),' Lenin and Philosophy and Other Essays, trans. Ben Brewster, New York: Monthly Review Press, 1971, p. 174-175

${ }^{5}$ Althusser, 1971. pp. 174-175
} 
evades the question of wrongdoing on the part of the man being interpellated. The scene begins with the call. The precision of Althusser's drama provides a means to think through what happens when one recognises, or misrecognises, oneself as an actor in a scene; as someone painfully present, and thereby vulnerable to being held with suspicion. Althusser perhaps overstates the extremity of interpellation by choosing to illustrate his theory with an exchange between an agent of the law and a suspect. If interpellation is the means by which individuals find themselves constituted as subjects of discourse, and thereby bound to the terms of that discourse, it may be useful to attend to the ways subjects find themselves interpellated in more mundane scenes of everyday life.

For Judith Butler, Althusser's illustration presumes a guilt on the part of the subject. In being constituted by the police officer, the subject is given reason, whether legitimate or not, to imagine themselves as having transgressed the law. 'To become a "subject,"' Butler writes, 'is thus to have been presumed guilty, then tried and declared innocent. Because this declaration is not a single act, but a status incessantly reproduced, to become a "subject" is to be continually in the process of acquitting oneself. ${ }^{6}$ Rosler's performer finds herself interpellated time and time again. With each direction she is made to make her body available for the men conducting their examination. But she finds herself interpellated, too, by the objects which compose the set - the tape measure, the clipboard, the white coats worn by the examiners. She becomes a subject of modern science, modern statistical analysis, and the subject of the modern liberal state which puts bodies within, as Michel Foucault writes, 'a field of visibility.'7 In becoming a subject, she composes herself accordingly - thereby, it would seem, granting legitimacy to the repressive matrix that holds her in place.

For Butler, the transgression implicit in interpellation is not always so easily identified as is it when one finds oneself accused by a police officer. The processes of socialisation, identification, and self-management described in the video - the application of make up, the adoption of certain poses, learning, as Rosler puts it, 'to see oneself as a map, a terrain, a product constantly recreating itself inch by inch' - are not always codified in law. The ideological apparatuses that propel and reproduce normative modes of gendered performance are often difficult objects to imagine and describe. Discourses of gendered

\footnotetext{
6 Judith Butler, The Psychic Life of Power, Stanford: Stanford University Press, 1997, p. 118, italics in original

${ }^{7}$ Michel Foucault, Discipline and Punish: The Birth of the Prison (1975), trans. Alan Sheridan, New York: Vintage, 1995, p. 202
} 
normativity find themselves sedimented in all manner of texts. Rosler's narrator lists several:

Read from a work on cybernetic servomechanisms.

Read from a work on self-abuse.

Read from a list of items for the trousseau, a list of gifts for the wedding guests to choose from.

Read from a list of do's and don'ts.

Read from a list of glamorous make-overs.

Read from a list of what men do and what women do.

Read from a list of girls' toys and of boys' toys.

Read from a list of average incomes of men and of women.

Read from a book of resignations and defeats.

Read from a manual on revolutionary society.

The 'Total Woman' of Rosler's narration, then, finds herself bound to the ritual application of 'paint on top of flesh' as a means of acquitting herself from any accusation of wrongdoing. Or, we might follow Rosler in saying, 'she sees herself from the outside with the anxious eyes of the judged who has within her the critical standards of the ones who judge.' The accusation from which Rosler's 'Total Woman' attempts, perpetually, to acquit herself is never so concisely enunciated as the kind of accusation voiced by Althusser's police officer. For Butler, the punishment for transgressing the boundaries of the interpellations of gendered normativity - such as those implicit in Rosler's narrator's list do not make themselves as transparent as those that fall under penal law. This leads Butler to ask,

\footnotetext{
What are the conditions under which our very sense of linguistic survival depends upon our willingness to turn back upon ourselves, that is, in which attaining recognizable being requires selfnegation, requires existing as a self-negating being in order to attain and preserve a status as "being" at all? 8
}

What is at stake here seems to be the very category of human itself. That is, certain transgressions leave those who perform them subject to forms of punishment that would place them outside the limits of the promises of humanism and the protections putatively offered by the democratic state. Both Althusser and Butler open a route to ask what might be meant by the 'citizen' of the work's title. What does the relation between the citizen, the state, and the agents of science ammount to? What promises are made to the citizen, and what keeps one from qualifying for that title?

${ }^{8}$ Butler, 1997, pp. 129-139 
In Vital Statistics, citizenship amounts to a failed scene of reciprocity. The video and its narration take place in several registers at once. That is, Rosler's narrator swings from describing the methods of biopower in the twentieth century, and the prosaic experiences of gendered normativity. For Rosler, it is impossible to discuss the way knowledge is made without discussing the way knowledge is lived. Rosler's narrator emphasises the political existence of the scientific, the means by which 'scientific human measurements have been used to keep people from access to education, to keep certain races and nationalities out of America, to keep women subordinate, to keep women in their place.' But there are gaps in the video's narration, too. In the video's opening sequence, before an image has appeared on screen, the narrator hails an audience already aware of the causal relationship between the collection and categorisation of human data and the kinds of violence that occur when subjects contravene these categories. Some things, for Rosler's narrator, need not bear repeating. She states, 'I needn't remind you about processing and mass extermination. You remember about the scientific study of human beings.' Of course, in drawing attention towards what need not be said, she emphasises it.

What may initially seem like hyperbole, like a flippant evocation of genocide for the purposes of mounting a polemic, ends up bearing a certain affinity with Giorgio Agamben's reconsideration of Foucault's work on the biopolitical. In Homo Sacer, the internment camp (and the possibility of mass extermination that accompanies the internment camp) acts as the central metaphor that propels Agamben's argument. The camp is, for Agamben, the 'fundamental biopolitical paradigm of the West.' ${ }^{9}$ Writing in the final decade of the twentieth century, and engaged in a project of tracing the lineage of the biopolitical body further back into European political history than Foucault initially did, as well as seeking to understand its mutations through the twentieth century, Agamben ends his book by arguing that the totalitarian regimes that have emerged over the past hundred years were not an historical anomaly, but the logical outcome of the biopolitical regime. ${ }^{10}$ The possibility for totalitarian rule (and the massive loss of life associated with it) is encoded into the mechanics of modern democracy. ${ }^{11}$ Further, Agamben seeks to understand the relationship between the power of the modern nation state and its citizens. 'Corpus,' or the modern political subject, 'is a two-faced being, the bearer both

\footnotetext{
9 Giorgio Agamben, Homo Sacer: Sovereign Power and Bare Life, trans. Daniel Heller-Roazen, Stanford: Stanford University Press, 1998, p. 102

${ }^{10}$ Agamben, 1998, pp. 95-96

${ }^{11}$ Agamben, 1998, pp. 89-91
} 
of subjection to sovereign power and of individual liberties.'12 If, under a representative system of governance, the subject becomes 'sovereign subject,' this sovereignty is granted (or withheld) by the state in which the subject was born. Agamben writes,

It is not possible to understand the "national" and biopolitical development and vocation of the modern state in the nineteenth and twentieth centuries if one forgets that what lies at its basis is not man as a free and conscious political subject but, above all, man's bare life, the simple birth that as such is, in the passage from subject to citizen, invested with the principle of sovereignty. ${ }^{13}$

The subject becomes a political entity only in relation to the state, and finds themselves bound to the limits, definitions, and measurements that state imposes upon legitimate life. The attribution of a value always implies the presence of a nonvalue, of an illegitimate other, in Rosler's case the non-standard, which is left open to vulnerability, erasure, or destruction. ${ }^{14}$

What does it mean to be a citizen? What qualifies one as a citizen, as someone bound to the state, and kept from flourishing by that very same state? Vital Statistics was produced almost two decades before the publication of Homo Sacer. It is telling, though, that Agamben refers to the political subject using the male third person pronoun. In the third and final act of Vital Statistics, a slideshow of archival images of medical examinations and exceptional patients, all bearing a striking resemblance to the gestures featured in the first act, appears on screen (fig. 3 and 4). Between and around microphone distortions and static, Rosler intones a litany of alarmingly common violent acts against women, 'Clitorecdectomy, brutalisation, pornography, sterilisation, forced motherhood, outlawed abortion, illegal abortion, women battering, assault, insult, loathing, derogation, victimisation, depredation, deprivation, femicide, femicide, crimes against women.' This litany, it would appear, is not intended to be a list of glitches in the biopolitical programme described by Rosler's narrator in the first act, rather, it represents its natural outcomes. If sovereignty is, when dispersed across the modern citizenry, a measure of, and assurance of, a set of codified liberties and rights, including the right to life, and including a certain degree of autonomy over how that life is lived, it is not a stretch to say that women have been, and may yet remain, not-yet-sovereign, and therefore, Rosler's designation of citizenship points towards the concept as a failed promise. The 'citizen' in the work's title points to a paradox, or a scene of failed reciprocity. It points towards the kinds of complications that arise when one is bound to the state and simultaneously not

\footnotetext{
12 Agamben, 1998, p. 73, italics in original

${ }^{13}$ Agamben, 1998, p. 76

${ }^{14}$ Agamben, 1998, p. 81
} 
recognised by it. Citizenship and its failures become, in Rosler's video, both intimate and overwhelming.

Lauren Berlant, in her essay 'The Subject of True Feeling: Pain, Privacy, and Politics,' examines the ways in which the minoritarian political movements of the latter half of the twentieth century refigured the failed reciprocity of citizenship into a woundedness that calls upon the state to better distribute the promises it makes. Rosler's list of 'crimes against women,' for instance was taken from the proceedings of the first International Tribunal of Crimes Against Women, which took place between 4th and 6th March 1976.15 For Berlant, such a tribunal typifies a certain kind of tactic of minoritarian politics, in which 'subalterns scarred by the pain of failed democracy reauthoriz[e] universalist notions of citizenship in the national utopia, which involves believing in a redemptive notion of the law as the guardian of public good.' ${ }^{16}$ I would argue, however, that Rosler's position is more ambivalent. She does not cite the Tribunal explicitly, and it might be presumptuous to assume that the inclusion of the list amounts to a endorsement of a reformist model of politics that would seek the redemption of a failed programme of law and order as the path to emancipation. Considered in relation to the first act of the video, it is necessary to bear in mind that the state that appears to have endorsed or allowed these crimes against women to continue is the same state for whom, presumably, the acts of measurement and standardisation are undertaken.

Between the first and the third act, some kind of slippage takes place. The second act of the video is described in the prologue by Rosler's narrator as 'symbolic.' She goes on, 'what is the same, what is different, what is outside, what is inside?' The camera is now positioned at a high angle, looking down upon a spotlit set containing bathroom scales, a white platter, a white bowl, and half a dozen eggs. Rosler's performer, nude, enters the scene and methodically cracks each of the eggs before tipping the bowl towards the camera (fig. 5). We are dealing here with chickens and with eggs. We are dealing with things in a causal relation to one another, and an argument regarding which precedes the

\footnotetext{
15 International Tribunal of Crimes Against Women, which took place between 4-8 March 1976 at the Palais des Congrès in Brussels. Diana E. H. Russell and Nicole Van de Ven, Crimes Against Women: Proceedings of the International Tribunal, Millbrae: Les Femmes, 1976; Whitney Museum of American Art,'Chrissie Iles in Conversation with Martha Rosler,' Youtube, 9 August 2010, accessed 14 September 2016

${ }^{16}$ Lauren Berlant, 'The Subject of True Feeling: Pain, Privacy, and Politics,' in Austin Sarat and Thomas R. Kearns (eds.), Cultural Pluralism, Identity Politics, and the Law, Ann Arbor: University of Michigan Press, 1999, p. 52
} 
other that circulates indefinitely. ${ }^{17}$ We are perhaps led to address the question of what might precede this woman, and the category of femininity against which she is measured. What mediates her access to citizenship, to subjectivity, to being addressed, to being recognised in public as something in particular, and to recognise herself as that something. In addition, perhaps, we are viewing an act of creative destruction akin to the aphorism of breaking eggs to make an omelette. ${ }^{18}$ The shock of the change in register, from the 'real time' to the 'symbolic,' forces a renegotiation of what we have just been witness to. For Rosler, the immanence of womanhood, the habits, learned behaviours, and codes of recognition of womanhood need to be dismantled before the work of building a better, more habitable, world is able to take place.

Rosler's performer is metonymic, a stand-in, a case study. She is so both in relation to the men who perform their analysis on her, and the narrator for the purposes of her argument, who is simultaneously Rosler herself. For the former, she is meat from which values are extracted and compared to the values of other bodies. For the latter, she is a means of demonstrating the violence of this exchange. Rosler, in playing both performer and narrator, speaks and is spoken for. But the actors in the scene do not speak on equal terms.

In speaking, Rosler's narrator performs an intervention into the narration of the scientists. If the scientists have claims towards the impartial, towards the objective, towards narrating for the ends of elucidation, regulation, and betterment, then Rosler's narrator can only clasp at the kind of authority endowed to these men of science. For Donna Haraway, the kind of narration undertaken by the men - where bodies are broken into elements, and read against a metric designed with transparency in mind - belongs to the 'modest witness.' The modest witness is invisible, he inhabits a 'culture of no culture,' he

\footnotetext{
17 In an interview with Martha Gever, Rosler explains the second act of Vital Statistics is a reference to Jean Luc Godard's Vivre Sa Vie (1962). Martha Gever, 'An Interview with Martha Rosler,' Afterimage 9:3, 1981, p. 13

${ }^{18}$ And we are, of course, dealing with a woman performing a domestic ritual in a nondomestic space, or rather, a space containing certain elements of the domestic, but arranged in such a way as to make the viewer all the more aware that they have been arranged as such on a film set.
} 
is, in all things, unremarkable. ${ }^{19}$ Rosler's narrator deploys the kind of syntactic arrangements that might constitute a counter-discourse to the reasoned, measured modest witnessing of the men in the scene. This gets complicated, however, for Rosler's video does not, necessarily, provide us with evidence to support her counter-discourse. Rather, it provides us with a fiction - a fiction which mingles intimately with archival images, 'symbolic' rituals, and realist gestures. In Vital Statistics, what constitutes evidence is expanded, or else done away with, making the kind of interpellation the narration performs one which both reproduces a model of forming arguments around a dialectic, in order to make oneself intelligible within the organisation of knowledge and senses within which Rosler speaks, but also shatters this presumption, making the argument strange. Vital Statistics, then, is both evidence, and not - and Rosler is both witness to this testimony, and not.

This chapter has, so far, paid attention to the ways in which Rosler's performer may come to recognise herself as a subject of biopower, as a subject of post-Enlightenment scientific technologies, as a gendered subject of the late twentieth-century liberal democratic state. All this, however, may seem redundant. This work is already done by the video's narration, much of which seems to predict Haraway's claim that the biological sciences 'narrate' the world and its inhabitants. ${ }^{20}$ It may be time, then, to adjust our understanding of recognition, by asking: who is this work for? Who is the subject of the work? Or, who is supposed to recognise themselves in this work, and what traction for social change might be encoded into that recognition? I have already mentioned that the subject hailed by Rosler's narrator is one able to fill in certain blanks - the blanks left by Rosler as she evokes the uncomfortable intimacy between the collection of data on populations and the mass extermination of certain categories of people within those populations. In hailing this audience, and proceeding to demonstrate some of the ways in which they find themselves named, and some of the meanings that attach themselves to these names, Rosler perhaps fulfils what Haraway, in her intervention into Althusser's scene of interpellation, describes as a means to 'refigure' the terms of the discourse in which this audience find themselves named. 'In the end,' Haraway writes, 'it is those who mis/recognise themselves in discourse who thereby acquire the power, and responsibility,

\footnotetext{
19 Donna Haraway, Modest_Witness@Second_Millenium.FemaleMan@C_Meets_OncoMouse ${ }^{T M}$, London and New York: Routledge, 1997, pp. 23-24; See also: Peggy Phelan, Unmarked: The Politics of Performance, London and New York: Routledge, 1993, p. 13

20 Haraway, 1997, p. 64
} 
to shape that discourse.' ${ }^{21}$ For Haraway, even the work of naming that which names us is valuable work in the project of undoing the damage of the negativity that attaches itself to those names. In order to better approach the question of who might be willing and able to recognise themselves in Rosler's work, though, it may be necessary to position Rosler's practice within its historical context, and to examine her work relation to the pedagogical project of activist art.

Rosler's practice, which spans over forty years, has consistently come from a place of skeptical political commitment - one which remains keenly analytical and which treats its objects of critique as moveable, malleable, and constantly in flux. This critique takes place at the level of form, as well as positioning itself diametrically against the socioeconomic conditions in which Rosler's practice takes place. Craig Owens, for instance, calls her series The Bowery in two inadequate descriptive systems (1975) a 'refusal of mastery.' ${ }^{22}$ For Owens, the series, which features twenty-one images of storefronts in the New York neighbourhood alongside twenty-four lists of words signifying inebriation, constitutes an 'undermining' of the conventions of liberal social documentary's reliance upon the production of empathy (or even pity) as a means of drawing attention to social ills. Owens writes, 'Rosler has refused to photograph the inhabitants of Skid Row, to speak on their behalf, to illuminate them from a safe distance.' Rosler neither speaks for the inhabitants of the neighbourhood, nor does she let the images speak for themselves. Language interrupts, or, in Allan Sekula's words, 'interposes itself between us' and the images. ${ }^{23}$ Rosler's subject, then, is less a neighbourhood in New York City as it is the process by which that neighbourhood gets conjured in the social imagination as a site of decay, decadence, and destitution. ${ }^{24}$ For

Owens, The Bowery 'upsets the (modern) belief in vision as a privileged means of access to certainty and truth.' ${ }^{25}$ We can, of course, detect the same operations of disruption in

21 Haraway, 1997, p. 50

22 Craig Owens, 'The Discourse of Others: Feminism and Postmodernism,' in Beyond Recognition: Representation, Power, and Culture, Berkeley and Los Angeles: University of California Press, 1992, p. 178

23 In Sekula's famous essay, Rosler is held as an archetypical example of a model of creative practice the author terms 'critical representational art.' For Sekula, critical representational art has an obligation to 'point openly to the social word and to possibilities of concrete social transformation... towards modes of address based on dialogical pedagogy.' Allan Sekula, 'Dismantling Modernism, Reinventing Documentary (Notes on the Politics of Representation),' The Massachusetts Review 19.1, 1978, p. 859

${ }^{24}$ Rosler herself writes, 'The photographs are powerless to deal with the reality that is yet totally comprehended-in-advance by ideology, and they are as diversionary as the word formations-which at least are closer to being located within the culture of drunkenness rather than being framed on it from without.' quoted in Owens, 1992, p. 178

25 Owens, 1992, p. 179 
Vital Statistics. In the latter, however, emphasis is placed upon the sites in which knowledge gets produced. Within Rosler's practice, the image and the language with which the image is able to be interpreted are ideologically bound. Seeing is suspect, but nonetheless able to be adjusted for emancipatory ends.

To refuse mastery might also describe Rosler's approach to form. Her practice ranges from postcard novels, to performance and video, to garage sales, to collage. For Rosler, form takes shape according to a pedagogical model of artmaking, according to what a work needs to achieve for a particular end. Which is not to say, of course, that Rosler's approach to form is purely teleological. 'The question of medium per se isn't terribly interesting to me.' Rosler says in an interview with Jane Weinstock, 'Meaning is, and I use the appropriate medium. Often it's not a decision so much as it is a matter of the way the work presents itself to me. ${ }^{26}$ Steve Edwards, in charting Rosler's career, quotes the artist in locating her interest in 'an imaginary space where different tales collide.'27 Edwards goes on to position Rosler within the San Diego group of political modernists. For Edwards, the political modernist outlook took up the legacies of the avant-garde movements of the first decades of the twentieth century and infused such a commitment with more recent theoretical interventions by Henri Lefebvre, Georg Lukács, Herbert Marcuse, and Jean Paul Sartre. ${ }^{28}$ 'Political modernism in this incarnation,' writes Edwards, 'entailed an alignment of the modernist critique of illusionism with the critique of ideology in a way that shifted concerns from "the representation of politics" to "the politics of representation." 29 This approach to form, and formalisms, was one keenly aware of the histories of documentary practice and popular and radical moving images. Edwards quotes Rosler's essay, 'In, Around, Afterthoughts: On Documentary Photography,' in saying she was committed to developing the 'germ of another documentary - a financially unloved but growing body of documentary works committed exposure of specific abuses caused by people's jobs, by the financier's growing hegemony over the cities, by racism, sexism, and class oppression.' 30

\footnotetext{
26 Jane Weinstock, 'Interview with Martha Rosler,' October 17, 1981, p. 78

27 Steve Edwards, Martha Rosler: The Bowery in two inadequate descriptive systems, London: Afterall, 2012, p. 69

28 Edwards, 2012, p. 99

29 Edwards, 2012, p. 94

30 Edwards, 2012, pp. 80-81; Martha Rosler, 'In, Around, and Afterthoughts (on Documentary Photography)' in Decoys and Disruptions, Cambridge, Massachusetts: The MIT Press, 2004, p. 196
} 
Vital Statistics was staged first as a performance at University of California, San Diego in 1974. ${ }^{31}$ In an interview with Jane Weinstock, Rosler describes the filming of the work, three years later, in pragmatic terms. That is, transferring the work into video allowed for a greater and easier distribution. It also, however, forces a reconsideration of the work as a video. The work does not sit easily when described exclusively as either documentary video, or as documentation of a performance. It seems to take place in a space adjacent to both of these things. In proximity to the real, or a staging of the real, but distinct from it. Where the formal specificities of the medium of video are used - for instance in the montage scene in which Rosler's performer prepares herself in two different outfits - it is done so sparingly.

In an essay published in Artforum in 2004, Rosler ponders what possibilities for social transformation might exist in contemporary art practice. She notes astutely that the present in which she writes (and her observation remains relevant in some ways) is marked by a certain kind of fatigue (in reference both to conditions under which late capitalism wears out bodies, and the ways in which resistance to global capitalism seems exhausted or ineffectual). Rosler notes that the modes, genres, and practices previously both hostile to the art market and optimistic in their ability to bring about a less cruel public sphere quickly lost steam through their recuperation into what she describes as 'museum mausoleums and collectors' cabinets.' Rosler admits, however, that although the institutionalisation of oppositional practice tends to exhaust that practice of its transformative potential, considering the acts and objects of opposition historically, as belonging to moments during which the horizon of possibility seemed to be expanded, we may be able to think through what it is that makes the political artwork work. 'The political work of the late '60s through 70's,' she writes, 'now purged of exigency and brought out of the closet by the market - may be evaluated differently. This work may be tinged with nostalgia to young artists likely to have encountered it in art-history classes, but it offers a starting point and a history to connect with, an ur-moment that all trends in art like to locate. What initially seemed attractive for its look becomes more compelling for

\footnotetext{
${ }^{31}$ It is notable that Edwards aligns Rosler with the San Diego group rather than with the furtive energy of Californian feminists during this decade. In an essay published in Artforum in 1977, Rosler herself, while acknowledging a sympathy with the project of women's emancipation, as well as several artists and writers working in California during the 1970s, stages a critique of what she terms a 'cultural feminism' which would bind all women into a shared oppression, over and above class and race, and 'stress separatism and a voluntary change in material cultural and in the organization of private life... rather than an active program of mass education and the seeking of political power.' Martha Rosler, 'The Private and the Public: Feminist Art in California,' Artforum 16:1, 1977,p. 67
} 
its commitment.'32 This comment describes succinctly what this chapter has attempted, and will continue to attempt to do. In beginning a study of contemporary forms of oppositional documentary practice by discussing an artwork produced in 1977, I hope to establish a robust ground from which to consider the transformative potential in the works of Bernadette Corporation, Hito Steyerl, and Zach Blas. This chapter is an attempt to think through how we might identify the artist as a political agent, as well as to consider how the political artwork lives on in the very circumstances it wishes to undo.

Though Rosler performs two distinct roles in the video, the distinction between narrator, subject, and filmmaker is not necessarily foreclosed. That Rosler's performer complies with the demands of the scientists even as her narrator engages in a monologue undermining any possibility of scientific objectivity outside of the ideological programme in which it emerges does not necessarily imply a disparity in the kinds of knowledge (and counter knowledge) available to each woman. We might rather read this distinction, or the lack of confirmation of a distinction, as evidence of the ways in which refusing the social, even when one finds oneself in a position to enunciate its violence, is work that cannot always be maintained. This is the kind of interpellation Althusser conceptualises, that recognition of oneself within an ideological programme does not offer a way to escape that programme. The man in Althusser's drama, who hears the police officer hail him and recognises himself, feels himself come together as a social being within a system of criminality is offered no reprieve by this criminality, whether he happens to believe in the legitimacy of the system or not. ${ }^{33}$ Admitting to ourselves that Rosler's performer is not naïve, then, points towards the difficulty of maintaining an attachment to the world while being cognisant of its hostility. That is, it means having to deal with the tentativeness of Haraway's proposition that naming that which names us may provide a means of escape. Haraway is clear in her assertion that naming might only achieve so much, that the work of the political is always ongoing, and always unfolding.

\footnotetext{
32 Martha Rosler, 'Out of the Vox: Martha Rosler on Art's Activist Potential,' Artforum 43.1, 2004, p. 218

${ }^{33}$ Louis Althusser, 1971, p. 174-175
} 
What Vital Statistics demonstrates is the means by which identity is a matter of interpretation. Identity is constituted by the instances of having a body in public and the proximity that body assumes to existing categories of knowing and being. It is in these acts of interpretation (in the scene of being acted upon) where my problems with Bersani's call to the unnamable emerge. Bersani perhaps overestimates the extent to which the subject can exert agency upon how they might inhabit the world. To what extent can refusing the names that are thrust upon us negate the possibility of violence when we encounter disciplinary or ordinary violence intended to maintain and police those very names? For Bersani, the body is a site of limitation, the frame within which identity is allowed to play. At times, however, the body contravenes the direction in which or extent to which this play is allowed to occur: 'It is as if it had its own intentionality, one that erodes the essentializing freedom of the imaginary.'34 The example at the centre of Bersani's essay, Todd Haynes' film Safe (1995), follows Carol, a middle-class housewife from suburban California, who, after suffering a violently allergic reaction to her surroundings (described at one point as an allergy to 'the twentieth century') retreats to an isolated New Age community headed by a charismatic leader. Carol's sickness, it eventuates, is more potent than that of other inhabitants of the community, and she is sequestered to a small shack to live in isolation. This retreat, and the philosophy of radical self-love it espouses, does little to cure Carol of her physical and psychological symptoms, but Bersani insists the film amounts to neither a sincere ecological argument against the conditions and attritions of late capitalism, nor a parodic criticism of a New Age philosophy that posits subjects might be able to 'will themselves out of distress.' 35 Bersani argues that Carol, who represents a case study of the exhaustion of being hailed into a hostile social world, 'enacts a shedding of identities that is also a shedding of the film's subjects: the strongly legitimized identity of a middle-class female homemaker, her identity as a victim of industrial waste, her symbolic identity as an immune-damaged carrier of a fatal infection, and finally her particular (and particularly thin) psychic identity as a person.' ${ }^{36}$ What is left ambiguous, however, is whether this shedding is a corollary to her retreat from the social world which made her sick in the first place, and her subsequent retreat, or rather removal, from the New Age community. Does Bersani overinvest in the agency of the subject to shed the names assigned to her at the expense of admitting that this assignation is primarily an act of being recognised as a social being in

\footnotetext{
34 Leo Bersani, Thoughts and Things, Chicago: University of Chicago Press, 2015, p. 20

35 Leo Bersani, 2015, p. 31

${ }^{36}$ Leo Bersani, 2015, p. 35
} 
a social world ${ }^{37}$ And is Bersani's model of radical refusal a politically irresponsible model of emancipation for those who, while named violently or inaccurately, might lack the means, or wherewithal, to enact a retreat akin to Carol's?

Vital Statistics, in drawing attention to the violence of the ideological programme that binds certain bodies to interpretation, misinterpretation, docility, enslavement and any number of forms of violence listed by her narrator, does not offer a way out - it does not offer a utopian alternative, but rather insists that being political, being aware of oppression, and even being able to articulate its mechanics, means being bound to the political programme in which the enunciation takes place. Rosler's performer is addressed by multiple names. She is called 'citizen' in the work's title, 'subject' in the work's closing credits, and referred to only in the feminine third person throughout the narration. In a way, this refusal to settle upon a name, broaches the problem of the case study. We are, throughout, witness to the bodily manipulation and measurement of one woman, who is supposed to stand-in for the category of woman, and whose very singularity is undermined by the process of identification and control she performs. We are forced to ask: what might mediate one's access to citizenship, to subjectivity, to be interpreted in a way that does not interfere with how a subject may want or need to be interpreted? Where does the general meet the specific? With whom does an audience identify? Might they identify with both - both bound to a programme of violence, and able and willing to articulate its workings? Might there be a way for politically vulnerable subjects to enact Bersani's model of negativity in a way that does not involve a retreat from the world, a separatist utopia whose efficacy seems dubious in the twenty-first century?

\footnotetext{
37 Following a lecture based on the chapter I am referring to, delivered as part of Norway's Office for Contemporary Art The State of Things programme in Venice in 2011, Bersani was asked by an audience member how his programme of unnamability might be taken up by racialised subjects, or those most vulnerable to the negativity that might attach to the names by which they find themselves interpellated. In response, Bersani proffers that his argument takes place in realm preceding the political. That is, it might be read in sympathy with Lee Edelman's argument in No Future: Queer Theory and the Death Drive. I would suggest, however, that this conception of unnamabilty jams when we try to interpret it within the kind of unapologetically materialist framework Rosler is committed to. Leo Bersani, 'Illegitimacy,' lecture delivered at The State of Things, Istituto Veneto di Scienze, Lettere ed Arti, Venice, 2 June 2011, http://www.oca.no/ programme/audiovisual/the-state-of-things-illegitimacy, Accessed 15 December 2016
} 
During the afternoon of 20th July 2001, Carlo Giuliani was shot and killed by a member of the Italian military police force. Giuliani was among hundreds of thousands of protesters gathered in Genoa, Italy at a demonstration to coincide with the 27th Group of Eight (G8) summit. Quickly following the incident, photographs of Giuliani began circulating among leftist publications and online forums. Giuliani became an icon of the protest and its violently enforced repression. He became a martyr for the anti-globalisation movement. Less than a year after his death, a documentary, titled Carlo Giuliani, Boy, premiered at the Cannes Film Festival. Murals commemorating the man appeared in Piazza Alimonda, where he was killed, as well as in Rome, Sardinia, and Berlin. ${ }^{1}$

These were not the only images of Guiliani that circulated. In the days following the protests, the 23-year-old was featured on the front pages of countless newspapers in Europe and the United States. In his analysis of mainstream news coverage of the events, Antigoni Memou draws particular attention to the discrepancies that appeared in different outlets from different locales. The majority of American outlets chose a picture taken moments before Giuliani was shot, captured by Reuters photographer Dylan Martinez, in which the protester wields a fire extinguisher in the direction of police. In Europe, the photograph chosen to adorn the front pages of newspapers on the morning of 21st July 2001 featured Giuliani's dead body, splayed out on concrete, blood pooling behind his head. ${ }^{2}$ Here, we witness an attempt to manipulate where emphasis should fall in this narrative of confrontation between the state and one of its citizens. The image circulated by the American press encourages this event to be read as a police officer defending themselves from a violent protester, thereby placing culpability at least partially on Giuliani

\footnotetext{
${ }^{1}$ Rory Carroll, 'The wild boy who became a martyr,' Observer, 22 July 2001. Accessed 25 January 2017, https://www.theguardian.com/world/2001/jul/22/globalisation.businessandmedia4; Chris Summers and Irene Peroni, 'Ghosts of G8 haunt Genoa,' BBC News, 7 February 2005. Accessed 25 January 2017 http:// news.bbc.co.uk/2/hi/europe/4217629.stm; Michael Leonardi, 'Remembering Carlo Giuliani,' Counterpunch, 22 July 2011, Accessed 25 January 2017 http://www.counterpunch.org/2011/07/22/remembering-carlogiuliani; Fabio Caffarena and Carlo Stiaccini, 'Piazza Carlo Giuliani: G8 Summit, Genoa 2001,' in P.J. Sanchez and Cristina Carretero (eds.), Grassroots Memorials: The Politics of Memorializing Traumatic Death, New York: Berghahn Books, 2011, pp. 308-309

2 Antigoni Memou, 'When it bleeds, it leads:' Dead and Press Photography in the Anti-Capitalist Protests in Genoa in 2001,' Third Text 24:3, 2010, pp. 342-343
} 
for his own death; the latter, however, seems to allow more room for the possibility that this may have in fact been an act of state violence against one of its own citizens. ${ }^{3}$

Giuliani's death and the protests during which it occurred are overdetermined events. It is not my intent to wade through the factors that led to Giuliani's killing, but rather to ask what, and who, makes it out of a protest? How does a site of political action find itself remembered as an event? How does an event crystalise into an image, or a series of images? What inevitably gets left out? The case of Giuliani highlights that historical memory is always a political exercise, and that images can intervene powerfully into this exercise. 'Images,' writes Victoria Hattam, 'draw us into the contested field of the unspoken political where looking remains intense and contentious on the one hand and speculative and creative on the other.' 4 The image acts as a screen upon which the fantasy of the political - that is, the fantasy of how life should be organised and reproduced - is able to be projected, or disavowed, or manipulated. The image might attach itself to already existing narratives, affinities, and identifications and end up affirming a dominant ideology. Or, it may allow the commonsense to be complicated, upset, or revised. At stake in the reception, transmission and circulation of images of Giuliani's death was the legitimacy of his complaint, and by extension, the legitimacy of mass protest. Simultaneously at stake, though, is what is missing from images. How does the energy, confusion, disorder, and dullness of political rupture find itself represented? And what, inevitably, gets left out of these representations?

With these questions in mind, I argue in this chapter that the subject of Bernadette Corporation's Get Rid of Yourself (2003) is not so much the event of the Genoa protests, but the ways in which protest fails to be represented. In a brief aside in her essay on the artists, Jian-Xing Too calls the film 'unconvincing' as a political documentary. ${ }^{5}$ This chapter takes up Jian-Xing's comment in order to ask what, exactly, about the film fails? And how might this failure be intentional, or even generative? How does the film position itself among, against, and adjacent to a lineage of radical activist art practice? And how

\footnotetext{
3 The question of culpability is one that remained (and perhaps remains) contested in a legal arena. In 2009, the European Court of Human Rights announced that the Italian state had not violated Giuliani's right to life, nor had they exercised excessive force. 'Chamber Judgement Giuliani and Gaggio v. Italy,' European Court of Human Rights, 25 August 2009, http://hudoc.echr.coe.int/eng?i=001-93948, accessed 15 January 2017

${ }^{4}$ Victoria Hattam, 'Image: Visual Speculation and Political Change,' in Vyjayanthi Venuturupalli Rao, Prem Krishnamurthy, and Carin Kuoni (eds.) Speculation, Now, Durham: Duke University Press, 2014, p. 140

5 Jian-Xing Too, 'Burn a Debt to the Present,' Afterall 14, 2006, p. 64
} 
are the historical terms and conventions of this practice problematised, abandoned, or revitalised?

Giuliani's image appears briefly in Get Rid of Yourself. His body interrupts a montage comprised of shaky clips of people marching in no discernable direction, protesters with their arms linked together, red flags bearing Che Guevara's face blowing in the wind. During this montage, we hear a woman describe a confrontation between a group of pacifists and the Black Bloc, a loosely organised set of protest tactics - including the destruction of property and deliberate hostility towards authority - which emerged in the late 1990s. The woman describes the two groups arguing over appropriate protocol for direct action. The pacifists accuse the Black Bloc of inciting a violent response from the police, while the Black Bloc accuse the pacifists of implicitly collaborating with the police. As the confrontation reaches its climax, the pacifists accuse the Black Bloc of being directly responsible for Giuliani's death, 'Because you rise up, it's your fault. You're the ones who really killed Carlo Giuliani.' As the woman recalls this part of her tale, what we see on screen seems to undermine the aggression of this exchange. A man appears, separated from any commotion. He is calm, perhaps waiting for something to happen. $\mathrm{He}$ wears a tie-dyed shirt, a lime green bandanna, and thin rimmed glasses. As he lights a pipe, a filter washes over the image, the colours become psychedelic. Quickly, the film cuts away to the still image of Giuliani, similar to the images that adorned the front pages of European newspapers (fig. 6). The image remains for a few seconds, punctuating the pacifist's accusation, before we return to the pipe-smoking man.

This scene is typical of much of Get Rid of Yourself. The film is full of tonal and temporal inconsistencies, of radical juxtapositions between disparate elements, making it almost impossible to anchor oneself. The film opens with images of a beach scene, cut between iconic shots of the World Trade Centre burning, over which cheap filters have been applied (fig. 7). The buildings turn, or are mirrored, or zoom in an awkward way. Eventually, Chloë Sevigny's voice is heard. She recites an essay published by Tiqqun in their eponymous journal in 2001 . The essay, the title of which translates to 'How is it to be done?' ${ }^{\prime 6}$ acts as something of a manifesto, first diagnosing the hostile living conditions of global capitalism, and then proposing a series of radical alternatives. The section quoted in the opening scenes of Get Rid of Yourself offers a litany of disparate resistance groups that emerged in the latter half of the 20th century, 'Twenty years, there was punk, the

\footnotetext{
${ }^{6}$ This is likely a reference to Vladimir Lenin's essay, 'What is to be done?' (1902)
} 
movement of 77, Autonomy, the City Indians, an eruption, a whole counter-world of subjectivities that no longer wanted to consume, that no longer wanted to produce, that no longer even wanted to be subjectivities.' This assemblage of movements, disparate in their ideological motivations and tactics, are bound, it appears, by a desire to refuse 'subjectivity'. This desire bleeds out onto the subjects of the film, and yet it is left unclear what this refusal may look like.

Get Rid of Yourself, as the title suggests, is a work of refusal. The film refuses existing conventions of narrative sense-making, as well as a stable, intuitive relationship between sound and image. The film refuses to allow the viewer to identify with any actants in the scenes it shows us, and in doing so, motions towards a radical reconception of political action. On their website, Bernadette Corporation describe the film as such,

Elaborating a complex and rhythmic form of address via sound/image disjunctions, cheap video effects and performance, the film declares its own exile from a biopolitical space-time where nothing ever happens. The crisis it announces is the sudden return of history, but this time without characters or a story, and of a politics without subjects. ${ }^{7}$

The film, then, seeks to demonstrate what a 'politics without subjects' might look like. The deferral of identification is one element of this demonstration. If we interpret Bernadette Corporation's use of the term 'subject' here to be similar to the ways in which identity was discussed in my previous chapter, that is, similar to Bersani's 'naming,' we are able to locate Bernadette Corporation's film, and wider practice, as a response to a context in which political engagements presupposed an attachment with an identity.

In his profile of the group, published in ArtForum in 2004, Bennett Simpson notes, 'in a cultural landscape littered with "alternatives"... Bernadette Corporation were quick to see identity as a fallacious term usurped by capital - and so they sought to undermine it from within.'8 In a similar vein, Jian-Xing Too quotes Bernadette Van-Huy (one of the original members of the group, along with Antek Walczak and John Kelsey) responding to being questioned about the group's anonymity,

When we say anonymous, we don't mean that we don't provide our names. It is more a way of being, as opposed to the more normative way of being an "individual" - living and making work that becomes assigned to one's own identity and to an individual subjectivity. Living and making work in

\footnotetext{
7 Bernadette Corporation, 'Get Rid of Yourself,' http://www.bernadettecorporation.com/getrid.htm, Accessed 22 August 2016

${ }^{8}$ Bennett Simpson, 'Techniques of Today,' Artforum 43:1, 2004, p. 222
} 
a manner that merges our subjectivities is a kind of disappearance of the individual, a disappearance of the individual into a communal subjectivity. ${ }^{9}$

It is important, I want to argue, to situate Bernadette Corporation's practice within a context in which questions of identity saturated the art market and biennial circuit, without dismissing their positioning as simply reactionary. ${ }^{10}$ At the risk of minimising a contested field of political action and theoretical intervention, I want to suggest that the form of identity politics being rejected by $\mathrm{BC}$, the form which perhaps has gained the most traction and has, over the last four decades, produced the most directly observable outcomes, is a form of politics that takes the state as both its antagonist and its route to emancipation. By which I mean the state is called upon to grant legitimacy to otherwise illegitimate subjectivities. The promise of reciprocity between a state and its citizens is called upon and the state is asked to provide protection where it previously did not. The flaw in this model, which has been pointed out and continues to be pointed out by many writers, is that an emphasis on individual freedom and state recognition can be transformed into an affiliation with neoliberal capital. ${ }^{11}$ Refusing to conduct their practice under the normative models of authorship and identity offered to them allows BC to open up space to move towards imagining new forms of collectivity, relationality, and political action in art. We cannot, however, simply dismiss identity and identification. Get Rid of Yourself, I believe, proposes identification with a negativity, with a force that does not respond to the call of interpellation, and thereby shatters the horizon of political possibility of a politics based upon shared attributes.

Get Rid of Yourself was produced out of a 'provisional' alignment with Genoa's Black Bloc, as well as the anarchist group Tiqqun. ${ }^{12}$ The nature of this collaboration, whether it amounts to either an endorsement or repudiation of the tactics employed by the Black Bloc, is a matter of ambiguity. The Black Bloc, as Jeffrey $\mathrm{S}$. Juris writes, is neither an

\footnotetext{
9 Jian-Xing, p. 63

10 The group were formed in a nightclub a year after the 1993 Whitney Biennial which, according to Nizan Shaked, 'forcefully brought art and identity politics into mainstream consciousness, placing them front and centre in intellectual debates.' This is not to suggest any causal relationship between the two events, but to reaffirm identity's currency as an urgent issue in art practice in the United States in the early 1990s. Nizan Shaked, 'The 1993 Whitney Biennial: Artwork, Framework, Reception,' Journal of Curatorial Studies 2:2, p. 143

${ }^{11}$ Adam Morris, 'Whoever, Whatever: On Anonymity as Resistance to Empire,' Parallax 18:4, 2012, p. 106-107; Lauren Berlant, The Queen of America Goes to Washington City: Essays in Sex and Citizenship, Durham: Duke University Press, 1997, p. 17; See also: Judith Butler, 'Merely Cultural,' Social Text 52/53, 1997, pp. 265-277 and Rosemary Hennessy's response to Butler's essay in Profit and Pleasure: Sexual Identities in Late Capitalism, New York: Routledge, 2000, pp. 57-60

12 Bernadette Corporation, 'Get Rid of Yourself,' Accessed 9 August 2016
} 
organisation nor a network, 'but rather a specific set of tactics enacted by groups of young militants during protests,' often including, 'destruction of private property, usually banks and storefronts of transnational retail chains, ritualised confrontation with police, and a series of more specific practices: such as 'de-arrests', marching in small, compact groups with elbows linked, or jail solidarity.' 13 These tactics are coupled with a uniform of black clothing, combat boots, and black balaclavas or bandanas covering the face. The purpose of this uniform is at once to distinguish Black Bloc militants from police and other protestors, and to avoid detection by surveillance cameras and police forces. In lieu of any coherent political project, then, the Black Bloc is bound by the spectacle of itself.

In the film, we experience the spectacle of the Black Bloc only briefly. Among the montage of protest clips, we catch glimpses of black-clad bodies, of projectiles flying in all directions, vehicles burning, smashed up shopfronts. Interspersed between these images are clips of a seaside retreat; a family swimming in the ocean, a table being set in a sunny courtyard. ${ }^{14}$ The most direct contact with the Black Bloc offered to the viewer is through testimony in French and English from unseen speakers. During the first half of the film, scenes of protest are narrated by Black Bloc participants attempting to access the affective quality of the protest at a temporal remove. These descriptions all circulate around the kind of transgression permitted when one becomes both anonymous and among others behaving similarly.

\section{There's a moment... when you arrive at these kinds of situations with some people you know, friends, people you meet, chance encounters. And then you begin to lose them, because the action makes everybody scatter... It's at that point where you feel something that goes beyond you. You're no longer a subject, the points of reference are lost.}

The loss of reference points, which seems to echo Sevigny's recital of the refusal of subjectivity practiced by the groups she lists, appears to represent the appeal of the Black Bloc. Some fleeting, affective pull occurs both in the adoption of certain modes of dress, and in the understanding that one is among allies. Both the mode of appearance (or disappearance) and what Jeffrey S. Juris calls 'performative violence' enacted by the Black Bloc participants work to bind participants to each other. ${ }^{15}$ Juris uses performative violence, in part, to stress that the destruction of property, and the hostile persona of the participants is, at least putatively, choreographed. The violence of the Black Bloc is a form

\footnotetext{
13 Jeffrey S. Juris, 'Violence Performed and Imagined: Militant Action, the Black Bloc and the Mass Media in Genoa,' Critique of Anthropology 25:4, 2005, p. 420

14 These scenes were filmed in Calabria, where the group retreated following the protests. Janet Sarbanes, 'An Independent Group? Bernadette Corporation, Post-Pop Collective,' Afterall 14, 2006, p. 52

15 Juris, p. 414
} 
of iconoclasm intended to target the symbols of global capitalism. ATMs, multinational retail chains, and banks are all legitimate targets for destruction. 'Destructive actions against ordinary cars, homes, and shops,' writes Juris, 'fall outside the bounds of accepted militant signification. ${ }^{16}$ Juris writes that 'performative violence' is 'productive' in the 'forging of political identities,' and later, 'Performative violence thus provides an important mechanism through which militants construct radical anti-capitalist subjectivities.' 17 There is, clearly, no politics without identification. Further, the kind of identification allowed for, invited by, the Black Bloc is one that takes place most potently at a visual register, whether it be through costuming, or performative violence. Though the testimony provided by protesters is often lucid, precise and visceral, we are still left with a partial view. The Black Bloc appears to us as a spectre, as something untenable outside the time and space of protest. 'You don't see much in these moments,' one protester says, as we witness a jet ski zip across an increasingly overexposed frame, 'You don't have a wide field of vision. There's a general opacity because everyone's masked... plus there's tear gas, and also the opacity of the crowd.'

During these moments of over- and underexposure, it is difficult not to recall the films and writings of Guy Debord. The influence of the Situationist International on Get Rid of Yourself is palpable. The leaps the viewer is forced to make between the chaos of protest and the interruptions of fashion shoots, luxury clothing stores, and idyllic beach scenes (images both filmed by the artists and détourned without citation) bear a striking resemblance to the composition of Debord's The Society of the Spectacle (1973). ${ }^{18}$ In the middle Get Rid of Yourself, at around thirty three minutes, the frame goes black for two minutes. The soundtrack continues, and we hear sounds from the streets of Genoa; indiscernible shouting, objects banging into each other, people running. Such a gesture speaks back to the interventions made by Debord into the continuity of filmed action present in a number of his films. The image track to Debord's first film, Hurlements en faveur de Sade (1952), made during his association with the Lettrists, is comprised entirely of alternating white and black frames, and the soundtrack to the film lasts for only twenty two minutes out of the film's one hour and twenty minute duration. For Debord, such a radical negation, as Thomas Y. Levin writes, 'is employed as the essential

\footnotetext{
16 Juris, p. 420

17 Juris, p. 416

18 The grammar of this montage, including the imposition of the Twin Towers burning, also bears a striking resemblance to Tiqqun's (sometimes credited as The Imaginary Party) film And the war has only just begun (2001).
} 
ingredient in a recipe of provocation intended to "radically transform" the cinematic "situation" from a shrine of passive consumption into an arena of active discussion, a shift away from the spectacular and toward critical engagement.' ${ }^{19}$ Debord's undermining of the sanctity of the image, through its détournement, or elsewhere its removal entirely, acts as an intervention into the terms by which images are received, and identifications are sought out. While we may read a sympathy between Debord's project and Get Rid of Yourself, the latter film also remains keenly aware that the conditions of image transmission and reception, as well as the necessary tactics for articulating and enacting dissent, had, in the five decades between the production of Hurlements and that of Get Rid of Yourself, changed dramatically.

Though the film's politics would appear to be Situationist in ancestry, it is through BC's engagement with Tiqqun that the film finds its pedagogical impulse. Texts by Tiqqun are détourned throughout the film, often without citation, and often read aloud by Sevigny. Tiqqun emerged in 1999, as a loose group of anonymous participants, with the collectively authored journal of the same name. ${ }^{20}$ The essay Sevigny quotes from at the beginning of the film, and continues to quote from throughout, was published in the first issue of this journal. Drawing on (and at times arguing against) a cacophonous host of unattributed theorists including Michel Foucault, Gilles Deleuze, Michael Hardt, Antonio Negri, and Giorgio Agamben, the tract stages a critique of a politics based around recognisable identity forms - that is, they argue against a Marxist unity of the proletariat, and the more recent emphasis on minoritarian politics - in favour of an unequivocal 'human strike.' For Tiqqun, a 'human strike' would constitute the joyous refusal of all that binds subjects to both exploitative relations of production and 'the affective relations that sustain' them. ${ }^{21}$ Any politics based around the liberation of specific identities, they claim, takes as its premise the promise of liberal individualistic sovereignty, and thereby leaves itself vulnerable to being recuperated by the technologies of neoliberal capital. While most of the theories mentioned provide a diagnosis of the authors' political present, Giorgio Agamben's work, in particular The Coming Community, provides the basis of Tiqqun's proposal for action. In lieu of political programme organised around the granting of

\footnotetext{
19 Thomas Y. Levin, 'Dismantling the Spectacle: The Cinema of Guy Debord,' in Tom McDonough (ed.) Guy Debord and the Situationist International: Texts and Documents, Cambridge, MA: The MIT Press, 2002, p. 347

20 See: Tom McDonough, 'Unrepresentable Enemies: On the Legacy of Guy Debord and the Situationist International,' Afterall 28, 2011, pp. 42-55

21 Juris, p. 221
} 
legitimacy to otherwise illegitimate identities, Tiqqun propose a politics based around Agamben's concept of the 'whatever singularity:'

Everything that isolates me as subject, as a body endowed with a public configuration of attributes. I feel it dissolve, bodies fray at their edges, at their limit, they blur, little by little, I achieve a new nakedness. That's what our need for communism is. A need for nocturnal spaces, where we can find each other beyond our qualities. ${ }^{22}$

A 'whatever singularity' describes a model of community devoid of the terms of inclusion and exclusion presupposed by existing models (most notably the state). Agamben describes 'whatever singularity' as 'a being whose community is mediated not by any condition of belonging (being red, being Italian, being Communist) nor by the simple absence of conditions (a negative community...) but by belonging itself.' ${ }^{23}$ 'Whatever,' here is taken to mean that which is neither general nor specific, ${ }^{24}$ or, we can interpret it as an ethical model which grants legitimacy to all regardless of particular attributes. Importantly, for both Tiqqun and the Black Bloc, Agamben's model of political organisation is one which has no use for the state. For Agamben, the state is responsible for either granting or denying legitimacy (and therefore, able to deny life to those deemed illegitimate). Agamben writes, 'The State, as Alain Badiou has shown, is not founded on a social bond, of which it would be the expression, but rather on the dissolution, the unbinding it prohibits... A being radically devoid of any representable identity would be absolutely irrelevant to the State. ${ }^{25}$ Get Rid of Yourself invites the viewer to detect lines of affinity between the 'whatever singularity' and the spectacular politics of the Black Bloc. In being, supposedly, free of all that might identify them as anything in particular - in being, supposedly ungendered, unracialised, unencumbered with anything that might attach itself to being named - the Black Bloc would appear to provide a model for the kind of community set out by Tiqqun and Agamben. We know, however, that the Bloc is unstable, fleeting, and impossible to access outside of moments of occasional rupture. The Bloc struggles to make itself seen in the film. The viewer is left to approximate, left to fill in the blanks opened up between what is spoken, and what images we find ourselves privy to. It seems necessary to ask whether the relationship between Tiqqun's essay and the Black Bloc which is established in the film aims to suggest that the Bloc is illustrative

\footnotetext{
22 The passages quoted by Sevigny differ slightly from the translation published by Semiotext(e) in Introduction to Civil War. I have here quoted directly from Get Rid of Yourself, though relied on the Semiotext(e) edition when consulting the prose in full. Tiqqun, Introduction to Civil War, trans. Alexander R. Galloway and Jason E. Smith, Los Angeles: Semiotext(e), 2010

23 Giorgio Agamben, The Coming Community, trans. Michael Hardt, Minneapolis: University of Minnesota Press, 1993, p. 84

24 Agamben, Translator's Notes, p. 107

25 Agamben, p. 84
} 
of what the 'whatever singularity' might look like, or whether, perhaps, they might be considered willing agents in bringing the 'whatever singularity' into being.

That 'whatever' bears a striking resemblance to the now outdated vernacular term denoting indifference, aloofness, or adolescent myopia is an awkward idiosyncrasy of translation. This inference, however, is only the more pronounced when the term is spoken in a dry monotone by Sevigny. Around sixteen minutes into the film, we see Chloë Sevigny sitting in a comfortable suburban kitchen, rehearsing the testimony we have just heard spoken by, what the viewer has previously assumed to be, protesters (fig. 8 and 9). Sevigny represents a very specific kind of celebrity. According to Jamie Sexton, she signifies 'uncool cool,' by which he refers to Sevigny's seemingly unaffected performance of reluctant stardom, her straddling of the fashion and art film scenes, and her apparent reluctance to appease the normative expectations of either world. ${ }^{26}$ What, then, are we to make of Sevigny's recital of Black Bloc testimony? If it amounts to parody, who is being ridiculed? Should the viewer be left to wonder, if Sevigny is seen rehearsing from a script, whether all other contributions to the film were also not also scripted beforehand? Sevigny is an affront. She unsettles. She stutters when trying to pronounce 'desubjectivisation.' She provides a thrift-chic counterweight to the grotesque Werner von Delmont, the aged Frankfurt School knock-off who appears in the film sitting by a stream, pontificating on the lack of 'strategic intelligence' in contemporary activism, who displays his blistered foot to the camera, who plucks a dead fish from the water and calls it ‘capitalism today' (fig. 10).

It is tempting to align Sevigny with Tiqqun's figure of the Young-Girl. The Young-Girl, according to a tract first published in 1999, is the ideal consumer under contemporary capitalism, or, we might say, the Young-Girl represents the ideal subject of the present historical moment. ${ }^{27}$ Though allegedly an ungendered term, Tiqqun's Young-Girl, by virtue of both her impressionability and her torment, 'epitomizes nothingness, the paradox, and the tragedy of visibility.' 28 She represents the 'absolute vulnerability of the separated individual, the weakness and isolation that nowhere find either the shelter, security, or

\footnotetext{
26 Jamie Sexton, 'Prisoner of Cool: Chloë Sevigny, Alternative Stardom and Image Management,' in Kate Egan and Sarah Thomas (eds.), Cult Film Stardom: Offbeat Attractions and Processes of Cultification, London: Palgrave, 2012, p. 75, italics in original

27 Tiqqun, Preliminary Materials For a Theory of the Young-Girl, trans. Ariana Reines, Los Angeles: Semiotext(e), 2012, p. 15

28 Tiqqun, 2012, p. 115
} 
protection they seem to be seeking everywhere.'29 This, I would argue, is too much for Sevigny to bear. Sevigny, stuttering away in a space which, in comparison to the chaotic street scenes, appears to be both bucolic and antiseptic, strips bare the affective potency of the Black Bloc. Whatever (at)traction, whatever potential for permanent change, for a coming community, may have seemed possible during the moment of protest gets lost somewhere between the capture of images and their transmission, and finds itself flaccid, out of place, or exhausted when enunciated by Sevigny. Political feeling is difficult to sustain. Sevigny brings to the surface the artifice of the film, as well as confirming the inadequacy of filmic representation to capture moments of political upheaval. In addition to this, however, Sevigny introduces into the film an acute awareness of branding, and in doing so, we witness the provisional alignment between Tiqqun and $\mathrm{BC}$ transform from a regurgitation of the arguments produced by the former into something more ambivalent.

Christa Blümlinger argues that for all the dead ends, inconsistencies, and complications we inevitably come across upon trying to position the film essay under a tidy rubric, what defines the film essay is the presence of doubt. Doubt, for Blümlinger, emerges from the discrepancy between sound and image, between one image and other. The film essay foregrounds the materiality of the film, of the inevitable omissions of the editing process. ${ }^{30}$ The space of doubt opened up by Sevigny's interruptions allows us to probe the discrepancies in how Tiqqun, the Black Bloc, and BC all approach anonymity, visibility, and political subjectivity. The model of political subjectivity proposed by Tiqqun, and apparently taken up by the Black Bloc, is one in the future tense. It is a mode of being in the world that does not yet exist, and therefore cannot be represented. It appears, then,

\footnotetext{
29 Tiqqun, 2012, p. 126; Nina Power, Moira Weigel, and Mal Ahern have offered responses to Tiqqun's text and its supposed non-gendered nature. Power writes that the text both 'parodies and mirrors the misogyny that resonates at the heart of a culture that celebrates youth and beauty above all else while simultaneously denigrating the bearers.' Weigel and Ahern offer a parody of their own in the figure of the Man-Child, they write, 'Forms of crypto- and not-so-crypto misogyny have proved startlingly persistent not just within the radical left but also in the bourgeois-left spheres of cultural production... We propose that a particular type is responsible for perpetuating such bad behaviour. Call him the Man-Child.' Jan Kennedy, though tentatively aligning herself with Power, Weigel, and Ahern offers her own détournement of Tiqqun's prose, at once placing it within a lineage of European critical theorists quick to invest the adolescent woman as both an ideal 'consumer of commodities and symbol of commodities, so devalued and so significant at the same time,' as well as speculating whether a modified Young-Girl may be a 'generative framework for exploring the complexities of subjectivity in neoliberal culture.' Jen Kennedy, 'The Young-Girl in Theory,' Women \& Performance 25:2, 2015, pp. 175-194. Nina Power, 'She's Just Not That Into You,' Radical Philosophy 177, 2013, radicalphilosophy.com/reviews/individual-reviews/rp177-shes-just-not-that-into-you, Accessed 26 August 2016. Moira Weigel and Mal Ahern, 'Further Materials Toward a Theory of the Man-Child,' The New Inquiry, July 9 2013, thenewinquiry.com/essays/further-materials-toward-a-theory-of-the-man-child, Accessed 26 August 2016

${ }^{30}$ Christa Blümlinger, 'Reading Between the Images,' in Erika Balsom and Hila Peleg (eds.) Documentary Across Disciplines, Cambridge: The MIT Press, 2016, pp. 176-177
} 
as negativity, as the absence of all that would force recognition under existing regimes of legibility. BC's attachment to anonymity is more flippant, more ambivalent, concerned less with absence than it is with its own mutability.

Doubt, in Get Rid of Yourself, enters the scene as an affront to enunciation. Repetition, here, estranges the enunciation of the protesters and forces the viewer to recalibrate their understanding of where emphasis should fall, and what argument might be being made by the film. This repetition, however, does not necessarily amount to an evacuation of conviction on the part of the film's creators, or the participants we see and hear. Sevigny's repetition may gesture towards something of an acknowledgement of the failure of the avant-garde of the twentieth century. A certain dissonance opens up when one compares Debord's fervent, measured narration of The Society of the Spectacle to Sevigny's stuttering drawl. To stutter, however, is not necessarily to disavow oneself of a committed position. To stutter may be to find oneself aware of the limits of political language, and to find oneself limited when uttering it. To stutter may be to find oneself at the limits of the representation of political rupture. There are other examples of stuttering in the film. At one moment near the beginning of the film, we see a couple waiting at a four-way intersection on a scooter (fig. 11). As they wait for a space to open up amidst the traffic, the driver inches forward, and then reverses back slightly, starting to turn, and then stopping quickly. He steadies the scooter with his foot. Eventually the scooter turns, and disappears offscreen. The scene hangs on for a few seconds, making all the anticipation and deflation of the previous minute of inaction all the more profound. The scene repeats at the end of the film - again swaying back and forth, again turning offscreen in a direction we cannot know.

In expanding upon her claim that Get Rid of Yourself is 'not convincing' as a political documentary, Jian-Xing Too turns towards an essay written by by the group in 1997, which represents a mock-defense of the corporate form. The author(s) describe the corporation as 'bands of people forming a bodiless/flexible entity in order to do whatever they want - and not be liable.' They continue by speculating on the potential of assuming a corporate form:

It might be possible to rethink the totality of the present system from the perspective of how your corporation is structured. While you were once dedicated to producing "loaded" products, you might take it up a level by enacting "loaded" modes of production... Take it up many levels, change patterns of brutality by encouraging negative business practices, sketchy follow-up, worthwhile 
delays, mysterious gaps in information, that force factors of patience into the market while trying to dispel anger and cruelty from client expectations. ${ }^{31}$

The corporation, we might say, is the only legitimate model of collective life available under the total domination of neoliberal capital. This, perhaps, over-invests in the revolutionary potential of BC's organisation, but it offers a way to think about their reinvention, their play, their détournement, as a series of strategies that bear a certain resemblance to the Black Bloc's spectacular politics while remaining ambivalent about the way in which the Black Bloc produce those politics. It allows us to think about the organisation of Bernadette Corporation as an entity without a face, without an identity, but not necessarily in the way the Black Bloc presents itself as faceless. The Black Bloc's mode of inhabiting facelessness is perpetually volatile, fleeting, and vulnerable to repression. By inhabiting facelessness in the corporate form, BC is able to reproduce itself as it sees fit. BC have, throughout their career, transformed themselves from party planners, editors of the magazine Made in USA, designers of several lines of clothing, and authors of the novel Reena Spaulings. Though the identities of the founding members are not kept secret, the Corporation itself expands and contracts, depending on the skills it needs to absorb in order to produce. The corporate form allows members of the group to eschew authorship, to avoid the possibility of having their work read against and among overdetermined identity categories. When, therefore, Bennett Simpson claims that BC 'undermine [identity] from within,' we might be able to the point to ways in which the corporate form is toyed with, performed, and perverted; the ways in which the corporate form provides a conduit through which something like the 'whatever singularity' can be imagined in the existing world.

We might also, then, consider Get Rid of Yourself a typical product of 'negative business practices, sketchy follow-up, worthwhile delays, mysterious gaps in information.' A product which gleefully fails to deliver the promises it makes - that is, the promise of the political. In interrupting itself, the provisional alignment between the Black Bloc and BC is splintered. The film's diagnosis of its present and its offer of a way out of the hostile living conditions the present produces do not cohere comfortably with either Tiqqun's screeds or what the Black Bloc's testimony would suggest. Tiqqun appears to retain faith in a kind of post-Situationist project of shattering the unlivable conditions of capitalist production through revolutionary praxis. Tiqqun (and the Black Bloc) share with the Situationists an 'antipolitical' position, in that they reject 'existing political forms, since these are exactly what maintain the separation between politics, art and everyday life on which the

\footnotetext{
31 Jian-Xing, p. 64
} 
spectacle is based.'32 Tiqqun and their inheritors propose a literal escape into the commune as a means of bringing about new modes of relation and personhood. ${ }^{33}$ BC's modus operandi is one of subterfuge. BC's position acknowledges that finding a way out of the political is more difficult than it appears. This position is perhaps elucidated in a short essay published in 2006, in which they appear to acknowledge the failure of the avant-garde project and its utopian fantasies:

Every utopia has been discredited, it seems, while bohemia and the seductive margins of urban life have vanished. For those who are extremely agitated and inflamed by their resolution to subvert the existing way of things, the dangers are quadrupled. No longer a hope for popular revolt and change, today's mass is completely middle class. The proletariat is gone, and in its wake there is only proletarianisation, a marginalisation and poverty without communal identification, without class politics. $^{34}$

We should consider Get Rid of Yourself as a product bound by a historical condition in which broken promises seem to be continually unfolding. Get Rid of Yourself was produced at a moment when socialism had failed, the Berlin wall had fallen, the welfare state had already largely been dismantled, and yet protesting the continuing unfolding of global capitalism's spread still seemed legitimate. The energy of the anti-globalisation movement, which seemed so promising during the protests in Genoa, was quickly swept away following the attacks on the World Trade Centre, to be replaced by an era of what Tom McDonough calls 'military neoliberalism.'35 Get Rid of Yourself acknowledges that existing political languages are haunted by their own failure; that the politics of the New Left, of the Situationist avant-garde, and the politics of identity, are liable to be usurped by capitalism; that projects that ostensibly appear antagonistic towards capitalism are able to be absorbed, turn out to be beneficial for capital's colonisation of the everyday. ${ }^{36}$ $B C$ acknowledges, too, the gravity of $9 / 11$ as a periodising event, in which the potential for transformation seized by Tiqqun and the Black Bloc seems to have dissipated; the film

\footnotetext{
32 Mikkel Bolt Rasmussen, 'Art, Revolution and Communisation,' Third Text 26:2, 2012, p. 241

33 Tiqqun produced two journals between 1999 and 2001 before the group dissolved. Members of the group, in particular Julian Coupat, are believed to have later published under The Invisible Committee, most notably The Coming Insurrection (2007). Tom McDonough notes that between the dissolution of Tiqqun and his arrest on spurious terrorism charges in 2008, Coupat enacted this physical retreat, living in on a compound in the rural village of Tarnac among his comrades. McDonough, 2011, p. 58; See also: Sven Lütticken, 'Personification,' New Left Review, p. 119

${ }^{34}$ Bernadette Corporation, 'Be Corpse,' Afterall 14, 2006, p. 58

35 McDonough, 2011, p. 52

${ }^{36}$ Mark Fisher, Capitalist Realism: Is There No Alternative?, London: Zero Books, 2009, pp. 8-9
} 
was produced during a time in which, they write, the 'increasing repression under which the feeling of 'civil war' has been buried.'37

Might there be any possibility of reconciling a hope for the 'whatever singularity' (however inconvenient this hope may seem) with the present conditions under which the violence of global capitalism is unevenly distributed? Perhaps by considering Get Rid of Yourself against a backdrop of broken promises of post-World War II social democracy in the west, we are able to think about the film as a cultural product unable to bear the overinvestment of the political that takes place in the situation it purports to document. For all their brash, daring iconoclasm, both Tiqqun and the Black Bloc exemplify a mode of political optimism that quickly became untenable in the months and years following Genoa (and may already have been belated at the moment of protest). The protest, we might say, represents a moment when the horizon of possibility gets shattered. These moments, and the alliances and communities that find themselves formed in these moments, are volatile, unstable, fleeting, and perhaps most importantly, struggle to make it into representation; or, when they do, are, like Giuliani, subject to manipulation. Get Rid of Yourself presupposes this. In the space opened between the capture of images, their arrangement, and their transmission, doubt (never productive in revolutionary settings) finds itself entering the scene. That the attacks on the World Trade Centre took place during this period of doubt's fermentation adds a strange, cataclysmic quality to the film and aids in foregrounding the difficulty it has sustaining commitment to the political project it provisionally aligns itself with. The time of film, unlike the time of protest, is ongoing, and in being ongoing it is forced to navigate unexpected contours, hurdles, blockages that spring up seemingly out of nowhere. Bernadette Corporation's performance of irony, its seeming parody, its apparent recognition of the exhaustion of the political, might be able to be reframed under these terms. We might think of BC's practice not as an abandonment of the political, or of the will to be otherwise, but as an attempt to maintain some kind of grip in unpredictable circumstances.

37 Bernadette Corporation, 'Get Rid of Yourself,' Accessed 9 August 2016 
Hito Steyerl's November (2004) is a work about afterlives. Ostensibly, the film concerns the transformation of Steyerl's teenage friend, Andrea Wolf, from militant feminist biker, to a member of the Kurdish Workers' Army, to a martyr for the Kurdish cause following her extrajudicial killing by the Turkish army. The film, however, is dense with other ghosts. We brush past, for instance, the journey taken by weapons that once belonged to Soviet states following the fall of the Berlin Wall, arriving in their eventual home in Turkey, and their possible implication in Wolf's death. We linger on footage of Bruce Lee's funeral, which resurfaced in the diegetic world of Lee's final film, Game of Death (1978), released five years after his death. Most insistently, though, we return to the still unfolding, still unreadable, moments which followed instances of political upheaval throughout the twentieth century; to the impacts, spillages, and fallout of coalition, revolution, and complaint.

As has already been examined, theories and tactics of refusal abound - whether they operate under the mantle of anonymity, invisibility, unnamability, whatever singularity, or disappearance. These theories are divergent in many ways, but they share a common belief that something of the political is broken. The composition of the subject, the role of the state, the efficacy of protest - all of these things seem beyond repair, and, according to these various theories, a new ethics of relation and subjectivity demands a kind of offensive retreat. In the context of an extended study of artworks engaged in projects of refusal, looking closely at November allows for a certain kind of lateral thinking. In November, the future of political agency comes into question. The film demands a rethinking of how resistance gets articulated and performed, and how social change may take place. In November, traces of the tactics of refusal emerge as footnotes, digressions, and asides. More pressingly, they emerge as well as ghostly repetitions. They slip between the realms of representation and reality and back again, and in doing so, get altered, or corrupted, or confused. The first half of this chapter will pay attention to this time out of joint, with a view towards examining to the subtle ways in which Steyerl's eulogy for now foreclosed political horizons might be interpreted as an appeal for a kind of political creativity appropriate for unpredictable times. Paying attention to the haunted time of November will provide a framework through which to examine Steyerl's How Not 
to be Seen: A Fucking Didactic Educational .MOV File (2013). In this latter video, a Monty Python sketch is repurposed as a lesson in surviving under contemporary regimes of surveillance. This framework allows us to ask: what about the strategies proposed by the latter video feels familiar? How is the form of political address composed, received, and problematised? What about this regime of surveillance is not new?

November opens to a whirling sound; something difficult to place, possibly a helicopter, possibly the sound of a spool of film winding its way around a projector. The first image we see does not seem to give us any clues as to the source of the sound. The first image we see can barely reveal itself. The camera is directed towards a faded, ghostly image of a woman's face (fig. 12). Shakily, the camera zooms in. Steyerl's voice sets a scene. 'My best friend when I was 17 was a girl called Andrea Wolf.' The image fades to white. 'In 1998, she was shot as a Kurdish terrorist.' The film cuts to Andrea as a teenager, shot from above the shoulders. Her hair is short and slick, she wears a leather biker jacket, a long earring. She turns towards the camera at the sound of a B-movie pow (fig. 13).

The Botsweeds' rendition of 'Faster Pussycat, Kill Kill,' the title song from Russ Meyer's 1965 exploitation film of the same name, begins playing over silent clips of Steyerl and Wolf's teenage films. We see the teenage friends as a girl gang, beating up men. 'It's impossible to reconstruct the story of the film. Only the fighting scenes were shot.' Steyerl goes on, 'There are strange coincidences with the footage we shot almost fifteen years ago.' In the teenage film, Steyerl gets shot, while Wolf survives. We see her riding a motorbike off into the sunset. And then her face again. 'Her body never came back. What came back instead was this poster.' The film cuts to the interior of a drab cinema, the walls of which are covered in posters for sex films and political ephemera - among them is Andrea's face (fig. 14).

Andrea's image persists. She becomes an 'unfamiliar kind of icon.' November asks its viewer to consider not only the unresolved traumas of a number of failed utopian projects, but also the nature of political identity under conditions in which images are produced, reproduced, and distributed at an unprecedented rate. It asks the viewer to consider how political complaint might be articulated when the meanings which attach themselves to these images are radically, and continually, destabilised. ${ }^{1}$ Andrea finds herself

\footnotetext{
${ }^{1}$ Pablo Lafuente discusses Steyerl's work through the frame of the plasticity of the political icon. The 'story of changes in the meaning of a sign,' he writes, 'of its appropriation and subsequent loss by a certain position, is key to understanding how individuals organise (or disorganise) their life in common.' Pablo Lafuente, 'For a Populist Cinema: On Hito Steyerl's November and Lovely Andrea,' Afterall 19, 2008, p. 65
} 
transformed, first from a militant feminist biker, into a comrade in the PKK's women's faction, and later, following her death, into a martyr. An image of her face - smiling, looking left into the distance, looking forthright and at peace - becomes, for a brief while, an iconic image of Kurdish independence. ${ }^{2}$ The poster initially introduced to us inside a gloomy cinema reappears throughout the film, most often as a placard wielded by protesters, amongst a sea of political iconography.

November is a film about the persistence of Andrea Wolf, but it might be best to say that it is a film about persistence more generally. As a term used throughout the film, 'November' is a temporal marker; 'November' is a means to describe a situation in which the potency of once revolutionary icons has dissipated, and the possibility of an international proletarian coalition seems unthinkable. Yet the ghosts of these icons of possibility live on in images. Steyerl uses 'November' against the 'October' of the Bolshevik Revolution, as represented in Sergei Eisenstein's October: Ten Days that Shook the World (1928):

We are not any longer in the period of the October, described by Eisenstein, when the Cossacks decide to join the Russian proletariat and Internationalist Brotherhood during the Bolshevik Revolution. Now, we are in the period of November. In November, the former heroes become madmen, and die in extralegal executions somewhere on a dirty roadside, and hardly anyone takes a closer look... November is the time after October, a time when revolution seems to be over and peripheral struggles have become particular, localist, and almost impossible to communicate. In November, a new, reactionary form of terror takes over, which abruptly breaks with the tradition of October. $^{3}$

'November' is awkward, messy, irresolvable, inescapable. There are no political heroes. Revolutionary potential seems to have dissolved and political actors are left to attempt to sort through the wreckage of unfinished histories.

\footnotetext{
2 The direction of Andrea's gaze demands attention. There are several ways of interpreting this gaze, and each of them approach the problem of interpreting a three dimensional world in two dimensional space. We can interpret the gaze both along a horizontal axis between left and right, but we can also posit that Andrea looks backwards, towards a past beyond the edge of the placard. This, in a way, mirrors the direction of the outlook of the film - towards a history of the left from a position in which a unified, coherent left seems distant, tricky, and no longer viable. In a more humourous register, a similar ambiguity in the interpretation of directional representation was brought to light following the revelation of Hillary Clinton's presidential campaign logo in April 2015. The logo, a red ' $\mathrm{H}$ ' in which the horizontal line in the middle is rendered as a thick, red arrow, is intended to signify progress, a will to move forward. But progress, here, also inadvertently points rightward. 'Twitter turns Clinton's 'H' Logo into target for ridicule,' Reuters, 13 April 2015, http:// www.reuters.com/article/us-usa-election-clinton-logo-idUSKBNON30XF20150413, Accessed 28 October 2016

3 Though not mentioned in the film, the firefight between the PKK and the Turkish Army in which Andrea was killed also took place in October. Michael Rothberg, 'Remembering Ronahî, Remembering Internationalism, Days and Memory, 3 August 2015, http://hgmsblog.weebly.com/blog/remembering-ronahi-rememberinginternationalism, Accessed 29 October 2016
} 
In 'November,' the distinction between representation and reality becomes blurred. Political agents get caught within a constant flow of images, and, it seems, find themselves turned into images. It is perhaps not insignificant, then, that as Steyerl describes a now inaccessible time of revolution, the images we see on screen are plucked from a fictionalised account of a revolutionary event. This, for Steyerl, is not a problem. It is not, necessarily, a hole in the archive plugged by a reconstruction of the real. It might rather be considered typical of Steyerl's treatment of the documentary form. In an a short essay titled 'Documentary Uncertainty,' Steyerl lays out a programme of contemporary documentary practice in which doubt becomes an organising principle. ${ }^{4}$ For Steyerl, uncertainty is not a lack of conviction, but a place from which one is able to scrutinise the composition of the social world and the networks of power that keep things in place. Criticising a documentary because it does not tell the truth, because it manipulates images and sound into an argument, would appear to be redundant. The purpose of documentary, in Steyerl's view, is not to attempt to reflect a certain truth about the world, but to produce a kind of truth effect. 5 'The political importance of documentary forms,' Steyerl writes, 'does not primarily reside in their subject matter, but in the ways in which they are organised. It resides in the specific distributions of the sensible implemented by documentary articulations. ${ }^{6}$ The production of truth, though, is not to be confused with a willful manipulation of the viewing subject. Steyerl claims that such a supposition would amount to a presumption of naïvete on the part of the viewer. The contemporary viewer, according to Steyerl, anticipates the presence of doubt, 'The only thing we can say for sure about the documentary mode in our times, Steyerl writes, 'is that we always already doubt if it is true.'

\footnotetext{
${ }^{4}$ We might here recall Christa Blümlinger's argument, as summarised in my previous chapter. Blümlinger's object of analysis is the formal innovations made by mid-century European and American filmmakers including Chris Marker, Orson Welles, and Alain Resnais. Blümlinger's essay was originally published in German in 1992, before the massive disruptions in image creation and transmission wrought by the internet. Doubt, then, means different things for each author, but both arguments are useful to consider. Christa Blümlinger, 'Reading Between the Images,' in Erika Balsom and Hila Peleg (eds.) Documentary Across Disciplines, Cambridge, MA: The MIT Press, 2016, pp. 174-177

${ }^{5}$ There is a sympathy here between Steyerl's argument and Jacques Rancière's comments on Chris Marker's films. In Film Fables, Rancière writes, "We cannot think of "documentary" film as the polar opposite of "fiction" film simply because the former works with images from real daily life and archive documents about events that obviously happened, and the latter with actors who act out an invented story. The real difference between them isn't that the documentary sides with the real against the inventions of fiction, it's just that the documentary instead of treating the real as an effect to be produced, treats it as a fact to be understood.' Jacques Rancière, Film Fables, trans. Emiliano Battista, Oxford: Berg, 2006, p. 158

${ }^{6}$ Here, Steyerl is obviously recalling Jacques Rancière's argument in The Politics of Aesthetics regarding the 'distribution of the sensible.' 'Documentary Uncertainty,' Re-visiones 1, 2011, http://www.re-visiones.net/ spip.php\%3Farticle37.html. Accessed 28 October 2016.
} 
Describing Steyerl's work as documentary, even in an expanded sense, even if we are able to acknowledge the reflexivity with which contemporary documentary operates, may not be the most precise means of approaching it. Steyerl's work has been considered, by both the artist and critics responding to her work, to belong to the lineage of the film essay, in the tradition of Chris Marker, Jean Luc Godard, and Harun Farocki. ${ }^{7}$ Though the identifying features of this genre are porous, for Nora Alter, as for other theorists of the genre, it is the presence of the first person which, above all else, can aid in our understanding of the claims the film essay would seek to make. This first person, however, is not necessarily a narrator, for the film essay might unfold from either a highly subjective or a more detached position. The film essay provides a means by which lines of inquiry might be played with, drawn out in unexpected ways, and be swallowed by fanciful digression. 'The essay film,' writes Alter, 'because it plays with fact and fiction, untruths as much as truths, poses problems without answers, and is deeply self-reflexive. As such, it is seen as the ideal genre by filmmakers who want to advance historical knowledge but recognize that this can only be done in a tenuous way.'8

For Steyerl, the film essay opens up the possibility of approaching objects of historical inquiry in unconventional ways, as a means of more accurately attending to the affective qualities of the document and its afterlives. Speculative logics get deployed in order to draw connections between things that, though they seem to make themselves evident intuitively, fail to add up empirically. In November, for instance, as the unseen voice of a former Kurdish fighter narrates the redistribution of weapons following the fall of the Berlin Wall from the former GDR to the Turkish army, we see a white screen with the words, 'Germany is in Kurdistan.' Slowly, these words fade into 'Kurdistan is in Germany.' Earlier in the film, we are reminded, by the same Kurdish fighter, that Kurdistan does not appear on commercially produced maps; or rather, it appears as a 'white spot' straddling the borders of Turkey, Syria, Iraq and Iran. Steyerl intervenes into the testimony of another, and in doing so, charts a new cartography of geopolitical space, a mixed territory in which, as Steyerl notes, 'the boundaries of war blur.' In this cartography, nation states past, present, potential, and suppressed - cease to be discrete entities, but become entangled, nebulous agents inside of which, and between which, both Steyerl and Andrea

\footnotetext{
${ }^{7}$ Lafuente, 2008; Hito Steyerl, Beginnings, e-flux 59, 2014, http://www.e-flux.com/journal/59/61140/ beginnings/, last accessed 28 October 2016; Paolo Magagnoli, Documents of Utopia: The Politics of Experimental Documentary, London \& New York: Columbia University Press, 2015, p. 55

${ }^{8}$ Nora M. Alter, 'Translating the Essay into Film and Installation,' Journal of Visual Culture 6:1, 2007, p. 52
} 
find themselves caught. In this cartography, the Cold War did not end with the collapse of the Berlin Wall. Periodising moments of history always fail to account for the inevitable aftershocks, for the ways conflicts transform and get lost inside of other conflicts. Periodising fails to account for how history gets lived in. For Alter, the film essay presupposes a frantic archive; a cacophonous, slippery mingling of fiction and nonfiction footage as a means of both reproducing the sensorium from which the filmmaker speaks, and to act as evidence towards the argument the filmmaker wishes to stage. These arguments often find themselves unresolved, or speculative, or ask the viewer to participate actively in the production of their meaning. ${ }^{9}$ If the documentary, at least in a conventional sense, seeks to reveal 'things as they are, ${ }^{, 10}$ we might say that the film essay sways more towards locating itself within an unfinished world.

The surprising logics deployed by Steyerl are a matter of necessity. For in 'November,' the existing languages of political agency, collectivity, and representation all fail to maintain their currency. Speculation becomes a means of feeling through new modes of intelligibility in order to better come to terms with the conditions under which we live now; conditions in which political agents, like Andrea, find themselves multiplied, manipulated, and divorced from the realities of both living and dying. In November, we are asked to keep track of several Andreas: Andrea the feminist teenager, Andrea the freedom fighter, Andrea the terrorist, and Andrea the icon. These Andreas exist at once. In an essay published in 2012, Steyerl uses Erwin Schrodinger's famous 'cat inside a box' thought experiment to demonstrate this persistence. Both the German and Turkish governments maintain that Andrea is still alive, hiding underground. ${ }^{11}$ Maintaining such a position both absolves the states of any question of wrongdoing, and would seem to negate the necessity of any judicial body launching an investigation into the possibility of war crimes. For Steyerl, the fact that Andrea's body has never been recovered means that this official state position can never be definitively refuted. Andrea, therefore, like Schrodinger's cat, exists in a state of superposition, both alive and dead at the same time. ${ }^{12}$ The Andrea who lives on underground is an invention of language; she is the object of a speaker, the state,

\footnotetext{
9 Alter, 2007, p. 48

10 Magagnoli, 2015, p. 54

${ }^{11}$ In the film, Steyerl draws a connection between this 'official state fiction' and a popular rumour that emerged following the release of Game of Death. The rumour held that, just like Bruce Lee's character in the film, Lee faked his own death, and remained,and perhaps even now remains, underground.

12 Hito Steyerl, 'Missing People: Entanglement, Superposition, and Exhumation as Sites of Indeterminacy,' eflux 38, 2012, http://www.e-flux.com/journal/38/61209/missing-people-entanglement-superposition-andexhumation-as-sites-of-indeterminacy/, accessed 2 November 2016
} 
endowed with the authority to 'make live or let die.'13 'No authorized observer can break superposition,' Steyerl writes, 'not because there were no observers, but because they have not been authorized.' November is not necessarily an attempt to reinvent Andrea, rather, the lays out the multiple Andreas who exist simultaneously, and posits each one including, by implication, the friend Steyerl knew as a teeanger - as the invention of language, as an object of memory within an unfolding historical narrative. Andrea becomes something of a foil through which Steyerl is able to posit that this condition of superpositionality is common to all of those who inhabit the contemporary moment. The contemporary moment described by Steyerl is one in which subjects find themselves bound within complex networks of meaning.

November, and much of Steyerl's subsequent work, is concerned with articulating a renegotiation of the subject in relation to the object, and of the subject in relation to its representations. In her essay, 'A Thing Like You and Me,' Steyerl proposes that becoming a subject - what we might consider the desire that has sustained minoritarian politics for decades - may be, under contemporary circumstances, a misguided aim. Steyerl takes up the slipperiness of certain political languages as a point of departure. Here, 'representation' swings back and forth between denoting democratic participation and aesthetic mediation. 'Subject' refers to 'becoming a subject of history, of representation, or of politics... the promise of autonomy, sovereignty, agency.' That is, it denotes a position from which one is entitled to speak, rather than be spoken for, of, or over. But it is also able to be interpreted in a more archaic sense, as in, being 'being subjected to power relations. ${ }^{14}$

Using David Bowie as an example, Steyerl looks towards the ways mutable identities are able be changed at will, subjects become able to perform under guises, identity becomes 'an image and nothing but an image.' Her description of Bowie bears a resemblance to the kind of rhetoric that emerged at the intersection of identity politics and cyber utopianism in the $1990 \mathrm{~s},{ }^{15}$ but for Steyerl, this mutability is not necessarily a source of liberation. Considering the identity as image becomes a profoundly ambivalent means of thinking through political agency. She writes:

\footnotetext{
13 Michel Foucault, Society Must be Defended: Lectures at the Collége de France 1975-76, ed. Mauro Bertani and Alessandro Fontana, trans. David Macey, New York: Picador, 2003, p. 241

14 Hito Steyerl, 'A Thing Like You and Me,' e-flux 15, 2010, http://www.e-flux.com/journal/15/61298/a-thinglike-you-and-me/, accessed 2 November 2016

15 Deborah Lupton, 'The Embodied Computer/User,' in D. Bell \& B. Kennedy (eds.) The Cybercultures Reader, London: Routledge, 2000, p. 479
} 
The struggle over representation... was based on a sharp split between these levels: here thingthere image. Here I-there it. Here subject-there object. The senses here-dumb matter over there. Slightly paranoid assumptions concerning authenticity came into the equation as well. Did the public image-of women or other groups, for example-actually correspond to reality? Was it stereotyped? Misrepresented? Thus one got tangled in a whole web of presuppositions, the most problematic of which being, of course, that an authentic image exists in the first place. A campaign was thus unleashed to find a more accurate form of representation, but without questioning its own, quite realist, paradigm. ${ }^{16}$

In lieu of subjectification, Steyerl proposes contemporary political energy might best be directed towards 'becoming a thing.' For Steyerl, becoming a thing means admitting that 'things' are never stable, but have a force of their own. The image as thing, writes Steyerl, is 'simultaneously couched in affect and availability, a fetish made of crystals and electricity, animated by our wishes and fears. ${ }^{.17}$ Becoming a thing, then, is at once a decentering of the human, and a means to position the human within a network of nonhuman agents, which all at once circulate around, collide into, and are transformed by each other. Becoming a thing requires an altered relationship to history. Rather than occupying a position akin to Walter Benjamin's Angel, rather, that is, finding ourselves being pulled back by the invisible force of time, left only to survey the rubble we inevitably leave in our wake, we become the rubble itself; 'We are this pile of scrap.'

Being among human and nonhuman agents within a pile of rubble would thus require an adjusted conception of how time moves. Doing away with a conception of time mapped upon a single horizontal axis opens up space to consider the possibility of repetition, skips, glitches, and reversals. Inhabiting the rubble of history also means familiarising oneself with the possibility of not moving, familiarising oneself with, that is, the feeling of stuckness. This is the time of November. The narrative progression of the film, though structured loosely around the filmmaker's quest to probe the circumstances of Andrea's multiple lives, quickly dissolves. The promise of resolution emerges quickly as an impossibility as time finds itself both stuck on repeat; subject to an immovable impasse.

There are, of course, other formal qualities of the film in which time finds itself collapsed or altered. As Steyerl describes the formative impact the film Faster Pussycat, Kill Kill had on her teenage productions, we see Tura Satana deliver a blow to an unseen adversary, accompanied by a tacky B-Movie pow, over and over again. Elsewhere, in the middle of

\footnotetext{
16 Steyerl, 2010

17 Steyerl, 2010
} 
the film, Steyerl intervenes into one of the most iconic examples of Eisenstein's dialectical montage. In the scene, as Steyerl describes the revolutionary time of October, clips of combatants preparing themselves, in a theatrical manner, for conflict, quickly cut scenes of Bolsheviks and Cossacks dancing. Suddenly, as the jubilant orchestral soundtrack plays on, we cut to a black screen with only the word 'Und' written in the centre. Between three cuts, 'Und' grows bigger, as if threatening to breach the frame of the image (fig. 15). Suddenly, we cut to an image of Andrea's face, seen on a crumpled, washed out poster (similar to the image we saw at the beginning of the film). The soundtrack jars, as a sparse melancholic fiddle arrangement fades in. It is this persistence of the conjunction that most acutely marks the time of November. 'November' is a time of the 'und,' of an always ongoing, always unfolding, always unfinished present. In 'November,' as Steyerl says there are no innocent heroes, no easily identifiable villains, and no easily mapped trajectory out of the situation we find ourselves in.

In Steyerl's adjusted ontology of time, space, and matter, it is the gesture that emerges as the locus of political action. In November, the gesture is that which slips between representation and reality, an action whose purpose is never foreclosed, or, an action of resistance whose antagonist is able to be reimagined, readjusted. While recalling her teenage film, Steyerl describes the dearth of female role models in popular media. They were forced, instead, to turn to Russ Meyer's exploitation films, to copy gestures Steyerl describes as hovering 'between pornography and severe dilettantism.' In a kind of footnote to the film a former militant with the urban guerilla in West Berlin describes using films such as Battle of Algiers (1966) and State of Siege (1972) as 'historical documents' from which they were able to learn to mimic tactics of resistance. The militant goes on to tell an amusing anecdote in which the West German guerrillas attempted to restage a scene from Costa Gavras' State of Siege. In the film, militants board a bus, sit next to an unassuming man holding a newspaper, and cast a vote deciding whether or not to take a particular action, then disembark a few stops later. The West German guerilla attempted to restage this scene on Berlin's Metro line, but, as the militant describes, 'either people were too late, one could see them running after the train... or they boarded the wrong carriage.' The militant later learned that while much of Gravas' film was based on testimony from militants in Montevideo, this scene was one of the few that was purely fictional.

The gesture, as Steyerl describes it in the film, bears a resemblance to Agamben's definition of the term. 'Gesture is the name of [the] intersection between life and art, act 
and power, general and particular, text and execution.' Agamben writes, 'It is a moment of life subtracted from the context of individual biography as well as the moment of art subtracted from the neutrality of aesthetics: it is pure praxis.'18 The gesture, for Steyerl and Agamben, represents a disruption in the unfolding of time. For Steyerl, the gesture gets carried by images, it makes its way out of images into the realm of political action. Historical gestures, for both Steyerl and Rosler, are able to be repurposed, to be plucked from the wreckage of history and deployed in playful and unpredictable ways. Thus, the stuckness of November may not be as pessimistic as it initially reads. It may be more useful to describe November as a profoundly ambivalent film. Though the gestures, tactics, and models of collectivity that thrived under the revolutionary conditions of October may be worn out, inaccessible, or difficult to articulate in present circumstances, the film leaves open the possibility for renewal. Occupying the wreckage of history allows for political agents to rearrange already existing gestures - and the images which carry those gestures - in new and politically exciting ways.

There is a sympathy here between Steyerl's ambivalent diagnosis of November and the way in which Lauren Berlant describes the 'impasse of the present.' In Cruel Optimism, Berlant writes,

The impasse is a stretch of time in which one moves around with a sense that the world is at once intensely present and enigmatic, such that the activity of living demands both a wandering absorptive awareness and a hypervigilance that collects material that might help to clarify things, maintain one's sea legs, and coordinate the standard melodramatic crises with those processes that have not yet found their genre of event. ${ }^{19}$

Berlant's attention to the sensory composition of the present tense, to the means by which the present makes itself felt before it is able to be articulated into an event or a series of interconnecting events, makes itself evident in Steyerl's work. For Steyerl, however, being in the present means being inextricably bound to history, and being bound to history means being painfully aware of the failures of history. Through a close reading of How Not to be Seen: A Fucking Didactic Educational .MOV File, I examine the ways in which historical gestures are playfully rearranged in an effort to escape the impasse. The gestures of refusal, escape, and invisibility I have so far sought to describe in this thesis are not necessarily attempts to resign oneself to overwhelming magnitude of the impasse, but might rather be read as attempts to break through the skin of the present in order to

\footnotetext{
18 Giorgio Agamben, Means Without End: Notes on Politics, trans. Vincenzo Binetti and Cesare Casarino, Minneapolis: Minnesota University Press, 2000, p. 80

${ }^{19}$ Lauren Berlant, Cruel Optimism, Durham: Duke University Press, 2011, p. 4
} 
begin to articulate new modes of inhabiting the world collectively. For all their negativity, these works remain, perhaps perversely, optimistic.

In Steyerl's work, the messiness of the signifier is used as fertile material through which we might arrive at unexpected conclusions. How Not to be Seen: A Fucking Didactic Educational .MOV File (2013) deploys, even exacerbates, the unruliness of meaning in the form of a parodic instructional video which details strategies of escaping the apparatuses of contemporary surveillance technologies. In How Not to be Seen, the meanings and lived experiences of becoming and being invisible, of disappearing, of going off screen, and of being captured all change radically depending on the context in which these concepts and actions are conjured. Rather than providing a guidebook for escaping visibility, Steyerl's video demonstrates the complex, intersecting, and overlapping aspirations and dangers of being seen, heard, and represented.

The title of Steyerl's video references a Monty Python sketch, originally broadcast in 1970 . In the sketch, which takes the form of a parody of a public service announcement, we witness several people using camouflage to conceal their position within an open field. These attempts at hiding are foiled in ways that become increasingly and violently ridiculous as the sketch progresses. In one scene, a man, hiding in a field, responds to the authoritative call of the narrator (John Cleese) to stand up before being summarily shot. In another scene, the hiding place of a Mr. Nesbit is deemed inadequate. Though he refuses to respond to the call of the narrator, Mr. Nesbit appears to have chosen to hide behind a single small bush in the middle of a field. The bush explodes to the sound of laughter from an unseen audience. The subjects of this film all attempt, some more successfully than others, to deceive human eyes. In Steyerl's video, the eyes from which subjects must hide have become mechanical. In the first of the video's five sections, or 'lessons,' we see a resolution target in front of a chroma key backdrop. This lesson, we are told, advises 'how to make something invisible for a camera' (fig. 16). Contemporary camouflage becomes a means of escaping the gaze of the camera, and in a global 
context in which cameras seem to be ubiquitous, succeeding at contemporary camouflage means finding ways to trick the camera, to navigate around resolution. ${ }^{20}$ 'Whatever is not captured by resolution,' the narrator intones, 'is invisible.'

For Erika Balsom, Steyerl's resurrection of the Monty Python sketch suggests that the stakes of being seen have long been ambivalent. The sketch, Balsom says, 'might represent an instance of the profound truthfulness of farce because it gestures to [the] relationship between visibility and violence.' 21 This relation is, of course, a point of departure for Steyerl. And while the humour deployed by Steyerl might be even more outrageous than Monty Python's, it is deployed as a means of complicating the profoundly ambivalent status of visibility in the contemporary moment. As Balsom says, 'For Steyerl, the age of basing a politics around simple claims of visibility - the right to representation, for instance, - is over... to be visible is now no longer a promise of validation and civil participation, it's also a threat, a form of exposure and of vulnerability.'

The image of the resolution target returns throughout the video. Several scenes take place upon a strip of painted concrete in the California desert. This painted concrete strip is one of several resolution targets produced by the United States government for the calibration of analogue aerial photographs. The lined patterns mirror the one seen on the resolution target seen in the first chapter of the video, scaled up to aid in the production of a God's eye view (fig. 17). These devices were designed, the narrator says, to aid in the capture of 'the world as a picture.' The target upon which the video's action takes place is now disused, and in poor repair. It is possible that the repeated allusions to 'the world as a picture' is an implicit reference to Martin Heidegger's essay, 'The Age of the World Picture.' 22 Heidegger's essay attempts to describe the metaphysical ground upon which modern science is based. The world as a picture, as something which stands before an enquiring subject, becomes something that is able to be mastered. The age of the world picture marks the making-object of the world in relation to the subject, and it therefore presupposes that this world as object, and the objects contained therein, will yield to the scrutiny, or what Heidegger calls 'research, of the subject.' He writes,

\footnotetext{
20 See: Hanna Rose Shell, Camouflage, Photography, and the Media of Reconnaissance, New York: Zone Books, 2012

${ }^{21}$ Erika Balsom, 'Introduction to Hito Steyerl's How Not to Be Seen,' presented at the symposium Life Remade: The Politics and Aesthetics of Animation, Simulation and Rendering, Birkbeck, University of London. June 2015

22 Balsom, 2015
} 
The word "picture" now means the structured images that is the creature of man's producing which represents and sets before. In such producing, man contends for the position in which he can be that particular being who gives the measure and draws up the guidelines for everything that is. ${ }^{23}$ The position from which the modern subject enquires, therefore, is an imperialistic one, a position whose ultimate aim is a radical certainty about the world and the objects it contains. In How Not to be Seen, Steyerl literalises the programme of the 'world picture' through the imaging of the world. As the video's narrator first utters 'the world as a picture,' we see a satellite image of a resolution target (which is itself superimposed over a studio-based resolution target) smoothly zoom out further and further, to reveal first the desert in which the resolution target sits, then the continent in which that desert is located, before finally we arrive at an image of the globe, suspended in space. In this gesture, Steyerl toys with the scale of the world picture. The satellite image reveals the world as a whole, immovable object. The visibility or relative invisibility of the inhabitants of this world is subject to the same imperialist logics that ground the development of satellite imaging technologies. The inhabitants of this world become objects, and thereby, infinitely knowable, transparent to those willing to subject these inhabitants to scrutiny. ${ }^{24}$ The question that the video seeks to ask might be, how might we inhabit the world in the age of the world picture differently? How might we escape the age of the world picture when the world would appear to exist as something that is able to be known? And is it possible for other knowledges, other conceptualisations of the world, other relations between and among subjects and objects to exist simultaneously?25

How Not to be Seen stays with this uncomfortable convergence of scales. It remains, as well, in several registers at once; with each strategy, each solution, seeming outrageous, impractical, and comedic, and yet remaining strangely plausible as a means of comprehending, and resisting, the overwhelming volatility of the political contemporary. In the third lesson, the narrator proposes evading capture by becoming 'smaller than a

\footnotetext{
${ }^{23}$ Martin Heidegger, The Question Concerning Technology and other essays, trans. William Lovitt, New York: Harper \& Row, 1977, pp. 134-135

${ }^{24}$ As Lauren Berlant writes, 'One of security culture's open secrets is... that there were never free sovereign subjects of politics or the market, but rather monitored subjects who are permitted to pass by and get on with things if their comportment does not go awry. (The intensity of monitoring is more explicit in areas where targeted populations are deemed normatively incompetent to enact profitable forms of docility and reciprocity, but the distinction between normative and carceral control is mainly one of emphasis.)' We might say, then, that the surveillant present Steyerl responds to is one which relies on the docility of its subjects, which treats them as ultimately transparent, or else as a problem to be swiftly dealt with.' Berlant, 2011, p. 243

25 It is pertinent to mention that How Not to be Seen was first displayed as part of Massimiliano Gioni's exhibition for the 2013 Venice Biennale, the title of which was The Encyclopedic Palace. This title is drawn from Marino Auriti's unrealised project of a museum designed to hold all imaginable knowledge.
} 
pixel.' To illustrate this strategy, a group of figures with black, grey, and white boxes covering their heads dance in front of a rotating still photo of a contemporary resolution target (fig. 18). ${ }^{26}$ These figures are aided by another figure, who is translucent but clearly visible. This latter figure, dressed in what looks like a niqab, holds up limbs while the boxheaded figures strike uncomfortable poses, or carry figures across the frame, so that they almost appear to fly. The gesture is absurd, but its meaning is surprisingly rational. 'In 1996,' the narrator says, '[aerial] photographic resolution in the area [of the resolution target] is about twelve meters per pixel. Today, it is one foot.' One foot is not an arbitrary measurement. It is not a measurement imposed by technological limitations, but by legal ones. Under United States law, the upper limit of commercial aerial photographic resolution is kept at around 30 centimeters per pixel as this is around the size of a human body when seen from above. ${ }^{27}$ This is, in part, a privacy measure. It renders unnecessary the kind of blurring and pixelation of faces and car license plates programmers responsible for an application like Google Street View are forced to undertake. As Eyal Weizman notes, this limit also aids in keeping more sinister things unseen. For instance, contemporary drone ammunition is equipped with a detonation delay. Ammunition will pierce its target, usually a building, before exploding. Should the building still stand following the explosion, the hole left by the ammunition is too small to register on aerial photographs, rendering the violence inflicted by contemporary warfare difficult to trace. ${ }^{28}$ Aerial photographs are, of course, a single instance of a lens in a world of lenses. And most other cameras are not subject to the same kinds of legal restrictions aerial cameras are. The iPhone 7, for instance, boasts a camera capable of recording twelve million pixels. ${ }^{29}$ The impossibility of becoming smaller than a pixel, then, demands a rethinking of the terms and limits of invisibility. It begs us to ask, how might we hide when the whole world is imaged? By adopting the box-head, the figures become pixels, as illustrated by the resolution target behind which they dance. They become elements of a picture, the stuff of pictures, but recognisable as nothing beyond than that. This may suggest, then, that retreating from the image in the contemporary moment cannot take place by avoiding

26 The resolution target we see in the first two sections of the video (which returns later) was used by the United States government from the 1950s until 2006 and was designed to aid in the calibration of analogue photography. The latter resolution target, in front of which the box-headed figures dance, was produced to aid in the calibration of digital photographs. Its design is based on pixels, rather than the black and white lines we saw earlier.

27 Eyal Weizman, 'Violence at the Threshold of Detectability,' e-flux 64, 2015, http://www.e-flux.com/journal/ 64/60861/violence-at-the-threshold-of-detectability/, accessed 3 November 2016

${ }^{28}$ Note also that these laws do not apply to military satellite and drone cameras, and that the photographs obtained by these cameras are kept classified. Weizmann, 2015

${ }^{29}$ Apple, iPhone 7 Tech Specs, 2016. http://www.apple.com/nz/iphone-7/specs/, accessed 2 November 2016 
being in images, for the image is omnipresent. The withdrawal from the image that the video suggests requires finding ways to hide within the image, and in doing so, requires an expansion of the meanings and limitations of invisibility.

In the fourth lesson of the video, we enter a computer rendered gated community. The scene is bucolic, modern, and clean. We see steel framed buildings, with large, shining windows; we see a spotless shopping mall equipped with luxury stores; a vine covered deck looking over a crystal blue pool. While touring this idyllic community, the narrator lists several ways to 'disappear.' 'Living in a gated community, living in a military zone, being in an airport, factory, or museum... being female and over fifty... being a wifi signal moving through human bodies; being undocumented, or poor; being spam caught by a filter; being a disappeared person as an enemy of the state, eliminated, liquidated, and then dissimulated.' In this list, disappearing takes on several meanings at once.

Disappearing becomes a commodity, a privilege endowed to those with the capital available to inhabit a seclusionist bourgeois fantasy. Or, it is a state of exception in which the laws of civil society are suspended. ${ }^{30}$ Or, it is an absence from popular culture. Or, it means being an inconvenience to the state, a dissident in a state in which no room for dissent is allowed.

For Erika Balsom, these animated renderings reveal a 'rude secret' about the society that produced them. 'They offer us a fantasy,' Balsom says, 'of governance, of rationality, of mastery, a vision of a completely administered world that allegorises forms of social, biological, and informational control. ${ }^{31}$ The apartment complexes and shopping malls are inhabited by ghostly white figures. These animated figures interact harmoniously with their surroundings. They converse with each other, they sit, swim, run, and work just as they should because they have been programmed to. But there are other bodies in this scene. The pixel-headed and cloaked figures from the previous lesson contaminate the comfortable realm in which this scene takes place. These figures mime kung-fu moves inside a cafe, leap across a stone path that cuts through a pool, or stand awkwardly next to the ghostly figures, who appear unaware of, or unaffected by, the presence of the contaminating figures (fig. 19). These figures, though they appear to remain invisible to the ghostly inhabitants of this idyllic setting, become all the more visible to the viewer. They

\footnotetext{
30 Giorgio Agamben, State of Exception, trans. Kevin Attell, Chicago: University of Chicago Press, 2005; Dimitris Papadopoulos, Niamh Stephenson, and Vassilis Tsianos, Escape Routes: Control and Subversion in the 21st Century, London: Pluto Press, 2008, p. 175

${ }^{31}$ Balsom, 2015
} 
are aberrations, interruptions, glitches in an otherwise perfect picture of a good life which persists as a structuring fantasy of the contemporary, while seeming all the more cruel for its unattainability. When we consider them alongside the narrator's list of strategies for 'disappearing,' it becomes evident that disappearing, for Steyerl, is a profoundly ambivalent gesture.

Disappearing, for Steyerl, is not just a novel site of political action in response to novel conditions of visibility, disappearing has a historical precedent - one that includes the extrajudicial execution of dissidents - that must be attended to before one is able to propose or commit to a programme of disappearance, whatever that programme may look like. The pixel-headed and cloak figures, then, might suggest that disappearance is not always an entirely negative exercise. In the case of the pixel-headed figures, the characters may not be visible to aerial cameras, but they do not constitute an absence. They disappear into something, becoming what Alexander Galloway might call a 'subtractive being.'32 Entering an otherwise cybernetically perfected scene, disappearing becomes a means of disruption, a means of upsetting the procedures of normalisation that keep the scene functioning. Disappearing, then, becomes less an exercise in not being seen than an exercise in refusing recognition. It does not mean a retreat from a scene of contestation, but might be more akin to Dimitris Papadopoulos, Nimah Stephenson, and Vassilis Tsianos' understanding of 'escape.' For them, 'Escape is not a ghost, merely a protean trickster. It is a means to experiment and to initiate speculative ways to deal with the immediate and concrete facts which dwell in our worlds, because our experience cannot simply neglect their stubborn persistence and their inescapable efficaciousness.' 33

The final lesson of the video, titled 'How to become invisible by merging into a world made of images,' is baffling. We return to the resolution target in the desert. Accompanied by The Three Degrees performing When Will I See You Again, the cloaked figures disrobe to reveal green bodysuits, the ghostly inhabitants of the idyllic community swarm into the desert, and titles appear on screen, describing a pixelated revolt (fig. 20). 'Pixels hijack camera crane... camera crew gets tied up by invisible people seen from above... U.S. Air Force drops glitter from stealth helicopter... happy pixels hop off into low resolution, gif loop!' The pixels, here, assume an unruly agency. Neither visible to human eyes nor

\footnotetext{
32 Alexander Galloway, 'Black Box, Black Bloc,' in Benjamin Noys (ed.) Communization and its Discontents: Contestation, Critique, and Contemporary Struggles, Wivenhoe: Minor Compositions, 2011, p. 248

${ }^{33}$ Papadopoulos, Stephenson, and Tsianos, 2008, p. 66
} 
amenable to human discipline, the picture elements seem to find themselves, in Steyerl's drama, hostile towards being captured, towards lending themselves to the production of meaning.

In her work, and her writing, Steyerl lays out an ecology of image circulation in the twenty first century. If, in November, formerly effective gestures have been remade into cheap icons, evacuated of meaning and degraded beyond efficacy, in How Not to be Seen, Steyerl grabs at a series of absurdist gestures in an attempt to direct them towards a site of political urgency. The gesture, as Lauren Berlant describes it, represents 'the performance of a shift that could turn into a disturbance... the initiation of something present that could accrue density, whether dramatic or not."34 The gesture is something as simple as placing a hand between one's face and a camera; or it might be as elaborate as painting one's face in chroma key green (fig. 21). For Berlant, who draws upon the work of Giorgio Agamben, the gesture is not oriented towards a means nor an end, but might rather be registered as a sign of being 'in the middle of the world.' 35 'The gesture does not mark time,' she writes, 'if time is a movement forward, but makes time, holding the present open to attention and unpredicted exchange.' In How Not to be Seen, the gestures enacted as pedagogy do not represent an effort to disengage with a present marked by overexposure, but rather a problematising of both the means by which this overexposure operates, as well as a complicating of what disengaging has meant in the past and might mean in the present. This would mean, then, that Steyerl's absurd humour is not a deflation of political urgency, but presents its own possibilities for sustaining commitment when commitment feels awkward, belated, or out of step. Humour allows for the exhausted, the unsayable, or the unthinkable to be said in new ways. The absurdist, or humorous, gesture expands the distribution of the sensible in ways that allow committed speech and action to remain surprising.

Giorgio Agamben's chapter on the gesture begins with a striking claim. 'By the end of the nineteenth century,' he writes, 'the Western bourgeoisie had definitely lost its gestures.' 36 Agamben goes on to describe the birth of popular cinema as a series of ongoing attempts to rearticulate a bourgeois lexicon of gestures, or, an attempt to come to terms with such a 'generalised catastrophe.' Rather than emphasising the impasse of November, then, it

\footnotetext{
34 Berlant, 2011, pp. 198-199

35 Berlant, 2011, p. 198

${ }^{36}$ Agamben, 2000, p. 49
} 
may be useful to think through November, as Steyerl describes it, as a time of transition. A time, that is, similar to, and radically different from, the time Agamben describes in his chapter on the gesture. In this time of transition, the fantasy of the good life that sustained an attachment to the capitalist state during the latter half of the twentieth century is no longer sustainable. The austerity measures of the last half decade (which can be considered either a culmination or just a worsening symptom of neoliberal structural adjustment, depending on how we frame them) have made painfully clear sustaining a population is too expensive for the state as it is organised now. The best we seem able to hope for is a distribution of vulnerability. The surveillance state belongs firmly to this historical situation. The surveillance state promises, instead of a distribution of wealth, a promise of safety - a kind of security to plug the wound of economic precarity wrought by accelerated capital accumulation. Thinking through November as a time of transition allows us to consider modes and methods of withdrawal, opacity, and disappearance, as discussed in this thesis, as a constellation of gestures enacted in an effort to comprehend and overcome the political exigencies of the present. Balsom ends her analysis of How Not to be Seen by referring to Deleuze's 'Postscript to the Societies of Control.' She notes that Deleuze's short essay deals with changing organisations and mechanics of power, capital, and the state. 'A changing diagram is no cause for hope or fear,' Balsom quotes, 'but simply means searching for new weapons.' ${ }^{37}$ Steyerl lays out an image ecology for transitional times that is at once speculative, fanciful, and deeply urgent. Steyerl's ecology of images presents a cautious blueprint for maintaining an attachment to remaking the world when the world seems continually overwhelming, overbearing, and precarious.

37 Balsom, 2015 
A pink blob throbs against a lilac background. A low synthesised hum fades in. The shape we see seems to recall only other blobs; a feminised Flubber (1997), perhaps, or hardened phlegm. It is a monstrous hybrid of organic form and artificial material; its provenance unknown, its purpose elusive. The video's title, superimposed in white sansserif, provides an indication of what we might call the form, a 'fag face,' but stops short of revealing any further indication of what a fag face might be (fig. 22). The shape is strange, alien, and yet, as the video unfolds, its gestures, or the uses to which it is put, begin to feel remarkably familiar.

The first section of Zach Blas' Facial Weaponization Communiqué: Fag Face (2012) provides a diagnosis; it proposes an argument in several stages. A figure appears against an off-white background. The pink blob we saw in the opening frames of the video is worn over the figure's face. A white sheet of paper is propped on the figure's legs (which are cut out of the frame). In the top-left corner, like a television channel logo, a smaller pink blob rotates, revealing its hollow inside (fig. 23). This scene is familiar; its staging the sparse mise en scene, the poor image quality and low saturation, the appropriation of television news iconography - recalls countless communiqués from countless militant or activist groups, as well as forms of popular media which flirt with the revolutionary as a means of entertainment: Anonymous, Al Qaeda, V for Vendetta (2005), Mr. Robot (2015).

The figure appears to speak in an automated voice; masculine, American, the default setting for the text-to-speech function on a Mac. The voice paints a dystopian picture of a present tense subject to massive programmes of surveillance, data collection, and an exponential growth in the development and implementation of biometric technologies for policing and marketing:

\footnotetext{
${ }^{1}$ This chapter is a close reading of a single video which belongs to a larger project undertaken by Zach Blas between 2011 and 2014, titled Facial Weaponization Suite. The 'suite' of Facial Weaponization Suite refers to a series of workshops and performances which took place in Los Angeles, San Diego, and Mexico City, as well as sculptures and videos that were produced by Blas and his collaborators between 2011 and 2014. I have chosen to limit my focus to the video, however, in part because it enabled the project to reach a broader audience than it otherwise would have, and because the video presents questions relating to the terms and conventions of critical documentary practice that this thesis seeks to examine. The video has been exhibited, either alone or with the Fag Face masks, in numerous cities around the world including New York, Amsterdam, Istanbul and Wellington. Zach Blas. Interview with the author (via Skype), Wellington and London, 17 October 2016.
} 
Today, in our world of information capital and global empire, biometric control has emerged as a golden frontier for neoliberal governments. A multi-billion dollar industry in security and marketing sectors, biometric companies produce devices like iris scanners and facial recognition machines with the hopes of manufacturing the perfect automated identification tools that can successfully read a core identity off the body.

As this description of the contemporary security state is read aloud, clips of corporate and advertising material appear on screen. People move through a public space, probably a train station, as green and blue frames flicker across their faces. The Xbox Kinect plugin camera, sleek, shiny, and black, softly spotlit against a grey background, completes a bow towards the viewer. A woman, in running gear, is seen tying her shoelace on a bucolic suburban street. As the camera pans up to her face - which is content, but determined, sweating lightly, but still demure - a transparent, blue tube moves up her body, as she is circled by numbers, surrounded by all manner of vital statistics. A sea of people, all wearing indistinguishable black suits, wait at a set of pedestrian lights. Again, their faces are framed by hovering green boxes (fig. 24). These images, which seem unremarkable for their quotidian nature, for how they circulate widely and frequently without any glitches in interpretation, turn the video into an archive of the iconography of contemporary surveillance culture.

Later in the video, the masked figure is joined by a second narrator. Again, the voice is the automated text-to-speech voice familiar to Mac users, but this time it is feminine. Still American, still with an awkward intonation and cadence, still mispronouncing the odd word. This voice, it appears, belongs to the mask itself. Suspended against the same lilac background we saw during the opening frames of the video, the mask throbs while the feminine voice continues the analysis of our biometric present. 'Biometric technologies rely heavily on stable and normative conceptions of identity.' The voice goes on, 'And thus, structural failures are encoded in biometrics that discriminate against race, class, gender, sex, and disability. The present tense described in the video is one in which the 'total field of visibility' outlined over forty years ago by Foucault has not only been achieved in ways that are difficult to comprehend, but has taken a particular interest in the 
face as the locus of identity. ${ }^{2}$ This field of visibility is fallible, though, and it is within the regime's failure to make itself both invisible and immanent that there opens a space for radical action.

Existing biometric technologies assume that bodies are able to be parsed; that they might be reducible to a set of coordinates that can reveal allegiance, modes of kinship, past behaviour, and likely future intention. Further, the logic of these technologies assumes the face can bear the weight of identity; that its contours, its tics, its bone structure reveal something essential about its owner. ${ }^{3}$ The narrators point towards several examples of biometric failure: fingerprint scanners that fail to detect the fingerprints of Asian women, iris scanners that do not recognise those with cataracts, but the failure the video's narrators seek to overcome is a structural one. ${ }^{4}$ Overcoming the failures of biometrics depends, that is, on undermining the logic of identity and identification which keeps this regime functioning.

The video then turns its attention towards a 2008 study published in the Journal of Experimental Social Psychology. The study involved 90 participants, all undergraduates from Tufts University, being shown 90 images of faces - 45 of men identified as heterosexual, and 45 of men identified as homosexual. ${ }^{5}$ Participants were shown images of the faces - all cropped from the body and placed against a white background, all devoid of any markers or accessories such as jewellery, piercings, or glasses - in quick succession and asked to identify the sexual orientation of the faces they saw. The study found that the participants showed a remarkable accuracy in being able to distinguish

\footnotetext{
2 In an interview with Simone Brown, Blas suggests adjusting Foucault's model of panopticon as a diagram of power. 'I think biometrics is one of today's major control diagrams.' In a more recent project, Blas has materialised the 'diagrams' used by many biometrics programmes to detect facial features. These diagrams are designed to plot features including the space between the eyes, the width of the nose, and the contours of the lips to create a unique, algorithmic illustration of the subject, which can then be transferred across different terminals - for instance, at customs and immigration checkpoints in airports. Blas' Face Cages (2013-2016), which recall torture devices in their form and restrict the breathing of those who wear them, 'intensify and dramatise the violence of biometrics.' Zach Blas and Simone Browne, 'Beyond the Internet and All Control Diagrams,' The New Inquiry, 24 January 2017, http://thenewinquiry.com/features/beyond-theinternet-and-all-control-diagrams/, Accessed 25 January 2017; Zach Blas, Interview with the author (via Skype), Wellington and London, 17 October 2016

${ }^{3}$ See Kelly A. Gates' discussion of 'the face of evil' in Kelly A. Gates, Our Biometric Future: Facial Recognition Technology and the Culture of Surveillance, New York: NYU Press, 2011, pp. 97-124

${ }^{4}$ See: Shoshana Amielle Magnet, When Biometrics Fail: Gender, Race, and the Technology of Identity, Durham: Duke University Press, 2011, p. 28

${ }^{5}$ This number was adjusted in subsequent experiments to better reproduce the distribution of homosexuals among the general population. Ambady Nalini and Nicholas O. Rule, 'Brief exposures: Male sexual orientation is accurately perceived at 50 ms,' Journal of Experimental Social Psychology 44:4, 2008, p. 1102
} 
sexual orientation, even when exposed to the images for as little as 50 milliseconds. ${ }^{6} \mathrm{~A}$ similar experiment even delivered similarly accurate results when participants were shown only a portion of the face, such as an eye, or a pair of lips. The masculine voiced narrator ends the explanation of the studies with a set of questions:

\footnotetext{
What could the benefits of proving to the world that such a recognition apparatus exists? Does it not only further confirm and scientifically validate one of the processes of LGBTIQ stereotyping, categories like fag face and gay face? It is easy enough to claim that these studies parse us into categories that will inevitably be used against us. It offers a visibility that will attempt to control, monitor, and police us. In response to facial recognition technologies, we ask, what are the tactics and techniques for making our faces non-existent? How do we flee this visibility into a fog of a queerness that refuses to be recognised? ${ }^{7}$
}

It is at this point the logic and praxis of the pink mask is finally revealed. The congruence of this latter day physiognomy with a programme of surveillance and capture grounded in a logic of identification and categorisation propels the narrator to announce a radical programme of opacity. Based, apparently, on a warped amalgamation of queer men's faces, the pink mask provides a means to avoid capture by facial recognition technologies, while simultaneously providing the means to identify and be identified collectively, as one pink blob among many (fig. 25). The mask represents, according to the video's narrators, a 'politics of escape.' That is, it enacts 'a politics that is anti-state, and anti-recognition... Escape not only expresses a desire to exit current regimes of control, but also to cultivate forms of living otherwise.' The mask is a 'weapon' in this project of escape. Its genealogy is traced, speculatively, from the female freedom fighters in the Battle of Algiers (1966) who 'break into the occupied territory of the colonisers, in part, by wearing their oppressor's faces, ${ }^{8}$ to more recent activist groups, the Black Bloc, Anonymous, Pussy Riot, and the Zapatistas. ${ }^{9}$ The mask, we might say, is a means of both appearing and disappearing.

\footnotetext{
6 Nalini and Rule, 2008, p. 1103

7 The use of the word 'fog' here is of interest. Later in the video, in a gesture that recalls Bernadette Corporation's practice of unattributed theoretical intervention, the female voice intones succinctly, 'fog makes revolt possible.' This sentence originally appeared in Tiqqun's The Cybernetic Hypothesis, and is elsewhere cited by Blas in an essay on recent theories and practice of obfuscation and anonymity. Zach Blas, 'Queer Darkness,' in Carolin Wiedemann and Soenke Zehle (eds.), Depletion Design: A Glossary of Network Ecologies, Amsterdam, Institute for Network Cultures, 2012, p. 127

8 That is, they deploy their unveiled faces as a means of evading scrutiny at checkpoints around the city, and are therefore able to covertly transport information and goods between militant groups.

${ }^{9}$ Much has been written in the last decade on the role of masks in protest movements as a means to appear as a collective force, free from individual identity. See, for example, Jennifer B. Spiegel, 'Masked Protest in the Age of Austerity: State Violence, Anonymous Bodies, and Resistance "In the Red,"' Critical Inquiry 41, 2015, pp. 786-810
} 
The threads this thesis has been weaving - the biopolitical, identification and disidentification, the use and reuse of political gestures, the limits of committed art - all come to a head in this video. There are moments where associations can be made across works - for instance, in the final moments of Hito Steyerl's November, a former militant active in West Germany at the end of the 1970s recounts the formative impact The Battle of Algiers had on the group's organisational strategies; or, we might point to the thinly veiled allusions to the writing of Tiqqun and Giorgio Agamben detectable in both Blas' work and the work of Bernadette Corporation. This chapter seeks to ask how the conclusions already arrived at might be applied to Blas' work without labouring any affinities that may make themselves legible. Further, it seeks to demonstrate that biometric technologies belong to a state epistemology of transparency, and while the technologies of capture and surveillance may seem novel in ways that are often confusing, terrifying, and spectacular, the logic that guides their development is by no means a recent invention. In following Blas' work, I hope to examine the ways in which the artist seeks to arrive at a collective politics that attends to the ways in which vulnerability is unevenly distributed among subjects depending on class, race, gender, sexuality, and ability, but refuses to settle for a solidarity that would be answerable to any single one of these identifications.

Through Rosler's Vital Statistics, I established that identity is always a matter of interpretation and interpellation. That is, it is a matter of being recognised, or misrecognised, and subsequently rendered in language. I also established that refusing the names by which we find ourselves addressed is an integral part of identity formation, especially when these identities are subject to violence. In my discussion of Bernadette Corporation's engagement with the Black Bloc, I attempted to think through the ways this interpellation might be evaded, how a gesture that seeks to flatten individual difference by binding subjects into a collectivity (if a fleeting, unstable collectivity) might provide its own means of escape. In Blas' work, both of these issues rise to the surface. The very interpellation identified by Rosler is here accelerated, mechanised, and made to operate invisibly for disciplinary ends. The ecstatic, unstable collectivity the Black Bloc provide is 
here redeployed, appropriated, made queer. ${ }^{10}$ Queer, here, might best be understood in terms of Michael Hardt and Antonio Negri's intervention into the term. In Commonwealth, the authors describe the term's potential as a 'proposition... to undermine and abolish all gender identities and set in motion a series of becomings. '11 Hardt and Negri acknowledge the necessary affective pull of identification, but propose to use identity only ever as a means to an end. In place of identity, they suggest, following Agamben, 'singularity.' 'Singularity is always in a process of becoming different - a temporal multiplicity. ${ }^{12}$ The mask, like the uniform of the Black Bloc, establishes a community, and yet the mask, in Blas' formulation, can only ever insist upon its own negativity. It can only ever admit to not admitting what it is, or what it may become. The logic of the biometric technologies of which Blas' narrators speak relies upon a model of human subjectivity that allows itself to be categorised as neatly as possible. The logic of the study mentioned in the video, even in the very posing of its question, again assumes an essentialism, a fixity, a necessary equivalence between what appears and what is. In this chapter, I argue that Facial Weaponization Communiqué attempts to provide a means to shatter this fixity; that ambiguity, opacity, and escape might all be used to broaden the possibility of political formations and identities, and to resist whatever violence goes alongside being named.

\footnotetext{
10 In his editorial to Camera Obscura 31:2 (92), Blas cites The Invisible Committee's The Coming Insurrection as one example among of a 'proliferation' of tracts in the past two decades all concerned with a mounting a politics of refusal that at once rejects the measures of surveillance and visibility, as well as the accelerated accumulation of capital, that typifies the contemporary western state. Julien Coupat, one of the founding members of Tiqqun, is believed to be one of the authors of The Coming Insurrection and one can easily read a formal and political continuity between the two groups and their output. In the same issue, Jacob Gaboury, in his introduction to an interview with Blas, includes Giorgio Agamben's The Coming Community and Tiqqun's Introduction to Civil War among a list of texts which offer a 'variety of methods for producing tactical invisibility.' Part of the renewed interest (especially among scholars, artists, and activists based in the United States) in publications produced by Tiqqun and The Invisible Committee might be attributed to the publication of a number of their texts in translation by Semiotext(e) between 2009 and 2012. Zach Blas, 'Opacities: An Introduction,'; Zach Blas and Jacob Gaboury, 'Biometrics and Opacity: A Conversation,' Camera Obscura $31: 2$ (92), 2016 p. 150 and p. 156

${ }^{11}$ Hardt was one of Blas' PhD supervisors at Duke University. Blas has noted Hardt and Negri's contribution for its ability to engage with the failures of the term 'queer' (that is, for its absorption into a liberal taxonomy of identity and difference), while remaining attached to the term's potentiality. Michael Hardt and Antonio Negri, Commonwealth, Cambridge, MA: Harvard University Press, 2009, p. 335; Zach Blas, Interview with the author (via Skype), Wellington and London, 14 December 2016

12 Hardt and Negri, p. 339
} 
In Blas' video, the face is a surface onto which fantasy can cling. The faces we see in the video, those which are not hidden behind a pink fleshy mask, and those which are not held up as examples of a genealogy of masked protest, are, generally speaking, exemplary faces. They are torn from advertising, from corporate materials, from demonstrations of new technologies. We see, for example, an animated laser-like strip run up and down a plainly handsome man's face, framed by the iOS interface at the top, and the message 'Verifying' at the bottom as the narrator describes the iPhone's ability to recognise its user. ${ }^{13}$ We see, too, facial abstractions; digital models, in blues and reds and pinks, used by the software being described, animations designed to demonstrate, illustrate, bear a resemblance while insisting on their status as simulations. At the time of writing, facial recognition technologies are not as reliable as one might assume based on the video alone. Other forms of biometric identification, such as iris scanning and fingerprint detection, are currently more effective means of distinguishing persons from one another. ${ }^{14}$ Why, then, does the face pose such a problem? Why is it a site of contestation not just for Blas, but for a number of other artists and writers?

The face, for Gilles Deleuze and Félix Guattari, operates at the intersection of signification (or the desire for interpretation, the 'white wall') and subjectification (consciousness, a turning inward, the 'black hole'). ${ }^{15}$ Something takes place at the face, but does not limit itself to the face; the body, objects around the body, might find themselves facialised. The face finds itself divorced from the body, and the body, in turn, finds itself subordinated as an object in proximity to the face. 'The form of subjectivity,' Deleuze and Guattari write, 'whether consciousness or passion, would remain absolutely empty if faces did not form the loci of resonance that select the sensed or mental reality and make it conform to a dominant reality. ${ }^{16}$ The face, as the locus of relationality, as an assemblage of bone, muscles, receptive organs, and skin, they argue, is created by power. The face is not immanent, but brought into being by certain organisations of power and made to bear the weight of whatever conception of personhood that organisation of power

\footnotetext{
13 With the release of the iPhone 6 in 2014, the 'recognition' that iOS itself uses to verify its owner is fingerprint scanning, as opposed to facial recognition, but there are individual apps which deploy facial recognition software for both entertainment and security - most notably Snapchat.

14 Kelly A. Gates, 2011, pp. 17-18

15 Blas has called upon this work multiple times in his own writing; Gilles Deleuze and Felix Guattari, $A$ Thousand Plateaus (1980), trans. Brian Massumi, London: Bloomsbury, 2013 p. 196; Simon O'Sullivan, 'Ten Concepts Following Cathy Wilkes' Practice,' Afterall 12, 2005, p. 70

${ }^{16}$ Deleuze and Guattari, p. 196
} 
conceptualises. ${ }^{17}$ The meanings that might be attributed to the face are always already in motion. The face, rather than belonging to the individual, belongs, and is measured against, an ideal face (Deleuze and Guattari cite 'the face of Christ') and inevitably finds itself wanting. Of course, there are those who find themselves more wanting than others.

Deleuze and Guattari's abstract machine of faciality is structured, implicitly, as a critique of Emmanuel Levinas' ethics of the face. For Levinas, an encounter with the face of the other elicits the moral demand, 'thou shalt not kill.' This demand, Levinas claims, emerges from an internal contradiction. It emerges in the threshold where the subject's desire to kill the other (in the service of self-preservation) is overwhelmed by the subject's desire to preserve the other:

My ethical relation of love for the other stems from the fact that the self cannot survive by itself alone, cannot find meaning within its own being-in-the-world... To expose myself to the vulnerability of the face is to put my ontological right to existence into question. ${ }^{18}$

Judith Butler's critique of Levinasian ethics is more direct. In Precarious Life: The Powers of Mourning and Violence, Butler seeks to arrive at an ethics of the face, or more broadly of relation, that does not begin with sublimated violence. In demonstrating her argument, she draws upon two distinct uses of representations of the face which circulated widely during the first decade of the twenty-first century. The former falls under the category of 'the face of evil,' and includes images of Osama Bin Laden, Saddam Hussein, and Yasser Arafat. The latter example involves an iconic image of unveiled Afghan women, published on the cover of the New York Times in the early days of the U.S. occupation of the country. The exposed faces of women featured in this latter image signify their apparent liberation, the apparent success of liberal democracy in the Middle East. ${ }^{19}$ The image invites the viewer not to identify with the women as subjects, but to circulate the site of identification back to the viewer's own attachment to American national mythology. The faces of these women 'became bared to us,' Butler writes, 'and we were, as it were, in possession of the face; not only did our cameras capture it, but we arranged for the face to capture our triumph, and act as the rationale for our violence.'20 The 'face of evil,' on the other hand, invites a disidentification from its viewer. Further, this disidentification spurs on the very desire to destroy this particular other identified by Levinas. ${ }^{21}$ Butler

\footnotetext{
17 Deleuze and Guattari, pp. 197-198

${ }^{18}$ quoted in Judith Butler, Precarious Life: The Powers of Mourning and Violence, London: Verso, 2004, p. 132

19 Butler, 2004, p. 141-142

20 Butler, 2004, p. 142

21 Butler, 2004, p. 142
} 
writes, 'If we are to understand ourselves as interpellated anywhere in these images, it is precisely as the unrepresented viewer, the one who looks on, the one who is captured by no image at all, but whose charge is to capture and subdue, if not eviscerate, the image at hand. ${ }^{22}$ Butler accepts Levinas' claim that the face acts as an address, that the face acts as the site from which the subject is hailed to enter into a relation, but in drawing upon these particular examples, examples in which the face is both a site of contestation and deployed in order to reinforce normative modes of nationalist sentiment, Butler emphasises the means by which this address is situated historically, and the means by which the face assumes its meaning through its historical and ideological appearances.

These theories of the face are distinct, even if both insist upon the means by which the face's significance is socially and historically produced. The face, for Butler and Deleuze and Guattari, is a matter of recognition, and a project of remaking an ethics of the face depends upon scrutinising how the mechanics of recognition operate. Butler's analysis pays attention to the face's role as something which addresses, as something which speaks prior to language and prior to will. Deleuze and Guattari's analysis invests in strategies to resist the significance that the face inherits. Both theories offer modes of repair. Butler, perhaps more pragmatically, posits that the burden of repair should fall on persistent cultural critique, that the face and the significance transcribed onto it must be subject to continued appraisal. 'One would need to hear the face as it speaks in something other than language to know the precariousness of life that is at stake...' Butler writes, 'If the humanities has a future as cultural criticism, and cultural criticism has a task at the present moment, it is no doubt to return us to the human where we do not expect to find it.' ${ }^{23}$ Deleuze and Guattari's proposition is more radical. In his writings, Blas latches onto a passage in Deleuze and Guattari's chapter on faciality in which the authors propose an 'escape from the face.'

To the point that if human beings have a destiny, it is rather to escape the face, to become clandestine, not by returning to animality, nor even by returning to the head, but by quite spiritual and special becomings-animal, by strange true becomings that get past the wall and get out of the black holes, that make faciality traits themselves finally elude the organization of the face - freckles dashing toward the horizon, hair carried off by the wind, eyes you traverse instead of seeing yourself in or gazing in those glum face-to-face encounters between signifying subjectivities. ${ }^{24}$

\footnotetext{
22 Butler, 2004, p. 143

23 Butler, 2004, p. 151

${ }^{24}$ Deleuze and Guattari, 2013, p. 171; Zach Blas, “'A Cage of Information,” or What is a Biometric Diagram?' in Erika Balsom and Hila Peleg (eds.) Documentary Across Disciplines, Cambridge, MA: The MIT Press, 2016, pp. 88-89
} 
We shall return to what this escape may look like. For now, I would like to focus on the histories of recognition we inevitably find ourselves caught in when confronting the face as a means of biometric identification. What are the implications of this recognition when these modes of seeing and knowing are bound intimately to policies and institutions designed to control movement across borders and inside national territories, control access to wealth and potentially life saving services, and administer discipline to those found to be deviant?

The face's inheritance becomes striking at a point of transition in the video. Right at the point at which the video shifts from a description of contemporary biometric technologies to a discussion of the scientific study regarding the recognisability of homosexual men's faces, a small slippage takes place. The masculine narrator inserts a brief structural transition at this moment, saying, 'Facial recognition has even ventured into the terrain of sexual orientation.' What is left unsaid is an acknowledgement that, with this transition, the subject of the video's critique shifts from one kind of eye (the mechanical eye of the biometric machine) to another (the eyes of the human test subjects). There is, of course, less separating these things than we might think. The composition of the biometric lens has encoded within it the very same imbalances of power that human perception inevitably endows upon its objects. A distinction, nonetheless, between the human and the mechanical is still useful. The desire that drives the development of biometric technologies is a rationalism that seeks to minimise the risk of human error. ${ }^{25}$ As Kelly $A$. Gates writes, 'The desire to overcome the ambiguities and the interpretive flexibility inherent in human perception and social interaction is driving the development of incredibly complex machines that can do what humans do every day but in a totally imperfect way. ${ }^{26}$ All technology is a product of desire and desire, it must be said, clouds vision. 'People come to believe in the power and sophistication of surveillance systems,' Gates writes, 'and this belief itself has important effects on social organization and practices.' Facial recognition technologies acknowledge at once the difficulty of binding identity to the body, as well as the failures of human perception in being able to recall and verify likeness. As Gates' analysis demonstrates, however, technological intervention is by no means a panacea to the failures of human vision. Popular media, marketing material, and dystopian fiction all contribute to an understanding of facial recognition technologies that overstate its current ability to detect and distinguishes faces. Without a standardised

\footnotetext{
25 Nitzan Lebovic, 'Biometrics, or The Power of the Radical Center' Critical Inquiry 41, 2015, p. 855

26 Gates, p. 11
} 
background, and the willingness of subjects to adopt normalised poses, many facial recognition systems have trouble distinguishing human faces from noise. ${ }^{27}$

Effectiveness, however, according to Kevin D. Haggerty and Richard V. Ericson is rarely measured by a straightforward 'appeal to science.' 'Instead,' they write, 'a determination of effectiveness is the net outcome of often contentious political struggles. ${ }^{28}$ When scrutinised in terms of their adoption by a network of state and non-state actors, facial recognition technologies, regardless of their capability, appear overwhelmingly successful. Gates goes on to claim that the development of facial recognition technology as an apparatus of identity verification and individuation 'builds' upon 'existing customs and practices.' 'With nearly everyone in the modern world accustomed to carrying a photo ID and presenting it on demand in a wide range of contexts, automated facial recognition systems could be positioned as continuous with document-based identification.'29 Bearing one's face, then, becomes part of an audition for citizenship. Bearing one's face demonstrates a willingness to comply with the demands of the state. ${ }^{30}$ The development of facial recognition technologies is intimately entangled with the new, often punitive, demands made by the state under neoliberal capitalism. Neoliberal capitalism demands mass individuation in myriad forms: under the auspices of national security and border control; under a rubric of individualising labour, so that each subject may be measured by their productivity, by what they cost to sustain; as part of a programme of criminalising the poor by combating unsubstantiated claims of welfare fraud; as an attempt to monitor exploding prison populations. ${ }^{31}$

\footnotetext{
27 Gates, pp. 58-59

28 quoted in Gates, p. 7

29 Gates also proposes a direct historical relationship between physiognomic analysis and the development of photography and the moving image. She quotes Tom Gunning, "The desire to know the face in its most transitory and bizarre manifestations was stimulated by the use of photography," writes Gunning, "but that desire, in turn, also stimulated the development of photography itself, spurring it to increasing technical mastery over time and motion, prodding it toward the actual invention of motion pictures."' Gates, pp. 8 and 47; Tom Gunning, 'In Your Face: Physiognomy, Photography, and the Gnostic Mission of Early Film,' Modernism/Modernity 4:1, 1997, p. 25

30 Maryam Monalisa Gharavi writes, 'The covered face resists the unwritten regimes of transparency (i.e., how in Western societies the open face is assumed to be the outward evidence of inner truth). As our environment is being rapidly equipped to survey us for various ends - through what technologists call "affective interfaces" - the nonrepresentational, private micro-territory of the covered face induces ever more fear by refusing signification.' Maryam Monalisa Gharavi, 'Who's Afraid of the Covered Face,' Harvard Design Magazine 42, 2016, p. 79

${ }^{31}$ Gates, pp. 54-58;
} 
The face, within this understanding, becomes less a site of relation than a site of admission. We might infer from this, then, that the very question asked by the researchers cited by Blas' narrators was formed, at least in part, by the regime of faciality under which the study took place; that is, the question was formed from the presumption that the face cannot help admitting to something. The study cited in the video posits that queerness might be a matter of proprioceptive recognition. That, for homosexual men, being 'out' might no longer be, or never have been, a matter of enunciation. The authors of the study end their published results with a short discussion. They muse, albeit briefly, on the possible implications of the study, and attempt to make suggestions that would account for the accuracy with which participants were able to judge sexual orientation. They suggest the results may indicate a biological mechanism for mate selection, 'it may be advantageous for heterosexual women to parse male sexual orientation to determine the boundaries of their opportunities for mates.' They go on to suggest that this recognition might, among heterosexual men, be a way to either 'assess competition for mates,' or establish their own, and determine others' position within 'the social dominance hierarchy.'32

The drawing together of a discussion of our biometric present and this specific study is a classic case of paranoid reading. It assumes the worst. It draws upon a history of unequally distributed violence to project a future in which these cases of violence repeat themselves via new apparatuses. Perhaps paranoia is justified here. The name of the video's mask, the Fag Face, is drawn from a commonly hurled schoolyard insult. In the video, we see a short clip purportedly documenting the violent implications of this insult. We can just make out what appears to be a confrontation between two men. Across the bottom of the screen, we see, subtitled, 'You want your fag face bashed?' (fig. 26). Blas' video brings together different but related modes of knowing and being in the world. Well intentioned (or at least not outwardly malicious) scientific positivism, the contemporary apparatuses of biopower, anecdotal histories of victimisation, and a form of critique that hopes to open up space for new modes of knowing and inhabiting the world all congeal around each other. The study seems to prove the existence of a perceptible difference in the queer bodies of those who might otherwise have presumed to be invisible. Though the validity of the study might leave itself open to a critique, the video demands that the study's conceit be followed in order for its proposition to be heard. The video takes up a paranoid reading of the political present and uses this as a means to describe a means of

\footnotetext{
32 Nalini and Rule, 2008, p. 1104
} 
escape. Paranoia provides a fertile ground from which a radical method of repair can be proposed.

Queerness has always flirted with negativity. Historically, queerness - as a political programme, and as a framework of analysis - has maintained an ambivalent and contested position in relation to identity and identification. Queerness' negativity relates both to a rejection of the inheritance with which queerness is recognised and interpreted as deviant, antisocial, and dangerous, as well as thinking through how that very symbolic negativity might provide a basis for solidarity, for worldmaking, for survival, and even flourishing. ${ }^{33}$ Queerness asks how a model of the good life which compels subjects into certain modes of living and relating to one another might be reimagined using queerness' own failures in living up to that model.

In the video, the feminine narrator speaks disparagingly of a queer politics organised around recognition from the state. This model of emancipation is predicated upon a willingness to comply with the demands of citizenship as established by the state. It relies, that is, both on liberalism's willingness to expand its tent to allow for certain kinds of difference, and upon queers insisting upon their proximity to already existing modes of citizenship and relationality. ${ }^{34}$ In the video, it is made clear that this would mean reconciling with a history of violence the state has perpetrated, allaying those modes of queerness that do not fit so easily with what the capitalist state demands from its populace. In this case, it would mean complying with a regime of radical transparency, a regime which demands a face and demands that the face reveal a stable, easily parsed identity. As the feminine narrator unpacks the dichotomy of a politics of recognition versus a politics of 'living otherwise' the mask's throbbing becomes more frantic and violent. The mask's distortions take the form of jagged peaks, jumping towards the

\footnotetext{
${ }^{33}$ See: Jack Halberstam, 'The Anti-Social Turn in Queer Studies,' Graduate Journal of Social Sciences 5:2, 2008, pp. 140-156

${ }^{34}$ See: Ryan Conrad (ed.), Against Equality: Queer Revolution Not Mere Inclusion, Oakland: AK Press, 2014; Janet R. Jakobsen, 'Sex+Freedom=Regulation: WHY' Social Text 84-85, 2005, pp. 285-308
} 
viewer. The distortions seem to stretch the limits of the mask's form, with each syllable enunciated seeming to bring the mask closer to shattering (fig. 27). One might be led to consider this a kind of turning point in the video, an indication of some kind of rupture to come.

The limits of queerness have always been porous. In an early evocation of the term, which has since been cited numerous times, David M. Halperin writes,

Queer is by definition whatever is at odds with the normal, the legitimate, the dominant. There is nothing in particular to which it refers. It is an identity without an essence... Queer, in any case, does not designate a class of already objectified pathologies or perversions; rather, it describes a horizon of possibility whose precise extent and heterogenous scope cannot in principle be delimited in advance. ${ }^{35}$

I quote at length not to suggest that Halperin's definition has been accepted as dogma. Halperin's writing has, since its publication in 1995, been subjected to sustained and productive critique. ${ }^{36}$ I quote Halperin in order to help clarify a discrepancy between vernacular understandings of queerness (which, using the same logic of the liberal state, expands continually in order to absorb any articulable sexual expression that falls outside of the limits of monogamous heterosexuality), and a historic project that takes as its ultimate aim the reconstitution of the entire realm of social relations. Queerness, as a horizon of possibility, leaves itself open to contingency, change, and surprising leaps in logic and sensemaking. For José Esteban Muñoz, it is within the very ambiguity of queerness as an exclusively oppositional term that its potential might be found. 'I suggest that holding queerness in a sort of ontologically humble state,' Muñoz writes, 'under a conceptual grid in which we do not claim to always already know queerness in the world, potentially staves off the ossifying effects of neoliberal ideology and the degradation of politics brought about by representations of queerness in contemporary popular culture. ${ }^{37}$ For Muñoz, queerness is necessarily oriented towards the future. Its impulse is utopian, and the possibilities it contains cannot be foreclosed. In this way, it is

\footnotetext{
${ }^{35}$ David M. Halperin, Saint Foucault, Oxford: Oxford University Press, 1995, p. 62, italics in original

${ }^{36}$ One of the most striking engagements with the limits of Halperin's definition and its subsequent use in the humanities is Janet R. Jakobsen, 'Queer Is? Queer Does? Normativity and the Problem of Resistance,' GLQ: A Journal of Lesbian and Gay Studies 4:4, 1998. More recently, in an interview with Sara Ahmed, Judith Butler has suggested that queer theory may need to adjust its definitions, priorities, and methods of critique in order to maintain its political efficacy. Sara Ahmed, 'Interview with Judith Butler,' Sexualities 19:4, 2016, pp. $482-492$

37 Blas, while acknowledging the limits of queer critique, has identified a sympathy between his thinking and Muñoz's insistence upon the utopian. Zach Blas, Interview with the author (via Skype), Wellington and London, 14 December 2016; José Esteban Muñoz, Cruising Utopia: The Then and There of Queer Futurity, New York: NYU Press, 2009, p. 22
} 
fundamentally hostile to the identitarian taxonomy the state demands. Muñoz's queerness cannot admit to itself, and it cannot be mastered.

What, we might ask, is Blas' queerness? What is the mask's queerness? What possibilities does it offer for reimagining existing models of relationality? Paying attention to Blas' own writing provides insight into the expanded possibilities the artist seeks to access. In The Queer Art of Failure, a work that has been cited multiple times by Blas, Jack Halberstam peers through an archive of clumsiness, silliness, awkward and shattered relations in order to ask whether these instances of loss or incompetence might hold in them potential for reimagining political formation and action. In a section discussing the work of painter Monica Majoli, whose paintings of her ex-lovers reveal only the faintest abstractions of shadowy figures sinking into the darkness of their surroundings, Halberstam proposes an aesthetic of queer darkness. Darkness, Halberstam proposes, might be used as an 'interpretative strategy,' one that would make 'failure its centerpiece and... cast queerness as the dark landscape of confusion, loneliness, alienation, impossibility, and awkwardness. ${ }^{38}$ Rather than throwing off the archive of symbolic negativity attached to queerness and its representations throughout the twentieth century in relentless pursuit of affirmation (such we would locate in mainstream discourses of queer representation in popular media), this archive might provide its own fertile ground from which to reconfigure the criteria by which a successful life is measured. 'Queerness,' Halberstam writes elsewhere, 'names the other possibilities, the other potential outcomes, the non-linear and noninevitable trajectories that fan out from any given event and lead to unpredictable futures.' 39

Blas' mask, of course, is by no means dark. Its plastic magenta sheen is almost sickly to look at. Blas' interpretation of queer darkness depends upon the term's relation to the withholding of meaning, or what we might call the refusal of illumination. Queer darkness does not enlighten. It strives to obscure, evade, and leave signifiers hanging. Queer darkness gets subsumed into an entire catalogue of strategies, terms, and concepts to describe ways of inhabiting the world and ways of forming relations that do not depend on a subject's willingness to be transparent. 40 Vitally, the mask has no eyes. The eyes contain a special resonance for both Deleuze and Guattari and Butler. For the former, the

\footnotetext{
38 Halberstam, 2011, p. 97-98

39 Halberstam, 2008, p. 153

40 Zach Blas, 'Informatic Opacity' Journal of Aesthetics and Protest 9, 2014, http://www.joaap.org/issue9/ zachblas.htm, Accessed 15 December 2016
} 
eyes are the black holes inside which subjectification takes place. For the latter, the eyes become what is able to be manipulated, made inhuman, that which would make the image of the 'face of evil' an image to be eviscerated. Unlike the masks deployed by the Black Bloc (and, we might say, Anonymous, the Zapatistas, and the archive of activists called upon in the video) Blas' mask commits even further to its negativity. It disallows the possibility of seeing, and therefore it disallows its wearer to recognise when they have been seen by another. It does not allow its wearer to locate other wearers who may be close by, so, if we are willing to follow the strange Schrodingerian logic this might present, the mask opens up the dual possibility that both everyone in proximity to the wearer wears the mask, and no one does.

The mask has a commercial sheen to it. In both its real-life (the one worn by the masculine narrator) and its computer generated (the feminine narrator) forms, the mask has the glint of fresh plastic, which sits uncomfortably with its fleshy form. The computer generated mask, which hovers against its soft spotlit lilac background, bears a relation to the brief clip we see of the Xbox Kinect, or, more generally, is rendered using a visual language reserved for the promotion and display of new technology commodities. Heather Davis describes plastic not as a substance, but a surface, all surface, all the way through. Plastic is, for Davis, paradoxically, both opaque, in that it reveals nothing, and transparent, in that it has nothing to reveal. ${ }^{41}$

Plastic has an inhuman temporality. It is made from long dead organic matter, plied and formed into all manner of shapes, and in its formation into a commodity attracts a profoundly ambivalent symbolic weight. A symbolic weight that speaks to both the convenience of consumer capitalism and the impossible damage such convenience inevitably causes. It will not go away. It will not break down. It will, in all likelihood, outlive its user by hundreds of thousands of years, either in a landfill or circulating as part of a massive trash island in the middle of an ocean. In Blas' work, the inhuman temporality of plastic is molded to the face - the site, if we recall Deleuze and Guattari, and Butler, where the human as we know it comes into being - and in becoming so creates some monstrous hybrid. The mask is made, putatively, from the face, or from a collective face,

\footnotetext{
${ }^{41}$ Heather Davis, 'Imperceptibility and Accumulation: Political Strategies of Plastic,' Camera Obscura p. 31:2 92, 2016, p. 188
} 
but it is not of the face. ${ }^{42}$ We see, as the mask appears to speak, its shape morph and stretch, but never rupture. It is the mask's mutable, unpredictable rearrangement of its form that makes its queerness evident. In her essay on the surface quality of plastic, Heather Davis goes on to ask what about plastic might be drawn upon for a programme of political resistance to the biometric regimes of identification and policing Blas' narrators describe. Plastic provides 'a lesson of shape-shifting, of assuming identities that defy coherent forms and change in response to particular contexts.' Plastic offers the means of 'appearing in unlocalizable formations, myriad forms, and identities that resist a 'suspicious hermeneutic impulse whereby sexuality [or other political categories of identity are] understood as concealed meaning that can nonetheless be made transparent to scrutiny.' ${ }^{43}$ Queerness' negative definition, the porousness of its limits, lends itself to appearing in plastic form because the project of queerness shared by Halberstam, Davis, and Blas is based upon solidarities being maintained through the use of identities that are always contingent, always able to change, that refuse to be made transparent, essentialised, or easily readable. It is a solidarity based upon refusing to heed to the call of interpellation, to refuse the addresses one might find themselves called by. The project of queerness always has to be ongoing, always has to be in a fugitive relation to that which would attempt to restrain it, to make it legible, to make it fit into the binary logics of categorisation and transparency that fuel the biometric regime within which we operate.

Blas' mask might be thought of as an object dense with intersecting desires; it contains a desire to depart from the transparency demanded by the capitalist state, as well as a desire to depart into forms of relation that cannot yet be imagined. The mask gestures towards a radical reconception of collectivity, solidarity, and individuation. It is essential, however, to emphasise that it only gestures. To acknowledge this is not necessarily to admit that the mask fails, but to arrive at the limitations of politically committed art. The gesture motions towards, points in the direction of, but never claims to arrive at its destination. The gesture, for Giorgio Agamben, is 'the communication of a communicability.' He goes on, 'It has precisely nothing to say because what it shows is the being-in-language of human beings as pure mediality. However, because being-inlanguage is not something that could be said in sentences, the gesture is essentially

\footnotetext{
42 The mask has long been associated with collective transgression, festivity, and a playful flirtation with the inhuman. As Mikhail Bakhtin writes of the mask in European folk traditions, 'the mask is connected with the joy of change and reincarnation, with gay relativity and with the merry negation of uniformity and similarity; it rejects conformity to oneself.' Mikhail Bakhtin, Rabelais and His World, trans. Helene Iswolsky, Bloomington: Indiana University Press, 1984, p. 40

${ }^{43}$ Davis, 2016, p. 190
} 
always a gesture of not being able to figure something out in language.'44 The gesture, then, is a performative act that points to the limits of language. Measuring the effectiveness of Blas' mask, as a technology, is not a matter of measuring how well it can evade existing facial recognition technologies. ${ }^{45}$ Such an exercise would misplace an emphasis on the teleology of the mask, and neglect that political resistance is always already in a fugitive state to the recuperative machinations of capital, state repression, and obsolescence. Where the mask succeeds is in gesturing towards the limitations of the languages by which subjects are constituted, called, and to which they find themselves answering. The mask succeeds in gesturing towards queerness' utopian desire not to be accounted for, not to be reducible, and not to be always awaiting legitimation from the state.

44 Giorgio Agamben, Means Without End: Notes on Politics, trans. Vincenzo Binetti and Cesare Casarino, Minneapolis: Minnesota University Press, 2000, p. 59

45 In his Master's thesis, artist Sterling Crispin claims Blas' mask fails as a technology designed to avoid capture. Crispin was able to train facial recognition software to identify Blas' Fag Face mask. Blas, however, is clear about the limitations of the mask, cautioning against a 'technologically solutionist' reading of the work. 'The moment that you might really want to wear these kinds of masks,' Blas says, 'you're not going to be able to. Like at an airport, for instance. I feel it's very important to not kid yourself into thinking you've solved the problem.' Sterling Crispin, Data-Masks: Biometric Surveillance Masks Evolving in the Gaze of the Technological Other, Masters of Science Thesis, University of California Santa Barbara, 2014, pp. 11-12; Zach Blas, Interview with the author (via Skype), Wellington and London, 17 October 2016 
The year during which this thesis was written was an an incredibly strange one. The rise of a nativist, xenophobic right wing has forced a renewed consideration of survival tactics, modes of engagement, and terms of reference on behalf of already vulnerable subjects. The events of the last twelve months provide cause to scrutinise the ethical implications of political withdrawal. If this juncture would seem to call for the exertion of sustained, critical attention simply to stay abreast of an increasingly volatile political landscape, does withdrawal constitute an acquiescence to this volatility? Is it a position able to be entertained only by the relatively privileged, by those lucky enough to be able to disengage from ongoing scenes of contestation regarding the nature and character of national citizenship, the distribution of economic, bodily, and emotional vulnerability, and the legitimacy or illegitimacy of attachments, kinships, and lifeworlds?

Withdrawal, as I have examined in this thesis, is not necessarily a disengagement. The programmes of withdrawal that have been discussed might better be considered examples of political fantasy. These programmes identify something broken in the social world, and gesture towards repair by gesturing outwards; towards a departure from the regimes of transparency, control, and production that constitute subjects. Political fantasy here refers to the kinds of impractical thinking art allows. It refers to a mode of discourse not limited by the pragmatics of everyday civic engagement; parliamentary and judicial processes, the formulaic prose of opinion pieces, or ordinary gossip. Entertaining political fantasy is a way to sustain the ethical commitments made by the artists in this study. 'The energy that generates [the] sustaining commitment to the work of undoing a world while making one,' writes Lauren Berlant, 'requires fantasy to motor programs of action, to distort the present on behalf of what the present can become.' ${ }^{1}$ The fantasy of withdrawal, then, is vital for sustaining an attachment to the project of making better worlds. It is also, as we have seen, a means to take that which is subordinated, exiled, or repressed in the social world we inhabit, and to use it as fertile ground upon which to build new relational modes.

The artworks analysed in this thesis engage in the political field by operating at the limits of existing political vocabularies. As Jacques Rancière writes, 'artistic practices are "ways of doing and making" that intervene in the general distribution of ways of doing and

${ }^{1}$ Berlant, Cruel Optimism, Durham: Duke University Press, 2011, p. 263 
making as well as in the relationships they maintain to modes of being and forms of visibility.'2 The works analysed in this thesis engage playfully with the conventions of documentary practice, problematising its truth value, its historically pedagogical impulse, and its use of archival evidence to supplement the claims the form makes. For Martha Rosler, in Vital Statistics of a Citizen, Simply Obtained, evidence might amount to the confirmation of what is already assumed. In performing in the role of case study, Rosler forces us to bear witness to the interpellative processes by which women come into being. Rosler's video also, however, affirms the ongoingness of political engagement, and points to some of the problems we may come across in conceptualising withdrawal. For Rosler, inhabiting an identity is always a matter of recognition - of being intelligible as something in particular and named as such. Bernadette Corporation, Hito Steyerl, and Zach Blas appear sensitive to this. For them, withdrawal becomes an exercise in making oneself unrecognisable to existing regimes of control. This takes place in the register of performance, adornment, and bodily alteration. Black uniforms, pixelated headgear, and fleshy masks allow for the creation of new political identities. Vitally, however, for both BC and Blas these identities are forced to remain ambiguous, fugitive, and endlessly open to change.

The works in this thesis all locate themselves among different political struggles, different historical lineages, and argue for competing strategies of resistance. What has become apparent, however, is that they all seem to share an objection to biopolitical models of control. The biopolitical is founded upon an epistemology of transparency. It assumes that subjects are ultimately knowable, able to be mastered, and willing to be accounted for. Further, under our current biopolitical regime, citizenship takes place as a perpetual audition, within which one is always already on the edge of failing to qualify. Increasingly, navigating daily life becomes an exercise in warding off suspicion. The technological apparatuses of the state's increasingly invasive gaze is foregrounded in the work of Steyerl and Blas, but by examining this selection of works from the last forty years, I have attempted to demonstrate that, although these technologies seem novel, and at times baffling, the matrices of power that produced them are by no means new.

Against the language of transparency, visibility, and security, the political utility of opacity, indeterminacy, and doubt have emerged as common themes. Opacity, indeterminacy, and doubt have also emerged as formal strategies. In the case of Bernadette Corporation's Get Rid of Yourself, the committed speech that traditionally belongs to the political

\footnotetext{
2Jacques Rancière, The Politics of Aesthetics, trans. Gabriel Rockhill, London: Continuum, 2004, p. 13
} 
documentary is rendered suspect when repeated, and stumbled over, by Chloë Sevigny. Sevigny's stuttering, however, does not necessarily amount to an evacuation of commitment. In Hito Steyerl's November, the viewer is forced to keep track of several competing versions of Andrea Wolf, with no one version taking precedence over the other. Reality, in Steyerl's film, becomes thoroughly mediated. These formal interventions which seem to defer identification, and undermine the indexical relation the lens-based image assumes with reality - speak directly to the precarious conditions of the present. These films assume a suspicious audience. As Steyerl writes in 'Documentary Uncertainty,' 'amidst all this ambivalence, our confusion is the one thing which remains certain... And it will invariably, if unconsciously, represent our reaction to documentary materials as such.' 3 These films use indeterminacy as a generative force. Indeterminacy is deployed as a means to take up and rearrange worn-out political languages; it becomes effective in making that which appears immanent mutable and able to be reimagined; and it becomes a way to remain committed to the creation of better future when the present appears troubling, groundless, and difficult to pin down.

\footnotetext{
${ }^{3}$ Hito Steyerl, 'Documentary Uncertainty,' Re-Visiones, 2011, http://www.re-visiones.net/spip.php \%3Farticle37, Accessed 20 February 2017
} 


\section{BIBLIOGRAPHY}

Agamben, Giorgio, Homo Sacer: Sovereign Power and Bare Life, trans. Daniel Heller-Roazen, Stanford: Stanford University Press, 1998

, Means Without End: Notes on Politics, trans. Vincenzo Binetti and Cesare Casarino,

Minneapolis: Minnesota University Press, 2000

, State of Exception, trans. Kevin Attell, Chicago: University of Chicago Press, 2005

, The Coming Community, trans. Michael Hardt, Minneapolis: University of Minnesota Press,

1993

Ahmed, Sara, 'Interview with Judith Butler,' Sexualities 19:4, 2016, pp. 482-492

Alter, Nora A, 'Translating the Essay into Film and Installation,' Journal of Visual Culture 6:1, 2007, pp. 44-57

Althusser, Louis, Lenin and Philosophy and Other Essays, trans. Ben Brewster, New York: Monthly Review Press, 1971

Apple, 'iPhone 7 Tech Specs,' 2016. http://www.apple.com/nz/iphone-7/specs, last accessed 2 November 2016

Bakhtin, Mikhail, Rabelais and His World, trans. Helene Iswolsky, Bloomington: Indiana University Press, 1984

Balsom, Erika, 'Introduction to Hito Steyerl's How Not to Be Seen,' presented at the symposium Life Remade: The Politics and Aesthetics of Animation, Simulation and Rendering, Birkbeck, University of London, June 2015

Balsom, Erika and Hila Peleg (eds.) Documentary Across Disciplines, Cambridge: The MIT Press, 2016

Bennett, Jill, Empathic Vision: Affect, Trauma, and Contemporary Art, Stanford: Stanford University Press, 2005

Berlant, Lauren, Cruel Optimism, Durham: Duke University Press, 2011

The Queen of America Goes to Washington City: Essays in Sex and Citizenship, Durham:

Duke University Press, 1997 , 'The Subject of True Feeling: Pain, Privacy, and Politics,' in Sarat, Austin and Kearns,

Thomas R. (eds.), Cultural Pluralism, Identity Politics, and the Law, Ann Arbor: University of Michigan Press, 1999, pp. 49-84

Berlant, Lauren and Sianne Ngai, 'Comedy Has Issues,' Critical Inquiry 43, 2017, pp. 233-249

Bernadette Corporation, 'Be Corpse,' Afterall 14, 2006, pp. 56-61

accessed 2 February 2017 , 'Get Rid of Yourself,' http://www.bernadettecorporation.com/getrid.htm, last

Bersani, Leo, Homos, Cambridge, MA: Harvard University Press, 1996 , 'Illegitimacy,' lecture delivered at The State of Things, Istituto Veneto di Scienze, Lettere ed Arti, Venice, 2 June 2011, http://www.oca.no/programme/audiovisual/the-state-of-things-illegitimacy, last accessed 15 December 2016 Thoughts and Things, Chicago: University of Chicago Press, 2015

Blas, Zach, 'Facial Weaponization Communiqué: Fag Face,' Vimeo, 21 January 2013, https://vimeo.com/ 57882032, last accessed 2 February 2017 , 'Informatic Opacity' Journal of Aesthetics and Protest 9, 2014, http://www.joaap.org/issue9/ zachblas.htm, last accessed 15 December 2016 , 'Opacities: An Introduction,' Camera Obscura 31:2 92, 2016, pp. 149-153 , 'Queer Darkness,' in Carolin Wiedemann and Soenke Zehle (eds.), Depletion Design: A Glossary of Network Ecologies, Amsterdam, Institute for Network Cultures, 2012, pp. 127-132 
Blas, Zach and Simone Browne, 'Beyond the Internet and All Control Diagrams,' The New Inquiry, 24 January 2017, http://thenewinquiry.com/features/beyond-the-internet-and-all-control-diagrams/, last accessed 25 January 2017

Blas, Zach and Jacob Gaboury, 'Biometrics and Opacity: A Conversation,' Camera Obscura 31:2 92, 2016 , pp. 155-165

Butler, Judith, Gender Trouble (1990), London and New York: Routledge, 1999 'Merely Cultural,' Social Text 52/53, 1997, pp. 265-277

Precarious Life: The Powers of Mourning and Violence, London: Verso, 2004 The Psychic Life of Power, Stanford: Stanford University Press, 1997

Caffarena, Fabio and Carlo Stiaccini, 'Piazza Carlo Giuliani: G8 Summit, Genoa 2001,' in P.J. Sanchez and Cristina Carteret (eds.), Grassroots Memorials: The Politics of Memorializing Traumatic Death, New York: Berghahn Books, 2011, pp. 304-318

Carroll Rory, 'The wild boy who became a martyr,' Observer, 22 July 2001, https://www.theguardian.com/ world/2001/jul/22/globalisation.businessandmedia4, last accessed 25 January 2017

'Chamber Judgement Giuliani and Gaggio v. Italy,' European Court of Human Rights, 25 August 2009, http:// hudoc.echr.coe.int/eng? $\mathrm{i}=001-93948$, last accessed 15 January 2017

Conrad, Ryan (ed.), Against Equality: Queer Revolution Not Mere Inclusion, Oakland: AK Press, 2014

Crispin, Sterling, Data-Masks: Biometric Surveillance Masks Evolving in the Gaze of the Technological Other, Masters of Science Thesis, University of California Santa Barbara, 2014

Cunningham, John, 'Clandestinity and Appearance,' Mute 2:16, 8 July 2010, http://www.metamute.org/ editorial/articles/clandestinity-and-appearance, last accessed 1 February 2017

Davis, Heather, 'Imperceptibility and Accumulation: Political Strategies of Plastic,' Camera Obscura 31:2 92, 2016, pp. 187-193

Deleuze, Gilles, Francis Bacon: The Logic of Sensation (1981), trans. Daniel W. Smith, London: Continuum, 2003

Deleuze, Gilles and Félix Guattari, Anti-Oedipus (1984), trans. Robert Hurley, Mark Seem, and Helen R. Lane, London: Continuum, 2004

2013

A Thousand Plateaus (1980), trans. Brian Massumi, London: Bloomsbury,

Demos, T.J., The Migrant Image: The Art and Politics of Documentary During Global Crisis, Durham: Duke University Press, 2013

Edelman, Lee, No Future: Queer Theory and the Death Drive, Durham: Duke University Press, 2005

Edwards, Steve, Martha Rosler: The Bowery in two inadequate descriptive systems, London: Afterall, 2012

Fisher, Mark, Capitalist Realism: Is There No Alternative?, London: Zero Books, 2009

Foucault, Michel, Abnormal: Lectures at the Collège de France 1974-75, trans. Graham Burchell, London: Verso, 2003

Vintage, 1995 , Discipline and Punish: The Birth of the Prison (1975), trans. Alan Sheridan, New York: 
Society Must be Defended: Lectures at the Collége de France 1975-76, ed. Mauro Bertani and Alessandro Fontana, trans. David Macey, New York: Picador, 2003

Galloway, Alexander, 'Black Box, Black Bloc,' in Benjamin Noys (ed.) Communization and its Discontents: Contestation, Critique, and Contemporary Struggles, Wivenhoe: Minor Compositions, 2011, pp. $237-252$

Galloway, Alexander and Eugene Thacker, The Exploit: A Theory of Networks, Minneapolis: University of Minnesota Press, 2007

Gates, Kelly A., Our Biometric Future: Facial Recognition Technology and the Culture of Surveillance, New York: NYU Press, 2011

Gever, Martha 'An Interview with Martha Rosler,' Afterimage 9:3, 1981, pp. 10-17

Gharavi, Maryam Monalisa, 'Who's Afraid of the Covered Face,' Harvard Design Magazine 42, 2016, p. 79

Goldsmith, Kenneth, 'Resources,' Ubuweb, 2011, http://www.ubu.com/resources, last accessed 2 February 2017

Gray, George W., 'Human Growth,' Scientific American 180:4, 1953, pp. 65-77

Gunning, Tom 'In Your Face: Physiognomy, Photography, and the Gnostic Mission of Early Film,' Modernism/ Modernity 4:1, 1997, pp. 1-25

Halberstam, Jack, 'The Anti-Social Turn in Queer Studies,' Graduate Journal of Social Sciences 5:2, 2008, pp. 140-156

Hall, Rebecca, 'Of Ziploc Bags and Black Holes: The Aesthetics of Transparency in the War on Terror,' The Communication Review 10:4, 2007, pp. 319-346

Halperin, David M., Saint Foucault, Oxford: Oxford University Press, 1995

Haraway, Donna, Modest_Witness@Second_Millenium.FemaleMan@__Meets_OncoMouse ${ }^{T M}$, London and New York: Routledge, 1997

Hardt, Michael and Antonio Negri, Commonwealth, Cambridge, MA: Harvard University Press, 2009

Hattam, Victoria, 'Image: Visual Speculation and Political Change,' in Vyjayanthi Venuturupalli Rao, Prem Krishnamurthy, and Carin Kuoni (eds.) Speculation, Now, Durham: Duke University Press, 2014, pp. 139-141

Heidegger, Martin, The Question Concerning Technology and other essays, trans. William Lovitt, New York: Harper \& Row, 1977

Hennessy, Rosemary, Profit and Pleasure: Sexual Identities in Late Capitalism, New York: Routledge, 2000

'Hito Steyerl, How Not to be Seen: A Fucking Didactic Educational .MOV File, 2013,' Artforum, 2013, https:// www.artforum.com/video/mode=large\&id=51651, last accessed 2 February 2017

Jakobsen, Janet R., 'Queer is? Queer Does? Normativity and the Problem of Resistance,' GLQ: A Journal of Lesbian and Gay Studies 4:4, 1998, pp. 511-536

, 'Sex+Freedom=Regulation: WHY' Social Text 84-85, 2005, pp. 285-308

Juris, Jeffrey S., 'Violence Performed and Imagined: Militant Action, the Black Bloc and the Mass Media in Genoa,' Critique of Anthropology 25:4, 2005, pp. 413-432

Kennedy, Jen, 'The Young-Girl in Theory,' Women \& Performance 25:2, 2015, pp. 175-194 
Lafuente, Pablo, ‘For a Populist Cinema: On Hito Steyerl's November and Lovely Andrea,' Afterall 19, $2008, \mathrm{p}$. 64-70

Lebovic, Nitzan, 'Biometrics, or The Power of the Radical Center' Critical Inquiry 41, 2015, pp. 841-868

Leonardi, Michael, 'Remembering Carlo Giuliani,' Counterpunch, 22 July 2011, http://www.counterpunch.org/ 2011/07/22/remembering-carlo-giuliani, last accessed 25 January 2017

Lupton, Deborah, 'The Embodied Computer/User,' in Bell, D. \& Kennedy, B. (eds.) The Cybercultures Reader, London: Routledge, 2000

Lütticken, Sven, 'Personification,' New Left Review 96, 2015 pp. 101-126

Magagnoli, Paolo, Documents of Utopia: The Politics of Experimental Documentary, London \& New York: Columbia University Press, 2015

Magnet, Shoshana Amielle, When Biometrics Fail: Gender, Race, and the Technology of Identity, Durham: Duke University Press, 2011

McDonough, Tom (ed.), Guy Debord and the Situationist International: Texts and Documents, Cambridge, MA: The MIT Press, 2002 , 'Unrepresentable Enemies: On the Legacy of Guy Debord and the Situationist International,' Afterall 28, 2011, pp. 42-55

Metambu, Tendai John, 'Potentially Yours, The Coming Community,' Artspace, November 2016, http:// www.artspace.org.nz/exhibitions/2016/default.asp, last accessed 2 February 2017

Memou, Antigoni, 'When it bleeds, it leads:' Death and Press Photography in the Anti-Capitalist Protests in Genoa in 2001,' Third Text 24:3, 2010, pp. 341-351

Morris, Adam, Whoever, Whatever: On Anonymity as Resistance to Empire,' Parallax 18:4, 2012, pp. 106-120

Muñoz, José Esteban, Cruising Utopia: The Then and There of Queer Futurity, New York: New York University Press, 2009

Nalini, Ambady and Nicholas O. Rule, 'Brief exposures: Male sexual orientation is accurately perceived at 50 ms,' Journal of Experimental Social Psychology 44:4, 2008, p. 1100-1105

O’Sullivan, Simon, 'Ten Concepts Following Cathy Wilkes's Practice,' Afterall 12, 2005, pp. 64-70

Owens, Craig, Beyond Recognition: Representation, Power, and Culture, Berkeley and Los Angeles:

University of California Press, 1992

Papadopoulos, Dimitris, Niamh Stephenson, and Vassilis Tsianos, Escape Routes: Control and Subversion in the 21st Century, London: Pluto Press, 2008

Phelan, Peggy, Unmarked: The Politics of Performance, London and New York: Routledge, 1993

'Power 100,' ArtReview 68:8, 2016, pp. 101-143

Power, Nina, 'She's Just Not That Into You,' Radical Philosophy 177, 2013, radicalphilosophy.com/reviews/ individual-reviews/rp177-shes-just-not-that-into-you, last accessed 26 August 2016.

Rancière, Jacques, Film Fables, trans. Emiliano Battista, Oxford: Berg, 2006

The Politics of Aesthetics, trans. Gabriel Rockhill, London: Continuum, 2004 
Rasmussen, Mikkel Bolt, 'Art, Revolution and Communisation,' Third Text 26:2, 2012, pp. 229-242

Rosler, Martha, Decoys and Disruptions, Cambridge, MA: The MIT Press, 2004

, 'Out of the Vox: Martha Rosler on Art's Activist Potential,' Artforum 43.1, 2004, p. 218-219

, 'The Private and the Public: Feminist Art in California,' Artforum 16:1, 1977, pp. 66-74

July 2016

, Vital Statistics of a Citizen, Simply Obtained Transcript, supplied to the author by the artist, 29

Rothberg, Michael, 'Remembering Ronahî, Remembering Internationalism, Days and Memory, 3 August 2015, http://hgmsblog.weebly.com/blog/remembering-ronahi-remembering-internationalism, last accessed 29 October 2016

Russell, Diana E. H. and Van de Ven, Nicole, Crimes Against Women: Proceedings of the International Tribunal, Millbrae: Les Femmes, 1976

Sarbanes, Janet, 'An Independent Group? Bernadette Corporation, Post-Pop Collective,' Afterall 14, 2006, pp. $46-55$

Sekula, Allan, 'Dismantling Modernism, Reinventing Documentary (Notes on the Politics of Representation), The Massachusetts Review 19.1, 1978, pp. 859-833

Sexton, Jamie, 'Prisoner of Cool: Chloë Sevigny, Alternative Stardom and Image Management,' in Kate Egan and Sarah Thomas (eds.), Cult Film Stardom: Offbeat Attractions and Processes of Cultification, London: Palgrave, 2012, pp. 73-89

Shaked, Nizan, 'The 1993 Whitney Biennial: Artwork, Framework, Reception,' Journal of Curatorial Studies $2: 2$, pp. $142-168$

Shell, Hanna Rose, Camouflage, Photography, and the Media of Reconnaissance, New York: Zone Books, 2012

Simpson, Bennett, 'Techniques of Today,' Artforum 43:1, 2004, p. 220-223

Spiegel, Jennifer B., 'Masked Protest in the Age of Austerity: State Violence, Anonymous Bodies, and Resistance "In the Red,"' Critical Inquiry 41, 2015, pp. 786-810

Stallabrass, Julian (ed.), Documentary, London: Whitechapel Gallery and Cambridge, MA: The MIT Press, 2013

Steyerl, Hito, 'A Thing Like You and Me,' e-flux 15, 2010, http://www.e-flux.com/journal/15/61298/a-thinglike-you-and-me, last accessed 2 November 2016

28 October 2016 Beginnings, e-flux 59, 2014, http://www.e-flux.com/journal/59/61140/beginnings, last accessed last accessed 20 February 2017

'Documentary Uncertainty,' Re-Visiones, 2011, http://www.re-visiones.net/spip.php\%3Farticle37, , 'Missing People: Entanglement, Superposition, and Exhumation as Sites of Indeterminacy,' eflux 38, 2012, http://www.e-flux.com/journal/38/61209/missing-people-entanglement-superposition-andexhumation-as-sites-of-indeterminacy, last accessed 2 November 2016

Summers, Chris and Irene Peroni, 'Ghosts of G8 haunt Genoa,' BBC News, 7 February 2005, http:// news.bbc.co.uk/2/hi/europe/4217629.stm, last accessed 25 January 2017

Tiqqun, Introduction to Civil War, trans. Alexander R. Galloway and Jason E. Smith, Los Angeles: Semiotext(e), 2010 2012 , Preliminary Materials For a Theory of the Young-Girl, trans. Ariana Reines, Los Angeles: Semiotext(e), 
Too, Jian-Xing, 'Burn a Debt to the Present,' Afterall 14, 2006, pp. 62-70

'Twitter turns Clinton's 'H' Logo into target for ridicule,' Reuters, 13 April 2015, http://www.reuters.com/ article/us-usa-election-clinton-logo-idUSKBNON30XF20150413, last accessed 28 October 2016

Weigel, Moira and Mal Ahern, 'Further Materials Toward a Theory of the Man-Child,' The New Inquiry, July 9 2013, thenewinquiry.com/essays/further-materials-toward-a-theory-of-the-man-child, last accessed 26

August 2016

Weinstock, Jane, 'Interview with Martha Rosler,' October 17, 1981, p. 77-98

Weizman, Eyal, 'Violence at the Threshold of Detectability,' e-flux 64, 2015

Whitney Museum of American Art, 'Chrissie lles in Conversation with Martha Rosler,' Youtube, https:// www.youtube.com/watch?v=pl-8j939qdM, 9 August 2010, last accessed 14 September 2016

Zaremba, Łukasz, 'To Work as a Pixel. Interview with Hito Steyerl,' Szum, 20 December 2014, http:// magazynszum.pl/rozmowy/to-work-as-a-pixel-interviev-with-hito-steyerl, last accessed 2 February 2017

Zorach, Rebecca, 'Love, Truth, Orthodoxy, Reticence; or, What Edgar Wind Didn't See in Botticelli's Primavera,' Critical Inquiry 54, 2007, pp. 190-224

\section{INTERVIEWS}

Blas, Zach, interview with the author (via Skype), Wellington and London, 17 October 2016

Blas, Zach, interview with the author (via Skype), Wellington and London, 14 December 2016 